\title{
Verification and Validation of the ENDF/B-VII.1 v4.3m1 MPACT 51-Group Cross Section Library
}

Revision 0

Kang Seog Kim Mark L. Williams Dorothea Wiarda Cole A. Gentry Andrew T. Godfrey

Kevin T. Clarno Oak Ridge National Laboratory

Yuxuan Liu University of Michigan

Scott Palmtag Core Physics

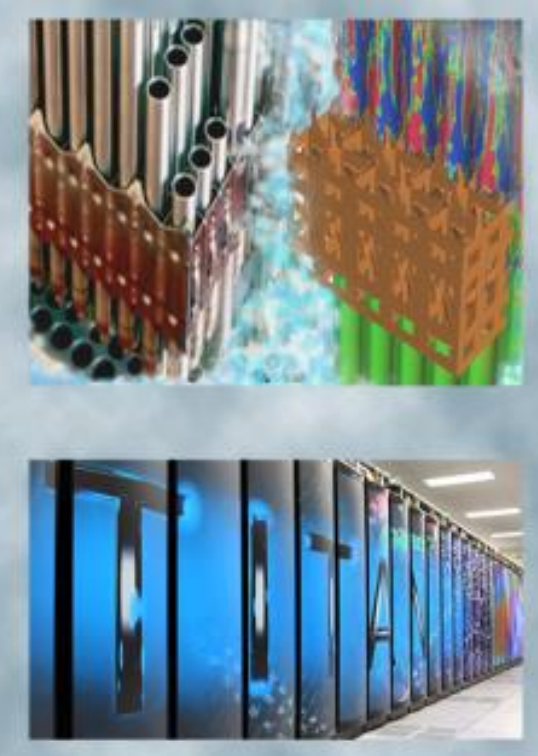

February 12, 2018
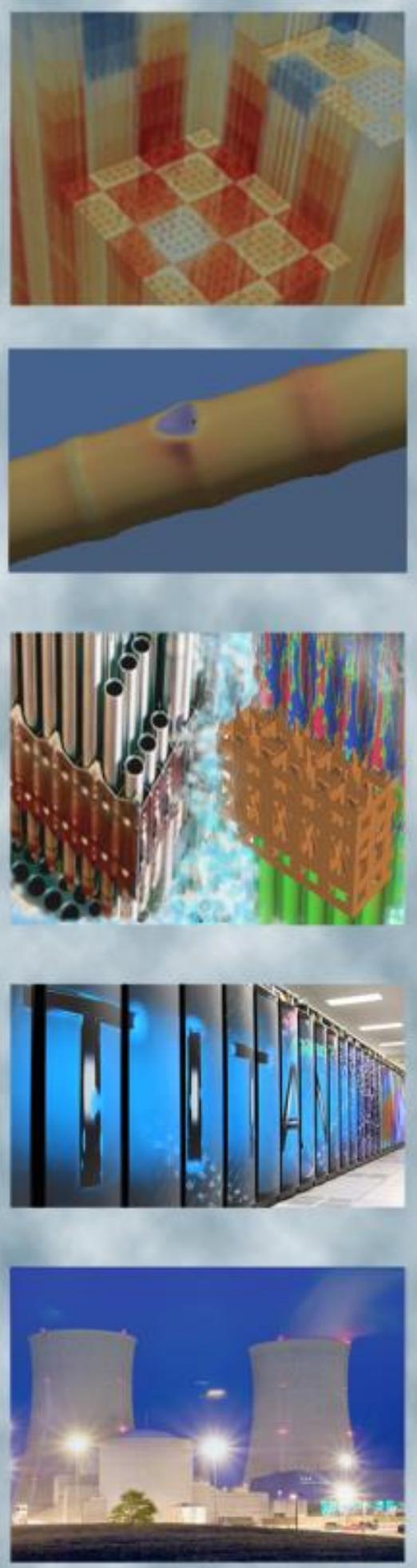


\title{
DOCUMENT AVAILABILITY
}

Reports produced after January 1, 1996, are generally available free via US Department of Energy (DOE) SciTech Connect.

Website www.osti.gov

Reports produced before January 1, 1996, may be purchased by members of the public from the following source:

\author{
National Technical Information Service \\ 5285 Port Royal Road \\ Springfield, VA 22161 \\ Telephone 703-605-6000 (1-800-553-6847) \\ TDD 703-487-4639 \\ Fax 703-605-6900 \\ E-mail info@ntis.gov \\ Website http://classic.ntis.gov/
}

Reports are available to DOE employees, DOE contractors, Energy Technology Data Exchange representatives, and International Nuclear Information System representatives from the following source:

Office of Scientific and Technical Information

PO Box 62

Oak Ridge, TN 37831

Telephone 865-576-8401

Fax 865-576-5728

E-mail reports@osti.gov

Website http://www.osti.gov/contact.html

This report was prepared as an account of work sponsored by an agency of the United States Government. Neither the United States Government nor any agency thereof, nor any of their employees, makes any warranty, express or implied, or assumes any legal liability or responsibility for the accuracy, completeness, or usefulness of any information, apparatus, product, or process disclosed, or represents that its use would not infringe privately owned rights. Reference herein to any specific commercial product, process, or service by trade name, trademark, manufacturer, or otherwise, does not necessarily constitute or imply its endorsement, recommendation, or favoring by the United States Government or any agency thereof. The views and opinions of authors expressed herein do not necessarily state or reflect those of the United States Government or any agency thereof. 
REVISION LOG

\begin{tabular}{|c|c|c|c|}
\hline Revision & Date & Affected Pages & Revision Description \\
\hline 0 & $2 / 12 / 2018$ & All & Initial version \\
\hline & & & \\
\hline & & & \\
\hline & & & \\
\hline
\end{tabular}

Export Controlled None

IP/Proprietary/NDA Controlled None

Sensitive Controlled None

Unlimited All Pages

\section{Requested Distribution:}

To: N/A

Copy: N/A

\section{Reviewed by:}

Date:

Reviewer: 


\section{承口งட}

\section{EXECUTIVE SUMMARY}

The MPACT neutronics module of the Consortium for Advanced Simulation of Light Water Reactors (CASL) core simulator is a 3-D whole core transport code being developed for the Virtual Environment for Reactor Analysis (VERA) CASL toolset. Key characteristics of the MPACT code include (1) a subgroup method for resonance selfshielding and (2) a whole-core transport solver with a 2-D/1-D synthesis method. The MPACT code requires a cross section library to support all of its core simulation capabilities; a cross section library would be MPACT's most influencing component for simulation accuracy.

Due to the limitation of computing capacity even in high performance computing, the cross section library must be developed to enhance computational efficiency in memory and computing time without losing accuracy and generality. This requires a very coarse energy group structure with about 50 groups. Multigroup (MG) neutron cross section libraries for the CASL VERA-CS neutronics simulator MPACT have been created by using the AMPX/SCALE code package developed at Oak Ridge National Laboratory (ORNL).

A new 51-group structure was developed for efficient simulation to be applicable for both pressurized water reactor (PWR) and boiling water reactor (BWR) simulations. New v4.3m1 MPACT 51-group library with the ENDF/B- VII.1 nuclear data were developed for MPACT. Since SCALE KENO has some issues in the probability table and has a low cutoff energy for the free gas model, this issue has been corrected. This study focused on the development of the ENDF/B-VII.1 v4.3m1 MPACT MG library, including verification and validation.

This document includes the library generation methodology and procedure, the verification procedure, and benchmark results compared to continuous energy Monte Carlo results using newly developed cross section libraries. 


\section{TABLE OF CONTENTS}

REVISION LOG iii

EXECUTIVE SUMMARY. iv

FIGURES vii

TABLES ix

ACRONYMS $x$

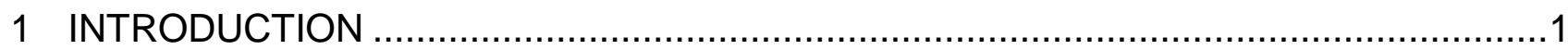

2 LIBRARY GENERATION METHODOLOGY AND PROCEDURE .................................

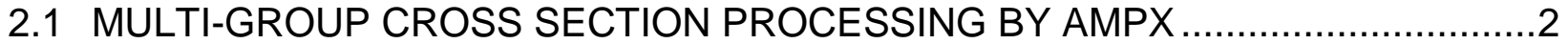

2.2 IMPROVEMENT OF RESONANCE DATA .................................................

2.2.1 Intermediate Resonance (IR) Approximation and Parameters .....................5

2.2.2 Resonance Self-Shielded Data by Homogeneous Models ............................

2.2.3 Resonance Self-Shielded Data by Heterogeneous Models ..........................9

2.2.4 Self-shielded data for within-group elastic scattering ................................10

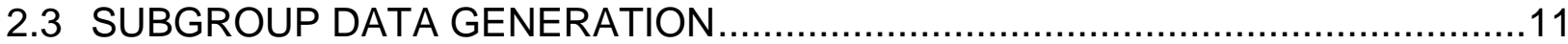

2.3.1 Subgroup method ........................................................................

2.3.2 Subgroup data generation ……...................................................13

2.3.3 Subgroup method for nonuniform temperature distribution........................15

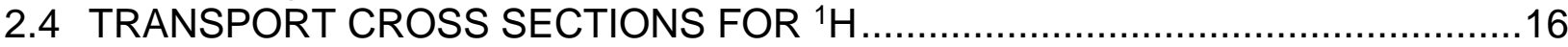

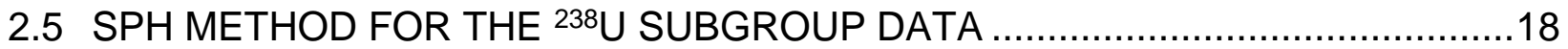

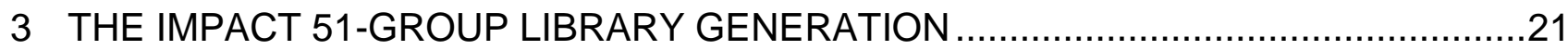

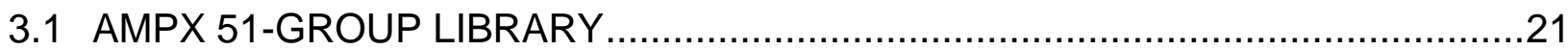

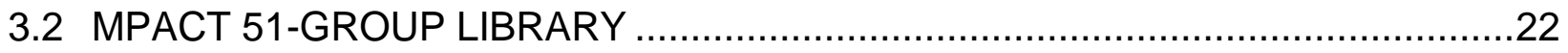

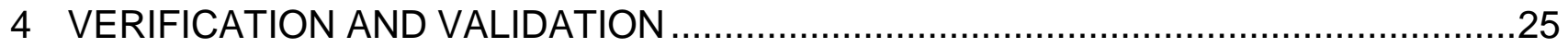

4.1 VERA CORE PHYSICS BENCHMARK PROGRESSION PROBLEMS …............25

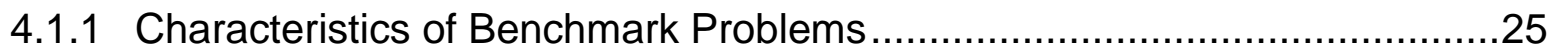

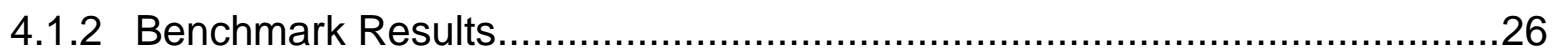

4.2 EXTENDED VERA BENCHMARK PROGRESSION PROBLEMS .......................29

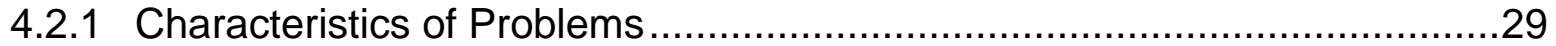

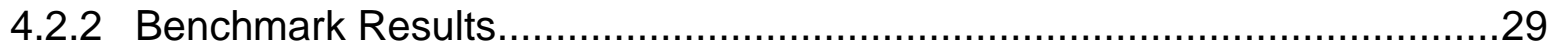

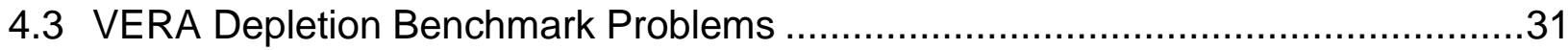

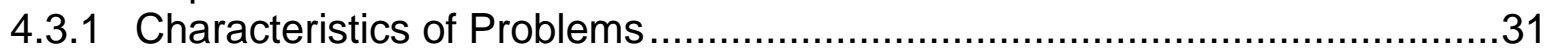

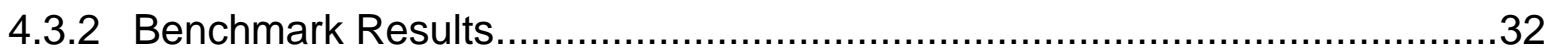

4.4 EXTENSIVE PWR PIN AND ASSEMBLY BENCHMARK PROBLEMS .................38

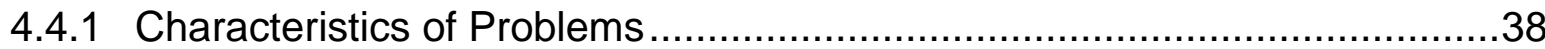

4.4.2 Benchmark Results................................................................... 40

4.5 NONUNIFORM FUEL TEMPERATURE BENCHMARK PROBLEMS ....................48

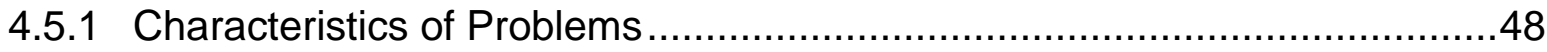

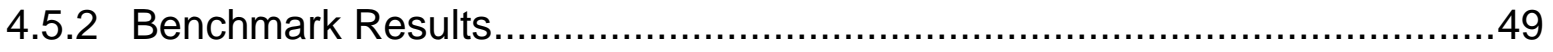




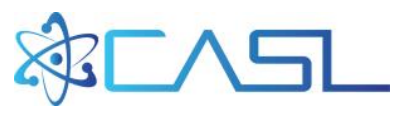

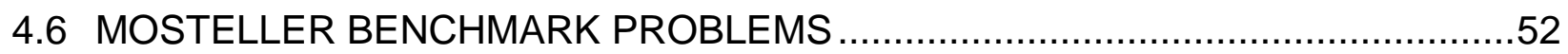

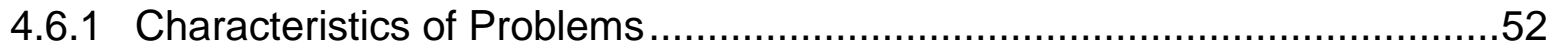

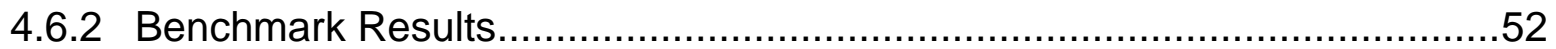

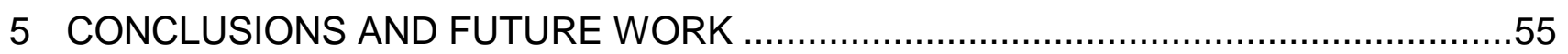

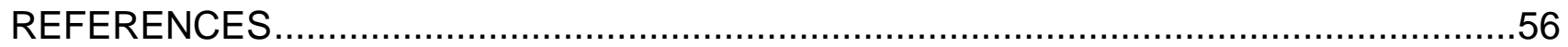




\section{FIGURES}

Figure 2.1. AMPX/SCALE Procedure to Generate the AMPX MG Library.................... 2

Figure 2.2. Pointwise Neutron Spectra Obtained by CENTRM.................................. 5

Figure 2.3. Resonances and Subgroups............................................................... 11

Figure 2.4 Resonance Data Generation Procedure. .................................................. 14

Figure 2.5. 51-Group Transport Correction Factors for ${ }^{1} \mathrm{H}$...................................... 18

Figure 2.6. SPH Method to Generate the ${ }^{238} \mathrm{U}$ Subgroup Data. ................................... 19

Figure 2.7. ${ }^{238} \mathrm{U} 51$-Group Absorption Reaction Rate Differences with/without

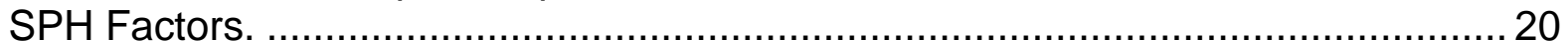

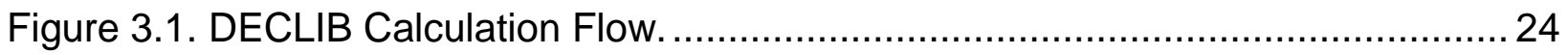

Figure 4.1. Problem 2 lattice Layouts (Octant Symmetry) ......................................... 26

Figure 4.2. Pin Power Comparisons for Problem 5A-2D. ......................................... 28

Figure 4.3. Comparison of Simplified Burnup Chain to Full Burnup Chain..................... 33

Figure 4.4. Comparison of Multiplication Factors between KENO and MPACT $\mathrm{P}_{2}$

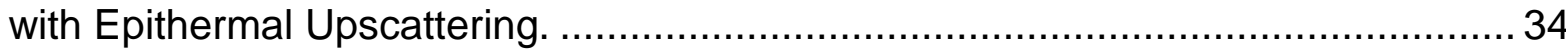

Figure 4.5. Comparison of Multiplication Factors between KENO and MPACT

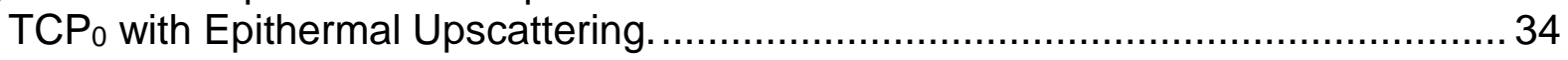

Figure 4.6. Comparison of Pin Powers between KENO and MPACT $\mathrm{P}_{2}$ with

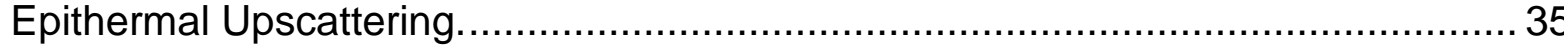

Figure 4.7. Comparison of Multiplication Factors between KENO and MPACT $\mathrm{P}_{2}$

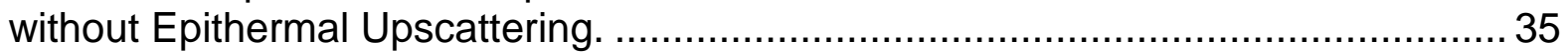

Figure 4.8. Comparison of Multiplication Factors between KENO and MPACT $P_{2}$

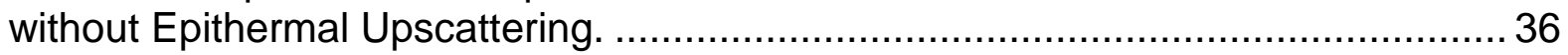

Figure 4.9. Comparison of Pin Powers between KENO and MPACT $\mathrm{P}_{2}$ without

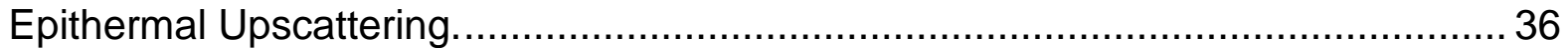

Figure 4.10. Comparison of Multiplication Factors between ENDF/B-VII.0 and ENDF/B-VII.1 using SERPENT without Epithermal Upscattering. 37

Figure 4.11. Pin keff Difference Distribution with Epithermal Upscattering.................... 43

Figure 4.12. Pin keff Difference Distribution without Epithermal Upscattering. ............... 43

Figure 4.13. Assembly keff Difference Distribution with Epithermal Upscattering........... 47

Figure 4.14. Assembly keff Difference Distribution without Epithermal

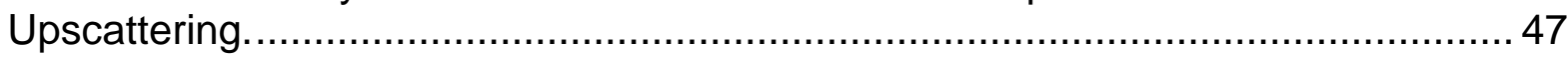

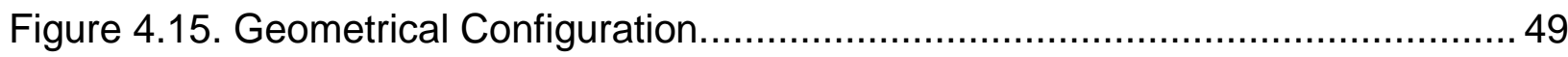

Figure 4.16. Comparison of Reactivities between Nonuniform and Uniform

Temperature Distributions. (KENO). 50 


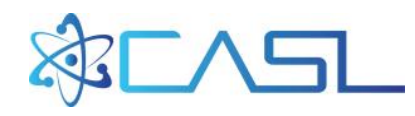

Figure 4.17. Comparison of Reactivities for the Uniform Temperature

Distributions.

51

Figure 4.18. Comparison of Reactivities for the Nonuniform Temperature

Distributions. 51

Figure 4.19. Comparison of Reactivities for the Nonuniform Temperature

Distributions with Epithermal Upscattering.

Figure 4.20 Comparison of Reactivities for the Nonuniform Temperature

Distributions without Epithermal Upscattering. 54 


\section{TABLES}

Table 2.1. Variations for ${ }^{238} \mathrm{U}$ for the Heterogeneous Models.................................... 10

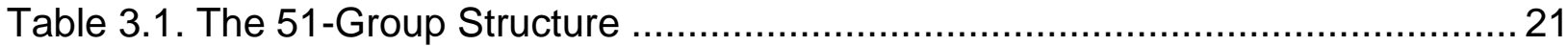

Table 3.2 List of Nuclides, Including Subgroup Data................................................... 22

Table 4.1. Details of the VERA Progression Problems ............................................ 25

Table 4.2. Results with the ENDF/B-7.1 MPACT 51-g Library ................................ 27

Table 4.3. Results for 2D Core Problems with the ENDF/B-7.1 Library. ....................... 28

Table 4.4. Extended VERA Benchmark Problems …….......................................... 29

Table 4.5. Benchmark Result with the ENDF/B-7.1 MPACT 51-g Library ..................... 30

Table 4.6. Single Pin and Assembly Depletion Benchmark Problems ......................... 31

Table 4.7. Moderator Temperatures and Densities .................................................. 38

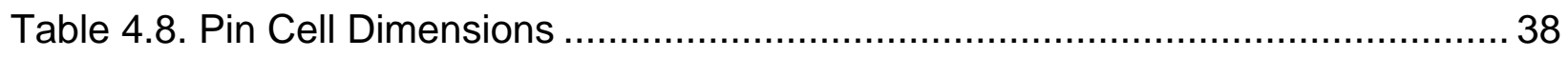

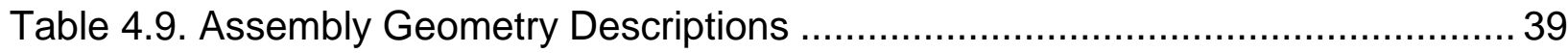

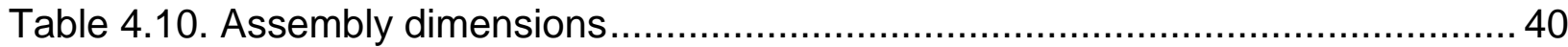

Table 4.11. Benchmark Result for Pin Cell Problems $\left(P_{2}\right)$...................................... 41

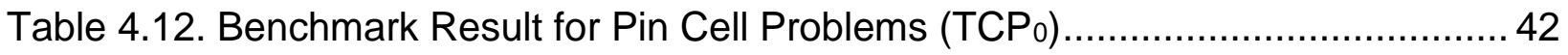

Table 4.13 Benchmark Result for Assembly Problems with Epithermal

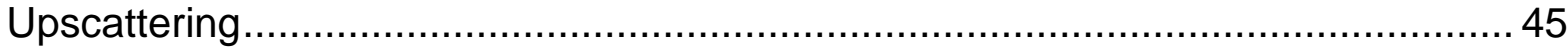

Table 4.14 Benchmark Result for Assembly Problems without Epithermal

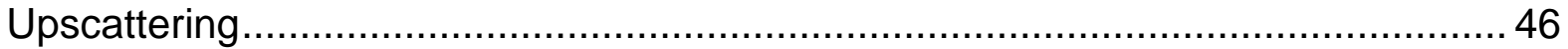

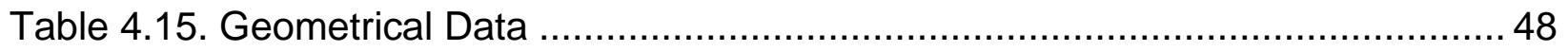

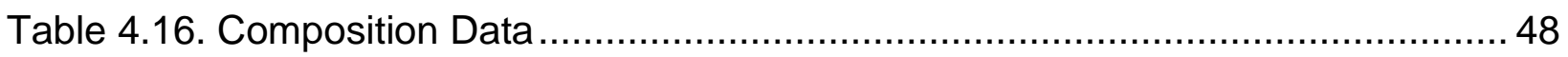

Table 4.17. Nonuniform Temperature Profiles as a Function Power ........................... 49

Table 4.18. Atomic Number Densities of $\mathrm{UO}_{2}$ Fuels................................................ 52

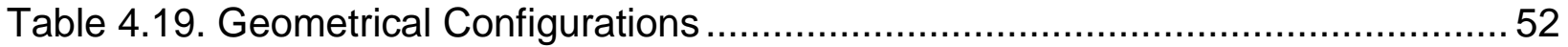

Table 4.20. Atomic Number Densities of Moderator and Clad .................................... 52

Table 4.21. Benchmark Results for Mosteller........................................................... 53

Table 5.1. v4.3m1 MPACT 51-Group Library ...................................................... 55 


\section{ACRONYMS}

$\begin{array}{ll}\text { AMPX } & \text { resonance processing code; the name is no longer an acronym } \\ \text { ANS } & \text { American Nuclear Society } \\ \text { CASL } & \text { Consortium for Advanced Simulation of Light Water Reactors } \\ \text { CE } & \text { continuous energy (as in cross sections) } \\ \text { CENTRM } & \text { PW transport code in SCALE } \\ \text { CMFD } & \text { coarse-mesh finite difference } \\ \text { CTF } & \text { COBRA TF } \\ \text { DBRC } & \text { Doppler broadening rejection correction } \\ \text { ENDF } & \text { evaluated nuclear data file } \\ \text { ESSM } & \text { embedded self-shielding method } \\ \text { GT } & \text { guide tube } \\ \text { IFBA } & \text { integral fuel burnable absorber } \\ \text { IR } & \text { intermediate resonance } \\ \text { IT } & \text { instrument tube } \\ \text { KERMA } & \text { kinetic energy released per unit mass } \\ \text { LWR } & \text { light-water reactor } \\ \text { MCNP } & \text { Monte Carlo N-Particle } \\ \text { MG } & \text { multigroup (as in cross sections) } \\ \text { MPACT } & \text { radiation transport code in VERA; the name is no longer an acronym } \\ \text { NJOY } & \text { nuclear data code } \\ \text { NLC } & \text { neutron leakage conversion } \\ \text { NR } & \text { narrow resonance } \\ \text { ORIGEN } & \text { Oak Ridge Isotopic Generation code in SCALE } \\ \text { ORNL } & \text { Oak Ridge National Laboratory } \\ \text { PW } & \text { pointwise } \\ \text { PWR } & \text { pressurized water reactor } \\ \text { RI } & \text { resonance integral } \\ \text { RIA } & \text { reactivity insertion accident } \\ \text { SAMPX } & \text { simplified AMPX } \\ \text { SCALE } & \text { Standardized Computer Analyses for Licensing Evaluations code } \\ \text { SNU } & \text { Seoul National University } \\ \text { SPH } & \text { super-homogenization } \\ \text { SQA } & \text { software quality assurance } \\ \text { T/H } & \text { thermal/hydraulic } \\ \text { URR } & \text { unresolved resonance } \\ \text { VERA } & \text { Virtual Environment for Reactor Applications } \\ \text { VERA-CS } & \text { VERA Core Simulator } \\ \text { WR } & \text { wide resonance } \\ \text { XS } & \text { cross section } \\ & \end{array}$




\section{INTRODUCTION}

The MPACT [Mpa13] neutronics module of the Consortium for Advanced Simulation of Light Water Reactors (CASL) [CAS15] core simulator is a 3-D whole core transport code being developed for the CASL toolset, Virtual Environment for Reactor Analysis (VERA) [Tur16]. MPACT is under development for neutronics simulation coupled with the COBRA-TF (CTF) code for thermal-hydraulics simulation for pressurized light water reactors (LWRs). Key characteristics of the MPACT code include (1) a subgroup method for resonance self-shielding and (2) a whole-core transport solver with a 2-D/1-D synthesis method. Thus, the MPACT code requires a cross section library to support all the MPACT core simulation capabilities.

Multigroup (MG) neutron cross section libraries for the CASL MPACT neutronics code [Mpa13], which is part of the VERA core simulator, have been developed by using the AMPX code package [Wia16] and the XSTools software in VERA. The native MPACT cross section library format, which is based on the HELIOS [Sta98] and DeCART [Cho02] formats, is the primary structure available for CASL. The ${ }^{238} \mathrm{U}$ resonance selfshielded cross section tables have been developed based on SCALE KENO, by which the super-homogenization (SPH) factors have been obtained. KENO has had several issues, including probability table and a low cutoff energy for the free gas mode. Since the KENO issues have been resolved, new ${ }^{238} \mathrm{U} \mathrm{SPH}$ factors have been estimated and used to generate the ${ }^{238} \mathrm{U}$ resonance cross section tables. The fuel temperature reactivity bias still needs to be resolved. MPACT is required to deliver verified and validated MPACT MG cross section libraries based on the CASL Software Quality Assurance (SQA) procedure.

This document includes the following:

- The library generation procedure, including the methodology and verification (Chapter 3),

- Generation of the v4.3m1 MPACT 51-g library with ENDF/B-VII.1 (Chapter 4), and

- Benchmark calculations and results (Chapter 5),

This study is a part of verification and validation for CASL VERA's MG cross section library. 


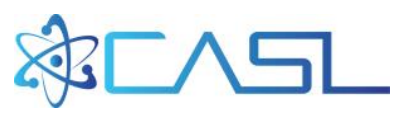

\section{LIBRARY GENERATION METHODOLOGY AND PROCEDURE}

The VERA neutronics simulator MPACT requires MG neutron cross section data to solve the Boltzmann transport equation in order to obtain neutron flux distribution. The evaluated nuclear data files (ENDF/B) are processed to generate MG cross sections by using the AMPX-6 [Wia16] and SCALE [Sca16] code packages developed at Oak Ridge National Laboratory (ORNL). The MPACT MG library is generated by using the CASL XSTools [Kim15] with the AMPX MG master library and other nuclear data. Figure 2.1 illustrates the AMPX/SCALE procedure to generate the AMPX MG library, where the left side of flow chart shows the conventional procedure, and the right side illustrates the new procedure to improve the Bondarenko resonance data. This section summarizes the methodology and procedure to prepare the VERA MPACT MG cross section library.
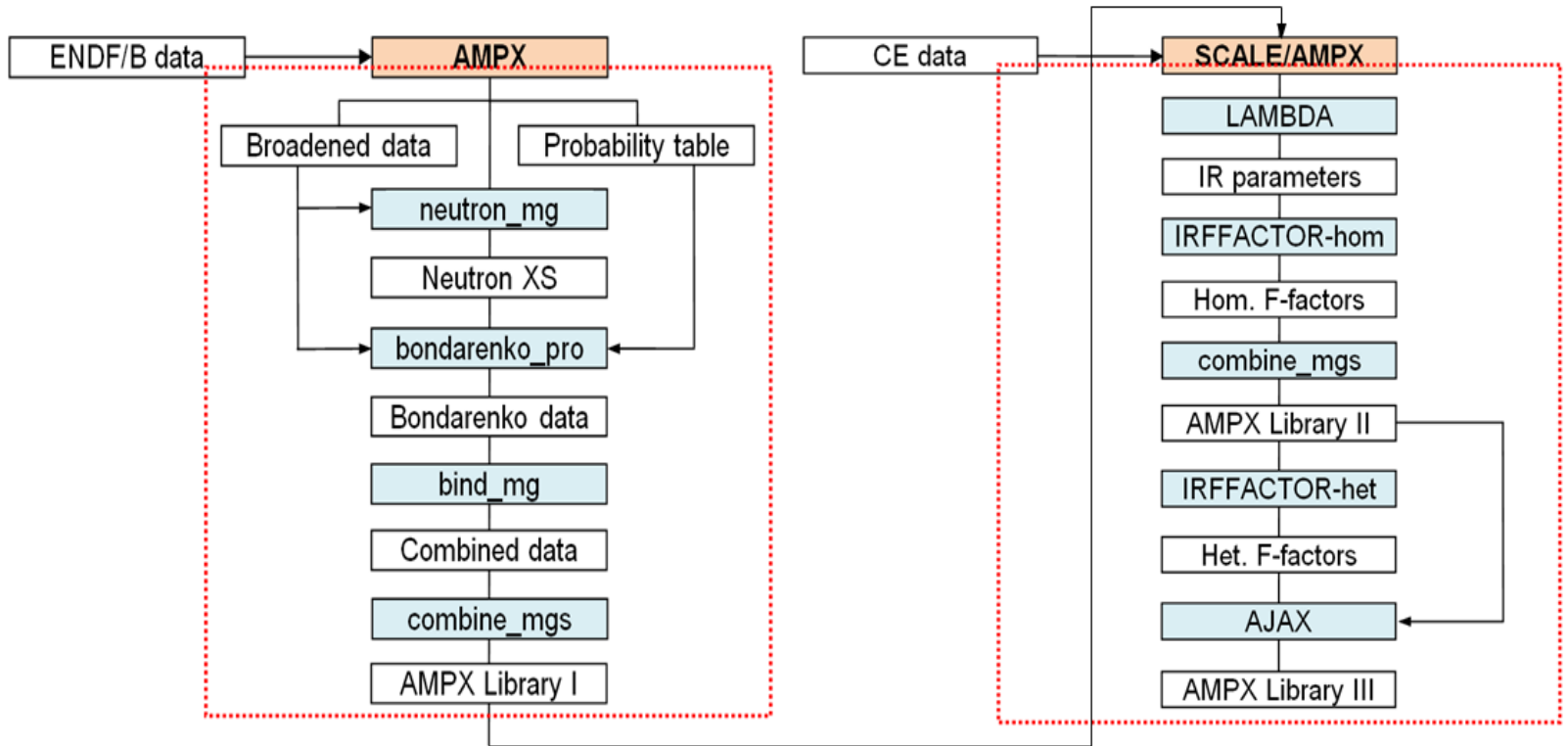

Figure 2.1. AMPX/SCALE Procedure to Generate the AMPX MG Library.

\subsection{MULTI-GROUP CROSS SECTION PROCESSING BY AMPX}

AMPX-6 [Wia16] is a modular system of FORTRAN computer programs that is used to generate the $M G$ and continuous energy (CE) cross section libraries for modern deterministic and Monte Carlo transport codes by processing ENDF/B libraries. Since the CASL neutronics simulator MPACT is a deterministic transport code, only the AMPX MG library generation procedure is discussed here.

The AMPX MG library includes various neutron reactions of the Bondarenko F-factors, which are defined as ratios of resonance self-shielded cross sections to infinite dilution cross sections as a function of background cross sections for all energy groups, including resolved and unresolved resonances. The resolved resonance F-factors have 
been generated by the narrow resonance (NR) approximation, and the unresolved resonance $\mathrm{F}$-factors have been generated by the probability table method based on the NR approximation [Cul74, Kim18]. MG cross sections and scattering matrices were obtained by using a weighting function of Maxwellian spectrum $+1 / E+$ fission spectrum. At low energies, the weighting function is a Maxwellian spectrum which has a flux shape that assumes the neutron scatters into a region with a free gas scatterer with no absorption. The Maxwellian flux spectrum has the following formula:

$$
\phi(E)=M(E)=E e^{-\frac{E}{k T}},
$$

where $E$ denotes neutron energy, $k$ denotes the Boltzmann constant, and $T$ denotes temperature of the material in Kelvin. In the slowing down range, $0.125 \mathrm{eV}<E<E_{\text {cut, }}$ the weighting spectrum is assumed to be $\phi(E)=1 / E$. The cutoff energy $E_{\text {cut }}$ for the slowing down range must be selected and is typically $55 \mathrm{keV}$ by default in the AMPX modules. In the region $E_{\text {cut }}<E<10^{7} \mathrm{eV}$, where fission neutrons are born, the following fission spectrum is used.

$$
(E)=(E)=E^{0.5} e^{\underline{E}}
$$

where $\theta$ is temperature of the fission spectrum (e.g., $1.2 \times 10^{6} \mathrm{eV}$ ). For energies above $10^{7} \mathrm{eV}$, the particles are considered to be in another slowing down region, so the spectrum is assumed to have a $1 / E$ shape.

MG self-shielded cross sections of reaction type $i$ (Bondarenko F-factors) as a function of background cross sections $(\sigma 0)$ and material temperature $(T)$ are calculated by using the following equation based on NR approximation:

$$
\sigma_{i, g}\left(T, \sigma_{0}\right)=\frac{\int_{g} \frac{\sigma_{i}(T, E) \sigma_{0} \phi(E)}{\sigma_{t}(T, E)+\sigma_{0}} d E}{\int_{g} \frac{\sigma_{0} \phi(E)}{\sigma_{t}(T, E)+\sigma_{0}} d E},
$$

where T denotes temperature, and $\sigma_{t}$ is total cross section. The MG scattering matrix can be obtained by

$$
\sigma_{s, l, g g^{\prime}}=\frac{1}{\int_{g} \phi(E) d E} \int_{g} y(E) \sigma_{s}(E) \phi(E) d E \int_{g^{\prime}} f_{l}\left(E, E^{\prime}\right) d E^{\prime},
$$

where $y(E)$ is a multiplicity which is unity for scattering, and $f_{l}\left(E, E^{\prime}\right)$ is a normalized double differential distribution. It should be noted that the scattering matrix data (not for thermal scattering matrices) are temperature-independent in the AMPX MG library. 
Typically, NR approximation could be a good solution for the unresolved resonance (URR) energy range in which pointwise (PW) neutron spectrum could be approximated in terms of total and background cross sections. Since the probability tables are provided at the URR energy range, including cross section levels and weights, MG selfshielded cross section tables (F-factor tables) could be obtained by using an NR approximation with a probability table, as follows:

$$
\begin{gathered}
\sigma_{x, g}\left(\sigma_{0}\right)=\frac{\int_{g} \sum_{m} p^{m} \sigma_{x}^{m}(E) \phi^{m}\left(E, \sigma_{0}\right) d E}{\int_{g} \sum_{m} p^{m} \phi^{m}\left(E, \sigma_{0}\right) d E}, \\
\varphi^{m}\left(E, \sigma_{0}\right)=\frac{\sigma_{0}}{\sigma_{t}^{m}(E)+\sigma_{0}} \phi(E),
\end{gathered}
$$

where

$$
\begin{aligned}
& \sigma_{0}=\text { background cross section, } \\
& \sigma_{x}^{m}=\text { a cross section level of the level } m \text { and reaction } x, \\
& \sigma_{t}^{m}=\text { a total cross section level of the level } m, \\
& p^{m}=\text { a probability of the level } m, \text { and } \\
& \sigma_{x, g}=\text { a self-shielded cross section of reaction } x .
\end{aligned}
$$

In the standard SCALE sequences (e.g., TRITON), self-shielded MG cross sections and scattering matrices for resolved resonance and thermal energy groups are determined by performing the problem-dependent CENTRM slowing down transport calculation for each pin cell type with Eq. (2.7). Therefore, the resolved resonance data in the AMPX MG library are not used.

$$
\hat{\Omega} \cdot \nabla \psi+\Sigma_{t}(\vec{r}, u) \psi(\vec{r}, u, \hat{\Omega})=\int_{4 \pi} d \Omega^{\prime} \int_{0}^{\infty} d u \Sigma_{s}\left(\vec{r}, u^{\prime} \rightarrow u, \hat{\Omega}^{\prime} \cdot \hat{\Omega}\right) \psi\left(\vec{r}, u^{\prime}, \hat{\Omega}^{\prime}\right)+q(\vec{r}, u, \hat{\Omega}),
$$

where

$$
\begin{aligned}
\hat{\Omega} & =\text { neutron direction, } \\
\vec{r} & =\text { space coordinate } \\
u & =\text { neutron lethargy, } \\
\psi & =\text { angular flux } \\
\Sigma_{t} & =\text { macroscopic total cross section, } \\
\Sigma_{s} & =\text { double differential scattering cross section, and } \\
q & =\text { external source. }
\end{aligned}
$$

However, since the Bondarenko approach for the resonance self-shielding calculation does not include any problem-dependent PW slowing down calculations, a weighting function would make a significant impact on the accuracy, mostly through the scattering matrix. The weighting function of Maxwellian spectrum $+1 / E+$ fission spectrum is far from realistic. Practical weighting functions for various temperatures can be obtained by performing the CENTRM MG/PW calculations for a typical PWR fuel pin. Figure 2.2 
provides a sample of PW neutron spectra obtained by CENTRM. This would be performed using the XSProc sequence with "parm=centrm"; the weight functions must be generated to include various temperatures.

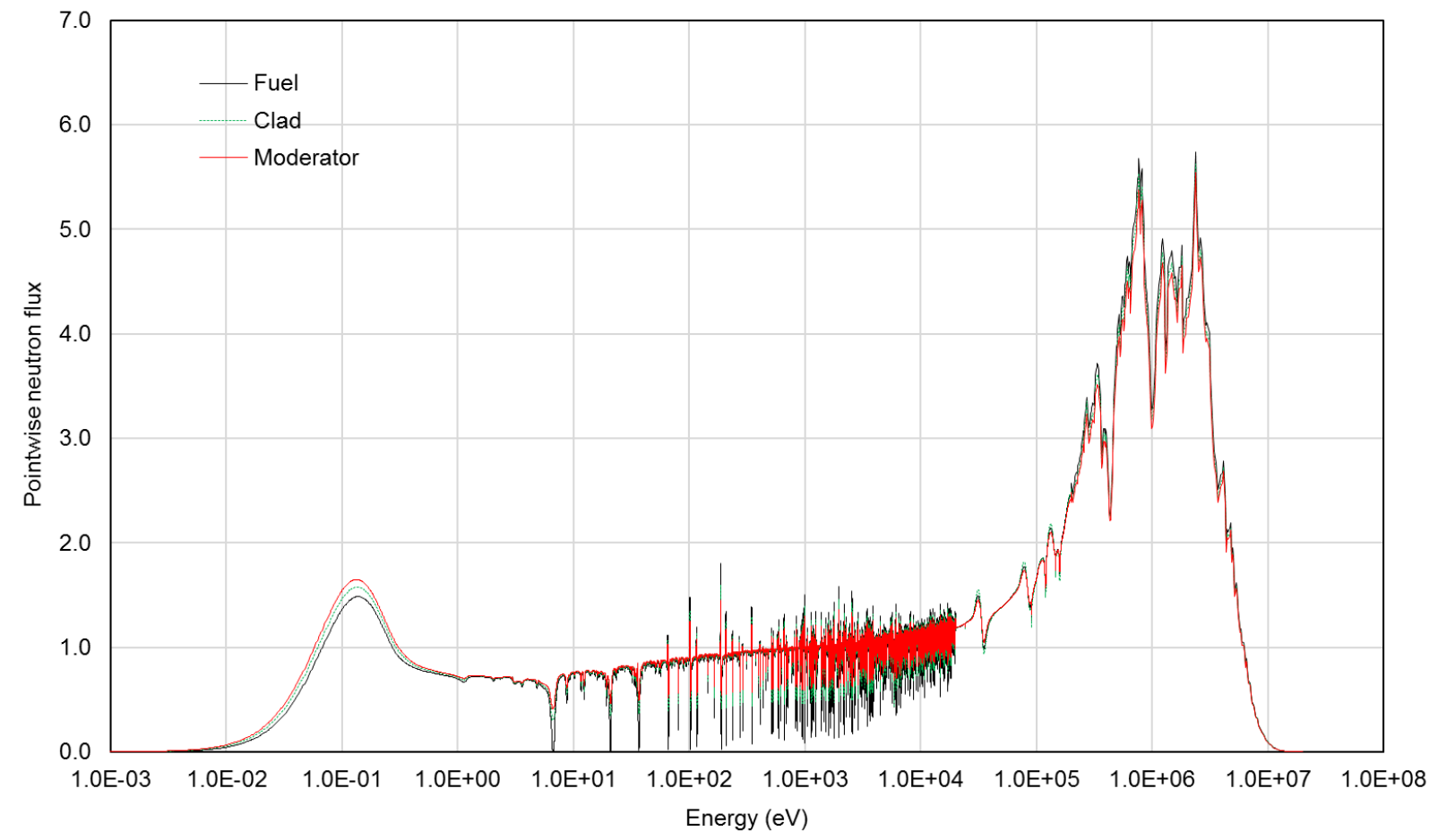

Figure 2.2. Pointwise Neutron Spectra Obtained by CENTRM.

There is a pending issue associated with the PW weighting function in the Bondarenko approach. Since resonance self-shielded cross sections are independently estimated, they are independent of the PW weighting function. In reality, since the current MPACT procedure includes resonance data only for the specified energy groups, self-shielded cross sections of nonresonance groups should be dependent on the weighting functions. MG scattering matrices are obtained by simple $P_{0}$ flux moment weighting, and renormalization is applied only to total scattering, within-group, and out-scattering components. Therefore, this procedure may introduce incorrect neutron fluxes, resulting in some errors in reaction rates. PW neutron spectra are very changeable according to ${ }^{235} \mathrm{U}$ enrichment, moderator-to-fuel ratio, burnup, and void fraction. Therefore, selecting the weighting function would be challenging.

\subsection{IMPROVEMENT OF RESONANCE DATA}

\subsubsection{Intermediate Resonance (IR) Approximation and Parameters}

To cast the scattering source term into a more tractable form, the intermediate resonance (IR) approximation is introduced. In this approximation, the fraction $\lambda_{i}$ of the scattering for each isotope $i$ is assumed to be so effective that the maximum lethargy gain per collision is significantly greater than the practical resonance width (i.e., the NR 
scattering) [Sta83, Sta03]. A resonance affects only a small interval of the integration range from $u$ - $\Delta_{i}$ to $u$, and its contribution to the scattering source $Q(u)$ is negligible. Outside the resonances, $\Sigma_{s i}(u)=\Sigma_{p i}$ and $\phi(u)=$ constant, so the contribution of isotope $i$ to $Q(u)$ is $\lambda_{i} \Sigma_{p i}$. This is the unperturbed slowing down source. Conversely, the remaining fraction $\left(1-\lambda_{i}\right)$ is assumed to be so ineffective that neutrons gain a negligible amount of lethargy compared with $\Delta u_{g}$ (i.e., the wide resonance [WR] scattering). The resonances are so wide that the integrand can be replaced by its average value, which leads to the $\left(1-\lambda_{i}\right) \Sigma_{s i}(u) \phi(u)$ contribution to the source $Q(u)$. Thus, this fraction of scattering does not provide source neutrons from outside the resonance widths, but it should be considered as a result of self-scattering, which neither adds nor removes neutrons. With these approximations, Eq. (2.7) can be rewritten for the coarse energy groups:

$$
\hat{\Omega} \cdot \nabla \psi_{g, k}+\sum_{i} \Sigma_{i, g, t}^{k} \psi_{g, k}(\hat{\Omega})=\sum_{i} \lambda_{i, g} \Sigma_{i, p}^{k}+\sum_{i}\left(1-\lambda_{i, g}\right) \sum_{i, g, s}^{k} \phi_{g, k} .
$$

Eq. (2.8) can be rewritten by assuming isotropic angular flux and $\Sigma_{i, p}=\Sigma_{i, g, s}$ as

$$
\hat{\Omega} \cdot \nabla \psi_{g, k}+\sum_{i}\left(\Sigma_{i, g, a}^{k}+\lambda_{i, g} \Sigma_{i, p}^{k}\right) \psi_{g, k}(\hat{\Omega})=\sum_{i} \lambda_{i, g} \Sigma_{i, p}^{k} .
$$

For the homogeneous mixture, the self-shielded flux can be obtained from Eq. (2.9) as

$$
\phi_{g}=\frac{\sum_{i} \lambda_{i, g} \Sigma_{i, p}}{\sum_{i=\text { resonance }} \Sigma_{i, g, a}+\sum_{i} \lambda_{i, g} \Sigma_{i, g, s}}=\frac{\lambda_{g} \Sigma_{p}}{\Sigma_{g, a}+\lambda_{g} \Sigma_{g, s}} .
$$

The IR parameter [Gol62] can be defined as a probability passing through resonance without any reaction, which correlates the NR and WR approximations. Since the atomic mass of hydrogen $\left({ }^{1} \mathrm{H}\right)$ is very close to unity, the lethargy gain of any neutron colliding with hydrogen is very large, and the neutron can scatter beyond a resonance without any collision. This is essentially the same as the NR approximation. Therefore, for hydrogen, the IR parameter is defined as unity. For other nuclides, the IR parameter is obtained by comparing results of various ${ }^{238} \mathrm{U} /{ }^{1} \mathrm{H}$ mixtures where the hydrogen is partly replaced by the other isotopes [Les87]. This is often referred to as a hydrogenequivalence parameter.

First, a self-shielded cross section table, $\sigma_{g, a}^{238}$ vs. $\sigma_{g, b}^{238}$, must be prepared by performing slowing down calculations with various hydrogen atomic number densities $\left(\mathrm{N}^{1}\right)$ with a fixed ${ }^{238} \mathrm{U}$ atomic number density $\left(\mathrm{N}^{238}\right)$. The background cross sections can be obtained using the following equation, assuming the ${ }^{1} \mathrm{H}\left(\lambda_{g}^{1}\right)$ and ${ }^{238} \mathrm{U}\left(\lambda_{g}^{238}\right) \mathrm{IR}$ parameters to be unity.

$$
\sigma_{g, b}^{238}=\frac{N^{238} \lambda_{g}^{238} \sigma_{p}^{238}+N^{1} \lambda_{g}^{1} \sigma_{p}^{1}}{N^{238}}=\frac{\sum_{i=a l l} N^{i} \lambda_{g}^{i} \sigma_{p}^{i}}{N^{R}} .
$$


Then the slowing down calculation is performed for a mixture of ${ }^{238} \mathrm{U},{ }^{1} \mathrm{H}$ and a target nuclide $x$. A new $\sigma_{g, a}^{238}$ is calculated, and the corresponding $\sigma_{g, b}^{238}$ is read from the prepared $\sigma_{g, a}^{238}$ table. The IR parameter $\left(\lambda_{g}^{x}\right)$ for a nuclide $x$ can be obtained by using Eq. (2.12),

$$
\lambda_{g}^{x}=\frac{\sigma_{g, b}^{238} N^{238}-N^{238} \lambda_{g}^{238} \sigma_{p}^{238}-N^{1} \lambda_{g}^{1} \sigma_{p}^{1}}{N^{x} \sigma_{p}^{x}}
$$

where $\sigma_{p}^{x}$ is the potential cross section. The IR parameter of ${ }^{238} \mathrm{U}$ should be determined first, and then the IR parameters of other nuclides should be evaluated. The LAMBDA program shown in Figure 2.1 computes all of the IR parameters for all nuclides by using this procedure.

\subsubsection{Resonance Self-Shielded Data by Homogeneous Models}

The energy dependence of the cross sections in the library has been discretized by dividing the energy range of interest, $10^{-5} \mathrm{eV}-20 \mathrm{MeV}$, into a number of broad groups. These cross sections have been obtained by flux-averaging PW cross sectionssometimes more than $10^{5}$ points with typical reactor spectra. However, this procedure is impractical for the resonance isotopes in the range from $100 \mathrm{KeV}-1 \mathrm{eV}$. In this range, the cross sections exhibit many resonances, so thousands of energy groups would be required for a satisfactory discretization. In general, the number of resonance groups is limited to 5-30 for very coarse group structures including 50-60 energy groups, though SCALE generally uses well over 250 energy groups. The objective of the resonance treatment is to evaluate the effective cross section for the resonance isotopes in all resonance energy groups:

$$
\sigma_{x, g}=\frac{\int_{\Delta u_{g}} \sigma_{x}(u) \phi(u) d u}{\int_{\Delta u_{g}} \phi(u) d u} .
$$

In Eq. (2.13), the lethargy ( $\left.u=\ln \left(E_{0} / E\right), E_{0}=10 \mathrm{MeV}\right)$ is used instead of the neutron energy, and $x$ represents a reaction type. However, the library data available for this purpose are in tables of group-dependent resonance integrals (RIs), or the numerator of Eq. (2.13) vs temperatures and background cross sections. In CENTRM, the flux in Eq. (2.13) is calculated by solving the neutron slowing down equation for homogeneous or heterogeneous system.

To describe the slowing down equation in a homogeneous infinite system containing a mixture of isotopes, indexed $i$, of which one is a resonance absorber, the following three assumptions are used:

a. Nonresonance isotopes have negligible absorption and a constant potential scattering cross section for the resonance energy range. 
b. Resonance isotopes have resonance absorption cross sections as represented by $\sigma_{a i}(u)$, and scattering cross sections as represented by $\sigma_{r s, i}(u)$, in addition to the potential scattering cross section, $\sigma_{p i}$. However, apart from the resonance energy region, these resonance absorption and scattering cross sections are negligible.

c. The resonances are so well separated that the flux between them has its constant asymptotic value, as it is set to 1 .

With these assumptions, the slowing down equation at the resonance energy region, away from fission sources, is given by

$$
\begin{aligned}
& \Sigma(u) \phi(u)=Q(u), \\
& Q(u)=\sum_{i} \int_{u-\Delta_{i}}^{u} \Sigma_{s i}\left(u^{\prime}\right) \phi\left(u^{\prime}\right) \frac{\exp \left(u^{\prime}-u\right)}{1-\alpha_{i}} d u^{\prime},
\end{aligned}
$$

where

$$
\begin{aligned}
& \sum_{x i}=N_{i} \sigma_{x i}, \\
& \sum_{s i}(u)=\sum_{p i}+\Sigma_{r s, i}(u), \\
& \sum_{i}(u)=\sum_{s i}(u)+\sum_{a i}(u), \\
& \sum(u)=\sum_{i} \Sigma_{i}(u), \\
& \alpha_{i}=\left(A_{i}-1\right)^{2} /\left(A_{i}+1\right)^{2}, \\
& \Delta_{i}=-\ln \left(\alpha_{i}\right) .
\end{aligned}
$$

In Eq. (2.15), $\Sigma(u)$ is the total macroscopic cross section, and $N$ is atomic number density, while $A_{i}$ is the atomic mass, and $\Delta_{i}$ is the maximum lethargy gain per collision with isotope i. $1-\alpha_{i}$ is the maximum fractional energy loss per collision with isotope $i$.

In a homogeneous system, for a given composition, the self-shielded cross section can be calculated using Eqs. (2.13) through (2.15), and the corresponding background cross section can be calculated using Eq. (2.16).

$$
\sigma_{b}=\frac{\sum_{i=a l l} N_{i} \lambda_{i} \sigma_{i, p}}{N_{R}} .
$$

Different background cross sections can be obtained by using various composition mixtures, typically a mixture of ${ }^{1} \mathrm{H}$ and a target resonance nuclide, creating a selfshielded cross section table as a function of background cross section. Therefore, for a given composition, the corresponding background cross section can be easily calculated using Eq. (2.16), and the self-shielded cross section can be read from the table directly. 


\subsubsection{Resonance Self-Shielded Data by Heterogeneous Models}

In a heterogeneous system, for a given composition and geometry, the self-shielded cross section can also be calculated using Eqs. (2.13) through (2.15). However, since there is a leakage effect in Eq. (2.7), Eq. (2.13) cannot be used to obtain the corresponding background cross section. Therefore, the equivalence theory between the infinite homogeneous and heterogeneous problems was devised by introducing an equivalence cross section $\left(\Sigma_{e}\right)$, as follows:

$$
\Sigma_{b}=\lambda \Sigma_{p} \rightarrow \Sigma_{b}=\lambda \Sigma_{p}+\Sigma_{e} .
$$

Thus, the balance equation with an equivalence theory and an elimination of the scattering resonance $\left(\lambda \Sigma_{r s}\right)$ becomes:

$$
\left(\Sigma_{a}+\lambda \Sigma_{p}+\Sigma_{e}\right) \phi=\lambda \Sigma_{p}+\Sigma_{e}
$$

The background cross section is not a physical quantity, but an artificial one used to retrieve the correct self-shielded cross section at a given composition and geometry. It is only important to be consistent in the procedures between its generation and its use. Therefore, the elimination of the scattering resonance is possible as long as consistency is maintained. In a heterogeneous system, the self-shielded scalar flux can be obtained by solving Eq. (2.8) with a self-shielded absorption cross section obtained by solving Eq. (2.7). The corresponding background cross section is obtained as follows:

$$
\sigma_{g, b}=\frac{\Sigma_{g, b}}{N_{R}}=\frac{\sum_{i} N_{i} \lambda_{i} \sigma_{i, g, p}+\Sigma_{g, e}}{N_{R}}=\frac{\sigma_{g, a} \phi_{g}}{1-\phi_{g}} .
$$

The following is a procedure to obtain the self-shielded cross section table by using the heterogeneous models.

a. Compute the PW slowing down calculations with Eq. (2.7) by using CENTRM for the heterogeneous models.

b. Edit various MG self-shielded cross sections for various reactions, including capture $\left(\sigma_{g, a}\right)$, fission $\left(\sigma_{g, f}\right)$, elastic scattering $\left(\sigma_{g, s}\right)$ and within-group elastic scattering, using Eq. (2.13).

c. Solve the MG fixed source Eq. (2.8) or (2.9), which is called the embedded selfshielding method (ESSM) [Wil12] equation, with $\sigma_{g, a}$ from step b to obtain the scalar flux $\left(\phi_{g}\right)$.

d. Obtain the corresponding background cross section $\left(\sigma_{g, b}\right)$ using Eq. (2.19) for the heterogeneous model.

e. Repeat steps a-d, changing the geometry and composition configurations to obtain different background cross sections.

f. Complete the self-shielded cross section tables as a function of background cross section for various reactions.

g. Repeat the above procedures for various temperatures. 


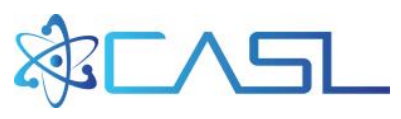

Various background cross sections can be achieved by changing geometrical and compositional configurations, as shown in Table 2.1.

Table 2.1. Variations for ${ }^{238} \mathrm{U}$ for the Heterogeneous Models

\begin{tabular}{|c|c|c|c|c|c|c|c|c|c|c|c|c|c|c|c|c|c|c|c|c|}
\hline \multicolumn{2}{|c|}{ Case } & 1 & 2 & 3 & 4 & 5 & 6 & 7 & 8 & 9 & 10 & 11 & 12 & 13 & 14 & 15 & 16 & 17 & 18 & 19 \\
\hline \multirow{3}{*}{ Volume } & Fuel & 1 & 1 & 1 & 1 & 1 & 1 & 1 & 1 & 1 & 1 & 1 & 1 & 1 & 1 & 1 & 1 & 1 & 1 & 1 \\
\hline & Clad & 1 & 1 & 1 & 1 & 1 & 1 & 1 & 1 & 1 & 1 & 1 & 1 & 1 & 1 & 1 & 1 & 1 & 1 & 1 \\
\hline & Mod & 1 & 1 & 1 & 1 & 1 & 2 & 5 & 5 & 5 & 5 & 5 & 5 & 5 & 5 & 5 & 5 & 5 & 5 & 5 \\
\hline \multirow{3}{*}{ Fuel } & ${ }^{235} \mathrm{U}$ & 1 & 1 & 1 & 1 & 1 & 1 & 1 & $\frac{1}{2}$ & $\frac{1}{4}$ & $\frac{1}{8}$ & $\frac{1}{16}$ & $\frac{1}{32}$ & $\frac{1}{10^{2}}$ & $\frac{1}{10^{2}}$ & $\frac{1}{10^{2}}$ & $\frac{1}{10^{2}}$ & $\frac{1}{10^{2}}$ & $\frac{1}{10^{2}}$ & $\frac{1}{10^{2}}$ \\
\hline & ${ }^{238} \mathrm{U}$ & 1 & 1 & 1 & 1 & 1 & 1 & 1 & $\frac{1}{2}$ & $\frac{1}{4}$ & $\frac{1}{8}$ & $\frac{1}{16}$ & $\frac{1}{32}$ & $\frac{1}{10^{2}}$ & $\frac{3}{10^{3}}$ & $\frac{1}{10^{3}}$ & $\frac{1}{10^{4}}$ & $\frac{1}{10^{5}}$ & $\frac{1}{10^{7}}$ & $\frac{1}{10^{8}}$ \\
\hline & ${ }^{16} \mathrm{O}$ & 1 & 1 & 1 & 1 & 1 & 1 & 1 & $\frac{1}{2}$ & $\frac{1}{4}$ & $\frac{1}{8}$ & $\frac{1}{16}$ & $\frac{1}{32}$ & $\frac{1}{10^{2}}$ & $\frac{1}{10^{2}}$ & $\frac{1}{10^{2}}$ & $\frac{1}{10^{2}}$ & $\frac{1}{10^{2}}$ & $\frac{1}{10^{2}}$ & $\frac{1}{10^{2}}$ \\
\hline \multirow{2}{*}{$\mathrm{H}_{2} \mathrm{O}$} & ${ }^{1} \mathrm{H}$ & $\frac{1}{400}$ & 0.2 & 0.5 & 0.75 & 1 & 1 & 1 & 1 & 1 & 1 & 1 & 1 & 1 & 1 & 1 & 1 & 1 & 1 & 1 \\
\hline & ${ }^{16} \mathrm{O}$ & $\frac{1}{400}$ & 0.2 & 0.5 & 0.75 & 1 & 1 & 1 & 1 & 1 & 1 & 1 & 1 & 1 & 1 & 1 & 1 & 1 & 1 & 1 \\
\hline
\end{tabular}

In Eq. (2.13), the numerator is defined as an RI with the flux and cross section. In Stamm'ler and Abbate's work [Sta83], the self-shield cross section is approximated using the background cross section and the RI:

and

$$
\sigma_{g, a}\left(\sigma_{b}\right)=\frac{R_{g, a}\left(\sigma_{b}\right)}{1-R_{g, a}\left(\sigma_{b}\right) / \sigma_{b}}
$$

$$
v \sigma_{g, f}\left(\sigma_{b}\right)=\frac{R_{g, v f}\left(\sigma_{b}\right)}{1-R_{g, a}\left(\sigma_{b}\right) / \sigma_{b}},
$$

where $v$ is the number of neutrons released from a fission, and $R_{g, a}$ and $R_{g, v f}$ are absorption and $v^{\star}$ fission Rls, respectively. Using Eqs. (2.20) and (2.21), the self-shield cross section table can be converted into the RI table.

\subsubsection{Self-shielded data for within-group elastic scattering}

The AMPX MG library does not include a temperature-dependent elastic scattering matrix, which results in temperature bias when performing self-shielding calculation based on Bondarenko approach. Recently, a new MT=2022 has been added to consider removal correction to generate a temperature-dependent elastic scattering matrix. The new MT=2022 is for the within-group cross section $\left(\sigma_{g}^{\text {within }}\right)$ for elastic scattering, which includes resonance self-shielded cross section tables. If the background cross section is determined by the ESSM or subgroup method, then the total elastic and within-group elastic cross sections can be obtained through 
interpolation. The temperature-dependent elastic scattering matrix at temperature $T$ can be obtained by using the following equations:

$$
\begin{gathered}
\tilde{\sigma}_{g g}^{\text {elastic }}(T)=\sigma_{g}^{\text {within }}(T) . \\
\tilde{\sigma}_{g g^{\prime}}^{\text {elastic }}(T)=\sigma_{g g^{\prime}}^{\text {elastic }}\left(T_{0}\right) \cdot \frac{\sigma_{g}^{\text {elastic }}(T)-\sigma_{g}^{\text {within }}(T)}{\sum_{g^{\prime}} \sigma_{g g^{\prime}}^{\text {elastic }}\left(T_{0}\right)-\sigma_{g g}^{\text {elastic }}\left(T_{0}\right)} .
\end{gathered}
$$

\subsection{SUBGROUP DATA GENERATION}

\subsubsection{Subgroup method}

Figure 2.4 shows the coarse energy group, including resonances. An effective selfshielded cross section for this group can be obtained by the following flux weighting using Eq. (2.13). In the subgroup method, the resonances are divided by the subgroup levels, and the corresponding probability for each subgroup level $\left(\sigma_{x n}\right)$ is defined as the subgroup weight $\left(w_{x n}\right)$, as shown in Figure 2.4. [Sta03] Therefore, Eq. (2.13) can be approximated with removing the coarse group index, as follows:

$$
\sigma_{x}=\frac{\sum_{n} w_{x n} \sigma_{x n} \phi_{n}}{\sum_{n} w_{a n} \phi_{n}},
$$

where the summation of the subgroup weights is unity.

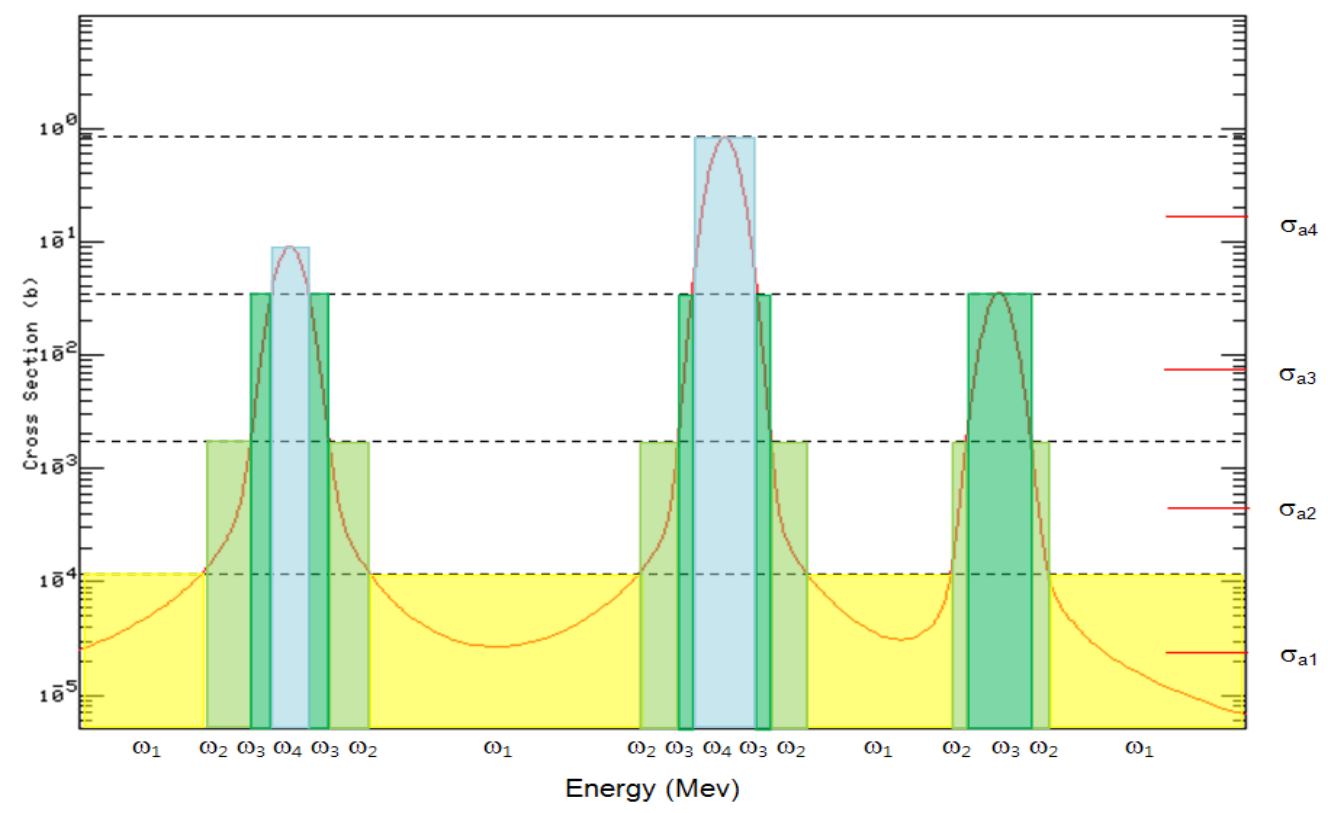

Figure 2.3. Resonances and Subgroups. 
In the transport calculation, the final goal of the resonance treatment is to construct a procedure so that the self-shielded cross section estimated by Eq. (2.24) will be identical to the self-shielded cross section by Eq. (2.13). The self-shielded scalar flux $\phi_{n}$ in Eq. (2.26) should be estimated from the fixed source transport calculation. If there is only one resonant nuclide, the fixed source transport equation will be

$$
\hat{\Omega} \cdot \nabla \psi_{n}+\left(N_{r} \sigma_{a n}+\sum_{i} \lambda_{i} \Sigma_{p}^{i}\right) \psi_{n}=\sum_{i} \lambda_{i} \Sigma_{p}^{i}
$$

and

$$
\phi_{n}=\int \psi_{n} d \hat{\Omega},
$$

where $N_{r}$ denotes the particle number density for the resonant nuclide, $\Sigma_{p}$ is a potential cross section, and $\psi_{n}$ is an angular flux. Equivalence theory enforces that the selfshielded scalar flux is expressed with the absorption $\left(\sigma_{a n}\right)$ and the background cross sections $\left(\sigma_{b n}\right)$.

$$
\phi_{n}=\frac{\sigma_{b n}}{\sigma_{a n}+\sigma_{b n}} .
$$

Typically, the background cross section in the heterogeneous model is divided into two parts.

$$
\sigma_{b n}=\lambda \sigma_{p}+\sigma_{e n}\left(\sigma_{a n}\right)
$$

where $\lambda$ denotes an intermediate resonance parameter, $\sigma_{p}$ is a potential cross section, and $\sigma_{e n}$ is an equivalence cross section. By using Eq. (2.27), Eq. (2.24) can be written as follows:

$$
\sigma_{x}=\frac{\sum_{n} w_{x n} \sigma_{x n} \frac{\sigma_{b n}}{\sigma_{a n}+\sigma_{b n}}}{1-\sum_{n} w_{a n} \frac{\sigma_{a n}}{\sigma_{a n}+\sigma_{b n}}} .
$$

Therefore, if the subgroup levels and weights are given for a certain nuclide, the effective self-shielded cross section can be obtained by estimating the corresponding background cross sections $\left(\sigma_{b n}\right)$ in the lattice calculation. Since the equivalence cross section is not sensitive to the absorption cross section but is sensitive to the geometrical configuration, $\sigma_{b n}$ is often approximated by a single background cross section $\sigma_{b}$. If there are several resonant nuclides, there will be a resonant interference between the resonant nuclides. Since this interference will have an effect on the self-shielded scalar flux, Eq. (2.29) can be written as follows: 


$$
\sigma_{x}=\frac{\sum_{n} w_{x n} \sigma_{x n} \frac{\sigma_{b n}}{\sigma_{a n}+\hat{\sigma}_{a}+\sigma_{b n}}}{1-\sum_{n} w_{a n} \frac{\sigma_{a n}}{\sigma_{a n}+\hat{\sigma}_{a}+\sigma_{b n}}},
$$

where $\hat{\sigma}_{g}$ is the total absorption cross section of the other resonant nuclides. The effective self-shielded cross sections are estimated iteratively.

\subsubsection{Subgroup data generation}

The $R I_{x}$ is defined as the numerator of Eq. (2.24), and the RI divided by lethargy width is also called $R_{x}$. The RI can be written as Eq. (2.31) by using the subgroup weights and levels from Eq. (2.29).

$$
R_{x}=\sum_{n} w_{n} \sigma_{x n} \frac{\sigma_{b n}}{\sigma_{a n}+\sigma_{b n}} \approx \sum_{n} w_{n} \sigma_{x n} \frac{\sigma_{b}}{\sigma_{a n}+\sigma_{b}}
$$

Since the denominator of Eq. (2.24) can be understood as a scalar flux ( $\phi$ ) for the coarse energy group, Eq. (2.24) can be rewritten as follows:

$$
\sigma_{x}=\frac{R_{x}}{\phi}
$$

As described previously, the constituent compositions and the geometrical configurations are varied to obtain various background cross sections to complete the $\mathrm{RI}$ table. Index ' $k$ ' for the variation cases can be added to Eq. (2.32).

$$
\sigma_{x, k}=\frac{R_{x, k}}{\phi_{k}} \quad(k=1,2, \ldots, K) .
$$

The $\mathrm{RI}\left(R_{x, k}\right)$ can be estimated directly from the IRFFACTOR program for the variation cases. The subgroup levels and weights can be obtained from Eq. (2.31) by the least square fitting to minimize the difference between the original $\mathrm{RI}$ and the reconstructed RI using Eq. (2.31). Subgroup levels are arbitrary, and the corresponding subgroup weights are obtained by minimizing the following function $f$.

$$
\begin{gathered}
f\left(w_{1}, \ldots, w_{K}\right)=\sum_{k} \frac{1}{R_{x, k}^{2}}\left(R_{x, k}-\sum_{n} w_{x n} \sigma_{x n, k} \frac{\sigma_{b n, k}}{\sigma_{a n, k}+\sigma_{b n, k}}\right)^{2} . \\
f\left(w_{1}, \ldots, w_{K}\right)=\sum_{k} \frac{1}{R_{x, k}^{2}}\left(R_{x, k}-\sum_{n} w_{x n} \sigma_{x n, k} \frac{\sigma_{b, k}}{\sigma_{a n, k}+\sigma_{b, k}}\right)^{2} .
\end{gathered}
$$




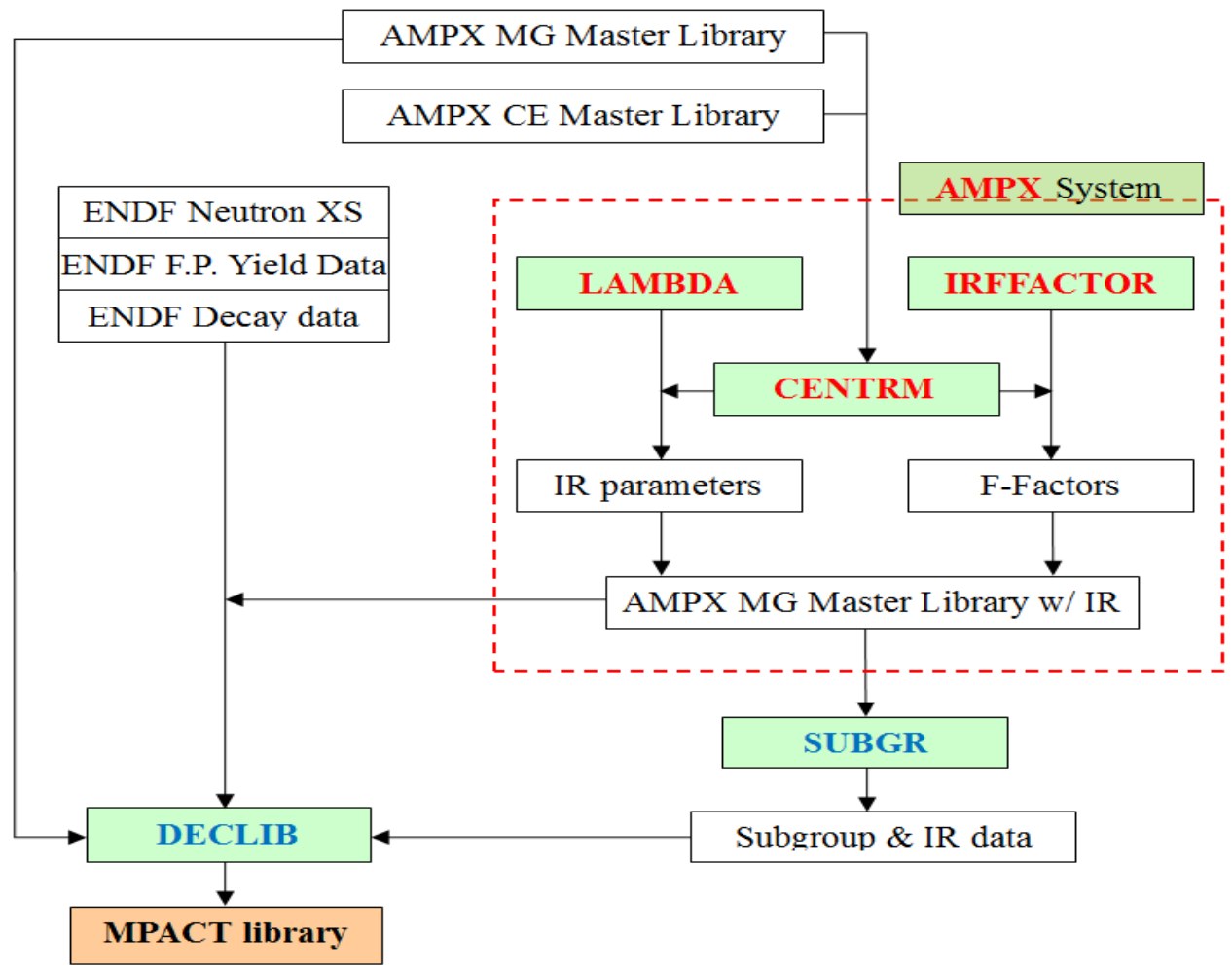

Figure 2.4 Resonance Data Generation Procedure.

Subgroup levels must be automatically adjusted to minimize the difference between the original $\mathrm{RI}$ and the reconstructed $\mathrm{RI}$ using the subgroup levels and weights. The $\mathrm{RI}$ table from the IRFFACTOR calculation includes the background cross sections as a function of the absorption cross section at each variation $k$ to cover all the subgroup levels. Although the subgroup levels are varied at iterations, the corresponding background cross section $\left(\sigma_{b n, k}\right)$ can be obtained through interpolation of the given table. SUBGR includes two options to generate the subgroup weights and levels by using Eq. (2.34), which uses the level dependent cross section, and Eq. (2.35), which uses the constant background cross section. Figure 2.4 provides a flow chart for generating the subgroup data.

When the resonance interference is neglected, errors in estimating the effective selfshielded cross section come mainly from the subgroup levels and weights themselves, as well as the scalar flux estimation. In the real application, the self-shielded scalar flux is estimated by the following equation.

$$
\hat{\phi}_{k}=1-\sum_{n} w_{a n} \frac{\sigma_{a n, k}}{\sigma_{a n, k}+\sigma_{b n, k}},
$$

where the subgroup weights and levels are given and the corresponding background cross sections $\left(\sigma_{b n, k}\right)$ are obtained by the fixed source transport calculations of the 
transport lattice code using Eq. (2.25). The difference between the scalar flux $\left(\phi_{k}\right)$ in Eq. (2.33) and the scalar flux $\left(\hat{\phi}_{k}\right)$ in Eq. (2.36) causes a difference in the effective selfshielded cross section.

To remove this error, a new method [Joo09] has been proposed to generate the subgroup weights in which the subgroup weights are to be estimated to conserve the self-shielded cross sections as follows:

$$
f\left(w_{1}, \ldots, w_{K}\right)=\sum_{k} \frac{1}{R_{x, k}^{2}}\left(\hat{R}_{x, k}-\sum_{n} w_{x n} \sigma_{x n, k} \frac{\sigma_{b n, k}}{\sigma_{a n, k}+\sigma_{b n, k}}\right)^{2},
$$

where

$$
\hat{R}_{x, k}=\sigma_{x, k} \hat{\phi}_{k}=\sigma_{x, k}\left(1-\sum_{n} w_{a n} \frac{\sigma_{a n, k}}{\sigma_{a n, k}+\sigma_{b n, k}}\right) .
$$

\subsubsection{Subgroup method for nonuniform temperature distribution}

In a heterogeneous system, the self-shielded resonance cross sections are estimated from the self-shielded scalar fluxes obtained by the following fixed source transport equation.

$$
\hat{\Omega} \cdot \nabla \psi_{g, m}+\sum_{i}\left(\Sigma_{i, a, g}^{m}+\lambda_{i, g} \Sigma_{i, p}\right) \psi_{g, m}(\hat{\Omega})=\sum_{i} \lambda_{i, g} \Sigma_{i, p}
$$

where subscript $m$ denotes a problem case with different absorption cross section levels at energy group $g$. In Eq. (2.39), $\Sigma_{i, a, g}$ and $\Sigma_{i, p}$ denote macroscopic absorption and potential cross sections of nuclide $i$, respectively, and $\lambda_{i, g}$ IR parameter.

Equation (2.39) should be modified for the resonance transport calculations involving nonuniform temperature distribution in which the macroscopic absorption cross sections should include the temperature distribution, as follows:

$$
\sum_{i, a, g}^{m}=N_{i} \sigma_{i, a, g}^{m}\left(T_{\text {ave. }}\right) \frac{\sigma_{i, a, g}^{m}(T)}{\sigma_{i, a, g}^{m}\left(T_{\text {ave. }}\right)} \approx N_{i} \sigma_{i, a, g}^{m}\left(T_{a v e .}\right) f_{i, a, g}(T),
$$

where $T$ and $T_{\text {ave. }}$ are local and volume-averaged temperatures, respectively. The function $f(T)$ was approximated by the following equation [Wem07].

where

$$
f_{i, a, g}(T)=\frac{R_{i, a, g}\left(T, \sigma_{p}\right)}{R_{i, a, g}\left(T_{a v e .}, \sigma_{p}\right)} \cdot \frac{\sigma_{p}-R_{i, a, g}\left(T_{a v e .}, \sigma_{p}\right)}{\sigma_{p}-R_{i, a, g}\left(T, \sigma_{p}\right)},
$$




$$
\sigma_{p} \approx \frac{\sum_{j=a l l} N_{j} \lambda_{j, g} \sigma_{j, p}}{N_{i}}
$$

$N_{i}$ is the particle number density of nuclide $i$, and $R_{i, a, g}$ RI. Equation (2.45) can be rewritten without any approximation, as follows:

$$
\sigma_{b, g}^{m}=\frac{\sum_{j=\text { all }} N_{j} \lambda_{j, g} \sigma_{j, p}+\sum_{e, g}^{m}}{N_{i}}
$$

Therefore, the explicit equation will be

$$
f_{i, a, g}^{m}(T)=\frac{\sigma_{i, a, g}^{m}(T)}{\sigma_{i, a, g}^{m}\left(T_{a v e}\right)}=\frac{R_{i, a, g}\left(T, \sigma_{b, g}^{m}\right)}{R_{i, a, g}\left(T_{a v e .}, \sigma_{b, g}^{m}\right)} \cdot \frac{\sigma_{b, g}^{m}-R_{i, a, g}\left(T_{a v e .}, \sigma_{b, g}^{m}\right)}{\sigma_{b, g}^{m}-R_{i, a, g}\left(T, \sigma_{b, g}^{m}\right)} .
$$

When performing a MPACT calculation with thermal-hydraulic feedback, $\Sigma_{e, g}^{m}$ can be obtained from the previous outer iteration.

Another better approximation is to obtain the correction factor from the previous step, as follows:

$$
\sum_{i, a, g}^{m(\ell+1)}=N_{i} \sigma_{i, a, g}^{m}\left(T_{a v e .}\right) \frac{\sigma_{i, a, g}^{m}(T)}{\sigma_{i, a, g}^{m}\left(T_{a v e .}\right)} \approx N_{i} \sigma_{i, a, g}^{m}\left(T_{a v e .}\right) \frac{\sigma_{i, a, g}^{(\ell)}(T)}{\sigma_{i, a, g}^{(\ell)}\left(T_{a v e .}\right)}
$$

\subsection{TRANSPORT CROSS SECTIONS FOR ${ }^{1} \mathrm{H}$}

The MOC eigenvalue calculation with high order $\left(\geq P_{2}\right)$ scattering requires 2 times more computing time compared to the $\mathrm{P}_{0}$ calculation. Typically, most of transport lattice codes are using an out-scattering based transport corrected $\mathrm{P}_{0}\left(\mathrm{TCP}_{0}\right)$ scattering matrix in which the diagonal terms of the $\mathrm{P}_{0}$ scattering matrix are subtracted by total $\mathrm{P}_{1}$ scattering cross sections. The $\mathrm{P}_{1}$ corrected $\mathrm{P}_{0}$ scattering matrix for ${ }^{1} \mathrm{H}$ may include negative value in the diagonal components. This causes negative flux, resulting in convergence error. Another issue of out-scattering-based transport correction shows significant global power tilt for whole core problems, including reflectors. Therefore, a proper transport correction method is needed to have reasonable neutron leakage, as high order scattering is considered and to guarantee no negative flux.

The Neutron Leakage Conservation (NLCP0) method [Her13] has been used to generate transport cross sections for ${ }^{1} \mathrm{H}$. The goal of $\mathrm{NLCP}_{0}$ is to obtain diffusion coefficients to have the same neutron leakage as that obtained in the high order scattering transport calculation, as follows: 


$$
\hat{\Omega} \cdot \nabla \varphi_{g}(\hat{\Omega})=-D_{g} \nabla^{2} \phi_{g}
$$

With a one-dimensional slab model, neutron leakages at the specified surfaces can be obtained from the high order scattering transport calculation.

$$
\text { Leakage }=J_{\text {right }}-J_{\text {left }} \text {. }
$$

Diffusion coefficients can be determined to have same leakage in the diffusion calculation by using the following derivation.

$$
\begin{gathered}
-D \nabla^{2} \phi+\Sigma_{a} \phi=\frac{1}{k_{e f f}} v \Sigma_{f} \phi . \\
\nabla^{2} \phi+B^{2} \phi=0 \rightarrow \frac{\partial^{2}}{\partial x^{2}} \phi(x)+B^{2} \phi(x)=0 . \\
\phi(x)=\cos (B x) . \\
J_{r i g h t}-J_{\text {left }}=\int_{0}^{W} d x\left(-D \frac{\partial^{2}}{\partial x^{2}} \phi(x)\right)=\int_{0}^{W} d x D B^{2} \phi(x)=D B^{2} \int_{0}^{W} d x \phi(x)=D B^{2} \hat{\phi} . \\
D=\frac{J_{r i g h t}-J_{l e f t}}{B^{2} \hat{\phi}} . \\
B_{\text {geom }}^{2}=\left(\frac{\pi}{W}\right)^{2} .
\end{gathered}
$$

When performing the MG transport calculation with high order scattering, he group-wise bucklings must be checked to ensure that they are constant, independent of the energy group. This work can be completed by drawing a normalized neutron spectrum shape for each group.

$$
B_{\text {geom }}^{2}=B^{2}=B_{g}^{2}
$$

Multigroup diffusion coefficients and transport cross sections can be obtained as follows:

$$
\begin{gathered}
D_{g}=\frac{J_{g, r i g h t}-J_{g, l e f t}}{B^{2} \hat{\phi}_{g}} . \\
\Sigma_{t r, g}=\frac{1}{3 D_{g}} .
\end{gathered}
$$

This computational model is from Herman et al. [Her13], as follows:

- slab $100 \mathrm{~cm} \mathrm{w/vacuum} \mathrm{boundary,} 0.005 \mathrm{~cm}$ mesh size,

- all ${ }^{1} \mathrm{H}$ with $4.780 \mathrm{E}+23$ atom $/ \mathrm{cm}^{3}$, 
- 9 temperatures: $293.6,350,400,450,500,550,600,650,800 \mathrm{~K}$, and

- source: ${ }^{235} \mathrm{U}$ fission spectrum with buckled cosine spatial distribution.

A new SCALE procedure-h1TransportXS-is based on one-dimensional slab discrete ordinate transport calculation and has been developed to generate transport correction factors by using the NLC method. Figure 2.5 provides the 51-group transport correction factors for ${ }^{1} \mathrm{H}$ with various temperatures.

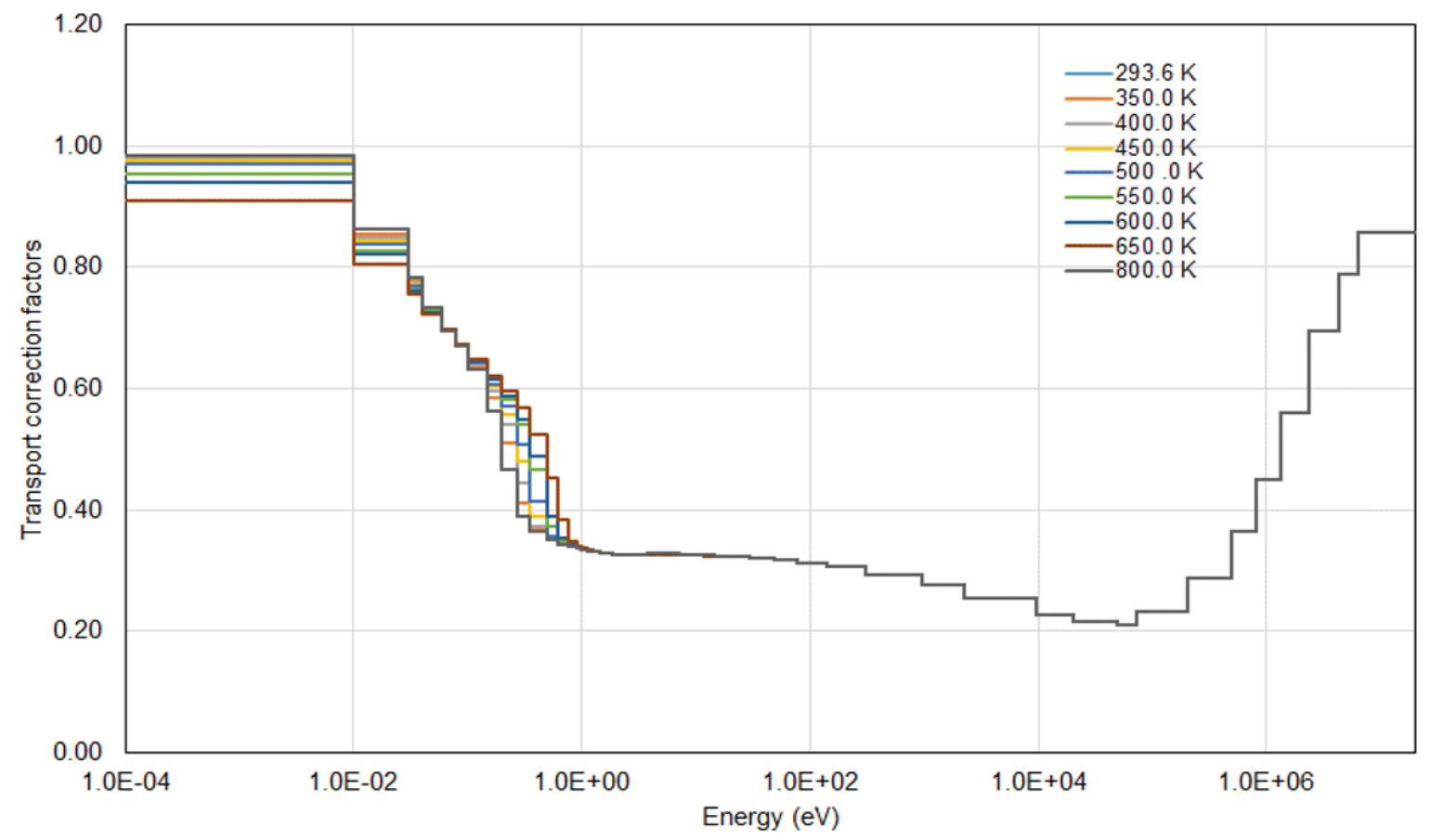

Figure 2.5. 51-Group Transport Correction Factors for ${ }^{1} \mathrm{H}$.

\subsection{SPH METHOD FOR THE ${ }^{238} \mathrm{U}$ SUBGROUP DATA}

Energy group collapsing from fine to coarse groups introduces angle-dependent total cross sections and high order flux moment weighted scattering matrices. Since the angular fluxes and high order flux moments are problem dependent, it is not possible to generate the coarse energy group resonance data and scattering matrices considering angle dependency of nuclear data. In addition, self-shielded cross section tables are generated by considering the resonance interference effect between resonance nuclides such as ${ }^{238} \mathrm{U}$ and ${ }^{235} \mathrm{U}$ in the CENTRM PW slowing down calculation. This method may provide better agreement for the specific cases in MG resonance selfshielded cross sections or reaction rates between the reference and MPACT solutions. However, resonance interferences are doubly considered due to the Bondarenko iteration of subgroup method for resonance interference, and this procedure would introduce significant ${ }^{235} \mathrm{U}$ enrichment bias, resulting in radial power tilt at the whole core calculation. 
A new SPH method has been developed to address the issues described above by conserving reaction rates between high order reference solutions and the low order MPACT calculations. The procedure in Figure 2.6 starts with the KENO models, including the same variation cases shown in Table 2.1 as the heterogeneous IRFFACTOR cases. Then the MG self-shielded cross sections are tallied, and the corresponding background cross sections are estimated by the ESSM calculations to complete the self-shielded cross section tables. The subgroup data are generated by SUBGR and incorporated into the MPACT MG library, and then the MPACT calculations are performed for the same variation cases to obtain the group-wise SPH factors defined in Eq. (2.57).

$$
\begin{aligned}
f_{x, g, i}^{n+1} & =\frac{\sigma_{x, g, i}^{n} \phi_{x, g, i}^{n}}{\sigma_{x, g, i}^{k e n o} \phi_{x, g, i}^{k e n o}} \\
\sigma_{x, g, i}^{n+1} & =f_{x, g, i}^{n+1} \sigma_{x, g, i}^{n}
\end{aligned}
$$

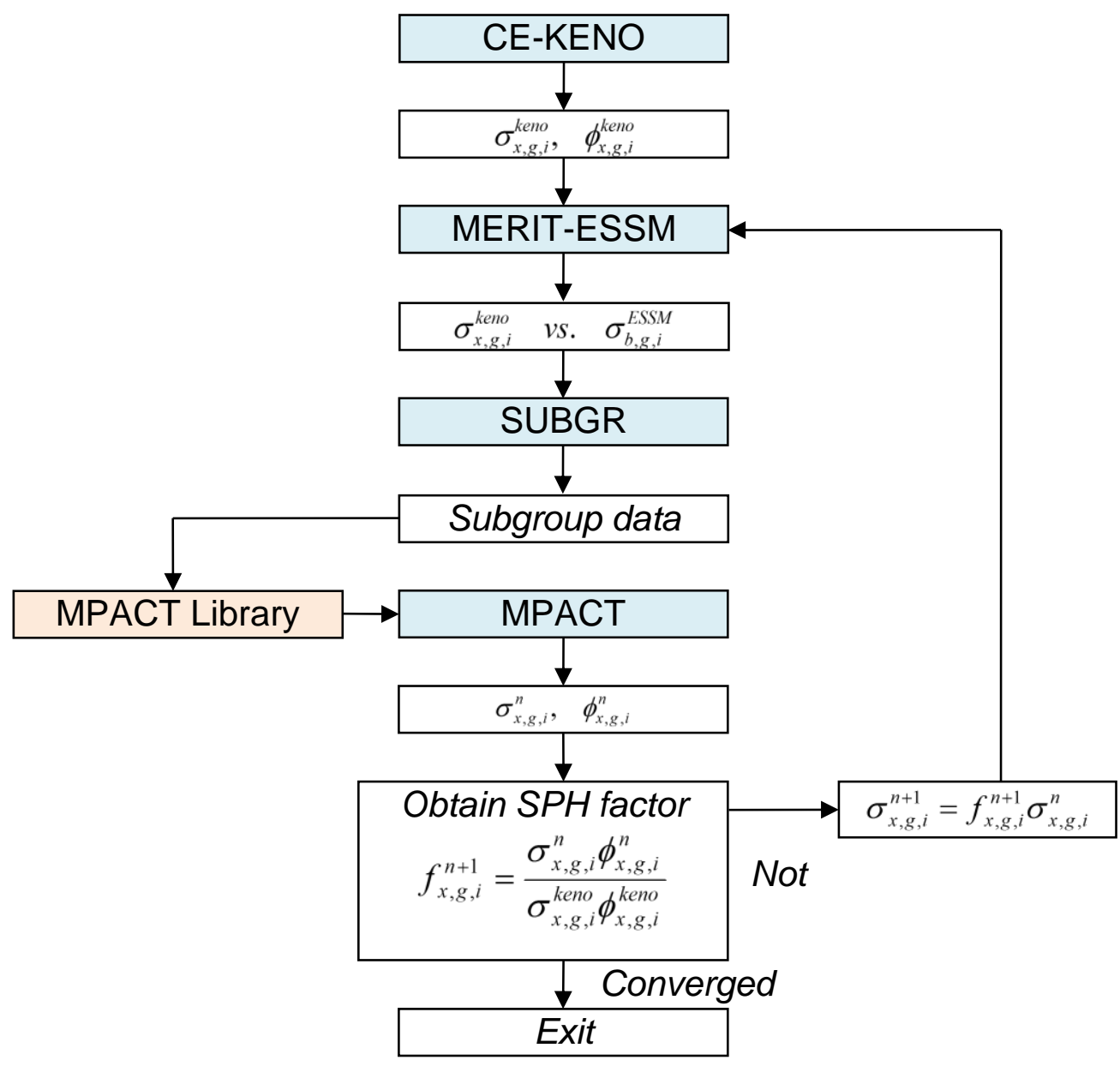

Figure 2.6. SPH Method to Generate the ${ }^{238} \mathrm{U}$ Subgroup Data. 


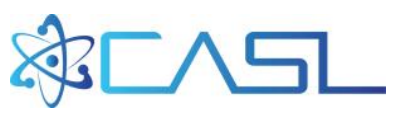

Newly adjusted self-shielded cross section tables are generated by using Eq. (2.58) and new corresponding background cross sections, and then new subgroup data are produced accordingly. The SPH factors can be selectively applied to the specified energy groups indicating significant reaction rate differences. Figure 2.7 compares reaction rate differences for ${ }^{238} \mathrm{U}$ with and without SPH factors. The differences are obtained from a comparison between the MPACT and CE-KENO reaction rates. The result indicates significant improvements in the largest resonance and high-energy resonances. This SPH method is simple and does not require any modification of the cross section library format. And this method effectively resolves the issues of angledependent total cross sections, resonance interference, and $\mathrm{P}_{0}$ flux moment weighted scattering matrices.

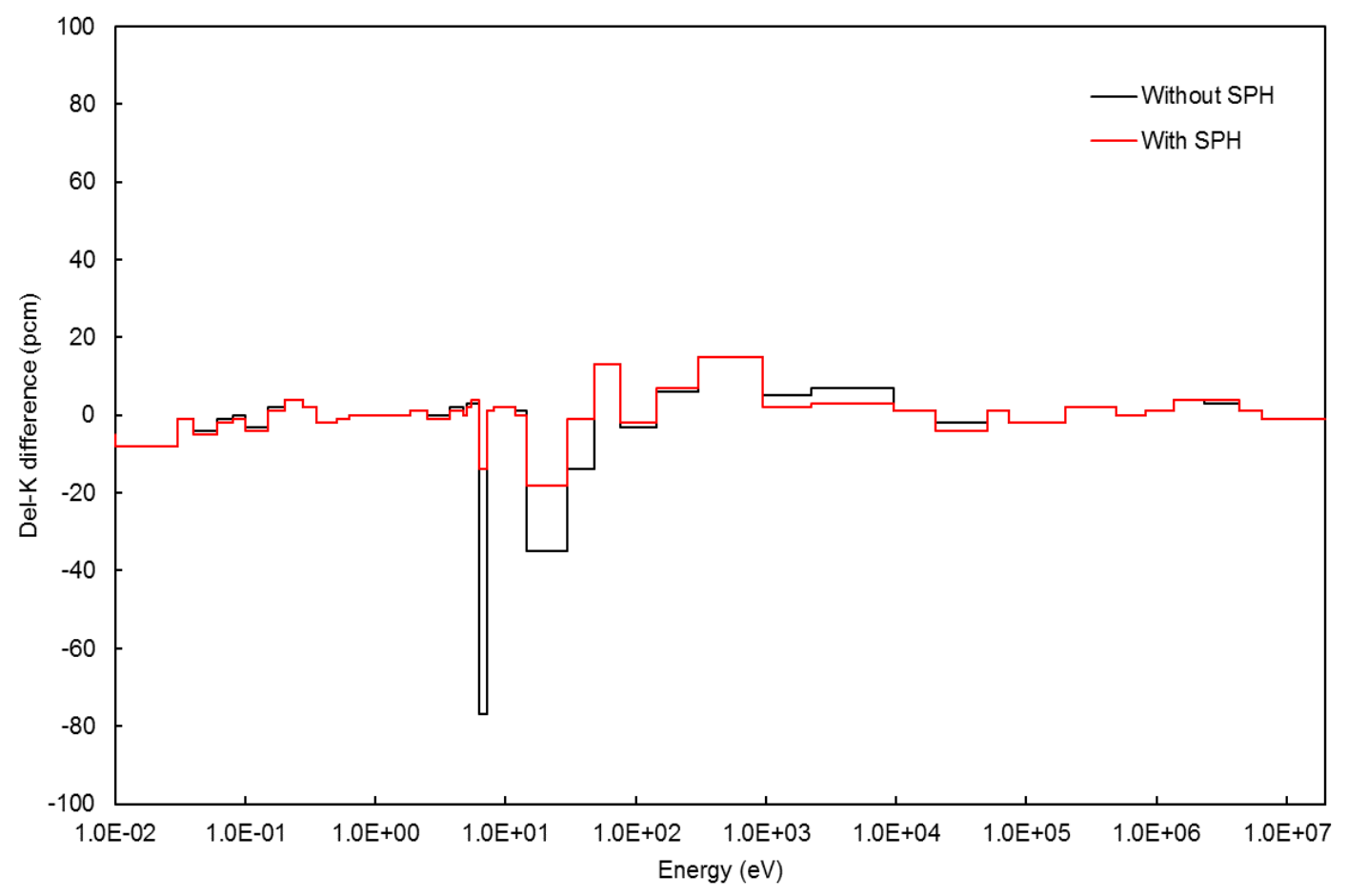

Figure 2.7. ${ }^{238} \mathrm{U}$ 51-Group Absorption Reaction Rate Differences with/without SPH Factors. 


\section{THE IMPACT 51-GROUP LIBRARY GENERATION}

A new ENDF/B-VII.1 v4.3m1 MPACT 51-group library was developed by the AMPX/SCALE and CASL XSTools code packages. The 51-group structure was developed to be a subset of the SCALE-6.2 ENDF/B-VII.1 252-group referring to the HELIOS-1.9 47-group structures, with evenly distributed group widths to exclude a stability issue due to negative cross sections that occur when performing transport corrected $\mathrm{P}_{0}$ calculations. Table 3.1 provides the 51-group structure; groups 10-31 include resonance and subgroup data.

Table 3.1. The 51-Group Structure

\begin{tabular}{|c|c|c|c|c|c|}
\hline Group & Upper bound & Group & Upper bound & Group & Upper bound \\
\hline 1 & $2.000000 \mathrm{E}+07$ & 18 & $4.830000 \mathrm{E}+01$ & 35 & $1.080000 \mathrm{E}+00$ \\
\hline 2 & $6.434000 \mathrm{E}+06$ & 19 & $3.000000 \mathrm{E}+01$ & 36 & $1.010000 \mathrm{E}+00$ \\
\hline 3 & $4.304000 \mathrm{E}+06$ & 20 & $1.440000 \mathrm{E}+01$ & 37 & $9.750000 \mathrm{E}-01$ \\
\hline 4 & $2.354000 \mathrm{E}+06$ & 21 & $1.190000 \mathrm{E}+01$ & 38 & $9.250000 \mathrm{E}-01$ \\
\hline 5 & $1.356000 \mathrm{E}+06$ & 22 & $8.100000 \mathrm{E}+00$ & 39 & $7.500000 \mathrm{E}-01$ \\
\hline 6 & $8.200000 \mathrm{E}+05$ & 23 & $7.150000 \mathrm{E}+00$ & 40 & $6.250000 \mathrm{E}-01$ \\
\hline 7 & $4.920000 \mathrm{E}+05$ & 24 & $6.250000 \mathrm{E}+00$ & 41 & $5.000000 \mathrm{E}-01$ \\
\hline 8 & $2.000000 \mathrm{E}+05$ & 25 & $5.400000 \mathrm{E}+00$ & 42 & $3.500000 \mathrm{E}-01$ \\
\hline 9 & $7.300000 \mathrm{E}+04$ & 26 & $5.000000 \mathrm{E}+00$ & 43 & $2.750000 \mathrm{E}-01$ \\
\hline 10 & $5.000000 \mathrm{E}+04$ & 27 & $4.700000 \mathrm{E}+00$ & 44 & $2.000000 \mathrm{E}-01$ \\
\hline 11 & $2.000000 \mathrm{E}+04$ & 28 & $3.730000 \mathrm{E}+00$ & 45 & $1.500000 \mathrm{E}-01$ \\
\hline 12 & $9.500000 \mathrm{E}+03$ & 29 & $2.470000 \mathrm{E}+00$ & 46 & $1.000000 \mathrm{E}-01$ \\
\hline 13 & $2.250000 \mathrm{E}+03$ & 30 & $1.860000 \mathrm{E}+00$ & 47 & $8.000000 \mathrm{E}-02$ \\
\hline 14 & $9.500000 \mathrm{E}+02$ & 31 & $1.450000 \mathrm{E}+00$ & 48 & $6.000000 \mathrm{E}-02$ \\
\hline 15 & $3.050000 \mathrm{E}+02$ & 32 & $1.250000 \mathrm{E}+00$ & 49 & $4.000000 \mathrm{E}-02$ \\
\hline 16 & $1.430000 \mathrm{E}+02$ & 33 & $1.175000 \mathrm{E}+00$ & 50 & $3.000000 \mathrm{E}-02$ \\
\hline 17 & $7.600000 \mathrm{E}+01$ & 34 & $1.130000 \mathrm{E}+00$ & 51 & $1.000000 \mathrm{E}-02$ \\
\hline
\end{tabular}

\subsection{AMPX 51-GROUP LIBRARY}

The ENDF/B-VII.1 AMPX 51-group library was generated by using the AMPX EXSITE utility to generate the AMPX input files for all nuclides by expanding a template. Figure 2.1 provides the AMPX procedure to generate the AMPX MG library, where the left side of the flow chart is for the conventional procedure, and the right side is for the new procedure that improves the Bondarenko resonance data. After completing the AMPX calculations for all nuclides, individual MG data files can be merged into an initial AMPX MG library using the AMPX AJAX module.

The IR parameters are generated for all nuclides by using the AMPX LAMBDA module using a procedure introduced in Section 2.2.1 in which the IR parameters are estimated only for the specified energy groups and unity is assigned to other energy groups. In addition, homogeneous Bondarenko F-factors (resonance self-shielded cross sections) are generated for nuclides with $\geq 40(\mathrm{Zr})$ atomic number, substituting the original F-factors based on the NR approximation.

Only selected resonance nuclides include heterogeneous F-factors; they have been determined to be important resonance nuclides because they can significantly impact 
the neutronics result. The 23 nuclides listed below were selected to have heterogeneous $\mathrm{F}$-factors. The subgroup data for these nuclides were generated by conserving cross sections.

- ${ }^{107} \mathrm{Ag},{ }^{109} \mathrm{Ag},{ }^{113} \mathrm{Cd},{ }^{113} \mathrm{In},{ }^{115} \mathrm{In},{ }^{133} \mathrm{Cs},{ }^{155} \mathrm{Eu},{ }^{155} \mathrm{Gd},{ }^{156} \mathrm{Gd},{ }^{157} \mathrm{Gd},{ }^{158} \mathrm{Gd},{ }^{167} \mathrm{Er}$, ${ }^{232} \mathrm{Th},{ }^{233} \mathrm{U},{ }^{235} \mathrm{U},{ }^{236} \mathrm{U},{ }^{238} \mathrm{U},{ }^{238} \mathrm{Pu},{ }^{239} \mathrm{Pu},{ }^{240} \mathrm{Pu},{ }^{241} \mathrm{Pu},{ }^{242} \mathrm{Pu}$, and ${ }^{241} \mathrm{Am}$

Since the Bondarenko approach is not typically capable of addressing resonance interference effects explicitly, heterogeneous F-factors can be generated in two different ways, with or without consideration of explicit resonance interference. The term single indicates without resonance interference, and Multiple indicates with resonance interference. The single absorber model has only been applied to 4 nuclides, including ${ }^{113} \mathrm{Cd},{ }^{113} \mathrm{In},{ }^{115} \mathrm{In}$ and ${ }^{238} \mathrm{U}$.

The heterogeneous IRFFACTOR results in two F-factor tables, the first of which can be incorporated by AMPX AJAX, and the second (subgrpdata) is for SUBGR to generate subgroup data. The first table (the AMPX MG master library) can also be used in subgroup data generation. However, to generate subgroup data to conserve cross sections, subgroup-level-dependent background cross sections should be added to the F-factor tables (self-shielded cross section table). The AMPX MG library does not include the subgroup-level-dependent background cross sections, but the subgrpdata file includes them.

\subsection{MPACT 51-GROUP LIBRARY}

The Bondarenko F-factors in the AMPX MG library should be converted into RI tables to be used in the subgroup data generation. Then the subgroup data are generated by using SUBGR. Subgroup data including weights and levels have been generated for 49 important resonance nuclides, as shown in Table 3.2 for all energy groups.

Table 3.2 List of Nuclides, Including Subgroup Data

\begin{tabular}{|c|c|c|c|c|c|c|c|c|c|}
\hline No. & Nuclide & No. & Nuclide & No. & Nuclide & No. & Nuclide & No. & Nuclide \\
\hline 1 & ${ }^{91} \mathrm{Zr}$ & 11 & ${ }^{131} \mathrm{Xe}$ & 21 & ${ }^{157} \mathrm{Gd}$ & 31 & ${ }^{177} \mathrm{Hf}$ & 41 & ${ }^{235} \mathrm{U}$ \\
\hline 2 & ${ }^{96} \mathrm{Zr}$ & 12 & ${ }^{133} \mathrm{Cs}$ & 22 & ${ }^{158} \mathrm{Gd}$ & 32 & ${ }^{178} \mathrm{Hf}$ & 42 & ${ }^{236} \mathrm{U}$ \\
\hline 3 & ${ }^{95} \mathrm{Mo}$ & 13 & ${ }^{152} \mathrm{Sm}$ & 23 & ${ }^{160} \mathrm{Dy}$ & 33 & ${ }^{179} \mathrm{Hf}$ & 43 & ${ }^{238} \mathrm{U}$ \\
\hline 4 & ${ }^{99} \mathrm{Tc}$ & 14 & ${ }^{151} \mathrm{Eu}$ & 24 & ${ }^{161} \mathrm{Dy}$ & 34 & $180 \mathrm{Hf}$ & 44 & $238 \mathrm{Pu}$ \\
\hline 5 & ${ }^{103} \mathrm{Rh}$ & 15 & ${ }^{152} \mathrm{Eu}$ & 25 & ${ }^{162} \mathrm{Dy}$ & 35 & ${ }^{182} \mathrm{~W}$ & 45 & $239 \mathrm{Pu}$ \\
\hline 6 & $108 \mathrm{Pd}$ & 16 & ${ }^{153} \mathrm{Eu}$ & 26 & ${ }^{163} \mathrm{Dy}$ & 36 & ${ }^{183} \mathrm{~W}$ & 46 & $240 \mathrm{Pu}$ \\
\hline 7 & ${ }^{107} \mathrm{Ag}$ & 17 & ${ }^{154} \mathrm{Eu}$ & 27 & ${ }^{164} \mathrm{Dy}$ & 37 & ${ }^{184} \mathrm{~W}$ & 47 & ${ }^{241} \mathrm{Pu}$ \\
\hline 8 & $109 \mathrm{Ag}$ & 18 & ${ }^{155} \mathrm{Eu}$ & 28 & ${ }^{166} \mathrm{Er}$ & 38 & ${ }^{186} \mathrm{~W}$ & 48 & $242 \mathrm{Pu}$ \\
\hline 9 & ${ }^{113} \mathrm{In}$ & 19 & ${ }^{155} \mathrm{Gd}$ & 29 & ${ }^{167} \mathrm{Er}$ & 39 & ${ }^{232} \mathrm{Th}$ & 49 & $241 \mathrm{Am}$ \\
\hline 10 & ${ }^{115} \mathrm{In}$ & 20 & ${ }^{156} \mathrm{Gd}$ & 30 & ${ }^{176} \mathrm{Hf}$ & 40 & ${ }^{233} \mathrm{U}$ & & \\
\hline
\end{tabular}

The following data files are required for DECLIB to generate the MPACT MG library.

- AMPX MG library, 
- ENDF/B files: neutron data, decay constants, fission product yields,

- subgroup data and RI table (49 nuclides, groups 10-31 in 51-g),

- transport correction factors $\left({ }^{1} \mathrm{H}\right)$,

- predetermined background cross sections (105 nuclides),

- transient data (21 nuclides), and

- subgroup data with epithermal upscattering $\left({ }^{238} \mathrm{U}\right)$.

Two sets of ${ }^{238} \mathrm{U}$ subgroup data with and without considering epithermal upscattering have been generated by using the SPH method introduced in Section 2.5, for which the CE KENO calculations were performed without and with the Doppler broadening rejection correction (DBRC) [Bec10] option. The MPACT MG library includes ${ }^{238} \mathrm{U}$ resonance and subgroup data with and without considering epithermal upscattering, one of which will be used according to a MPACT user option.

Figure 3.1 provides a flow diagram of DECLIB to generate the MPACT MG library. The required data for the steady-state transport calculation are the transport cross section, fission cross section, the average number of neutrons released from a fission reaction, and the fission spectrum for each nuclide. Since the absorption and fission cross sections are modified through the resonance treatment and are needed for the depletion calculation, those cross sections should be included. The $(n, 2 n)$ and $(n, 3 n)$ cross sections are required for the depletion calculation. High order $\left(P_{1}-P_{3}\right)$ scattering matrices are also included. Therefore, the multigroup data required in the library are as follows:
a. transport cross section $\left(\sigma_{t r}\right)$
b. absorption cross section $\left(\sigma_{a=} \sigma_{c+} \sigma_{f}\right)$
c. fission cross section $(\sigma t)$
d. neutrons released from a fission ( $v)$
e. scattering cross sections $\left(\sigma_{s 0 \sim 3}\right)$
f. $(n, 2 n)$ cross section $\left(\sigma_{n, 2 n}\right)$
g. $(n, 3 n)$ cross section $\left(\sigma_{n, 3 n}\right)$
h. P0 3 scattering matrix $\left(\sigma_{\text {sngg }}\right)$
i. fission spectrum $\left(\chi_{g}\right)$

Since the AMPX MG master library includes cross section data for various reactions, cross sections must be merged to generate the underlined data shown above. 


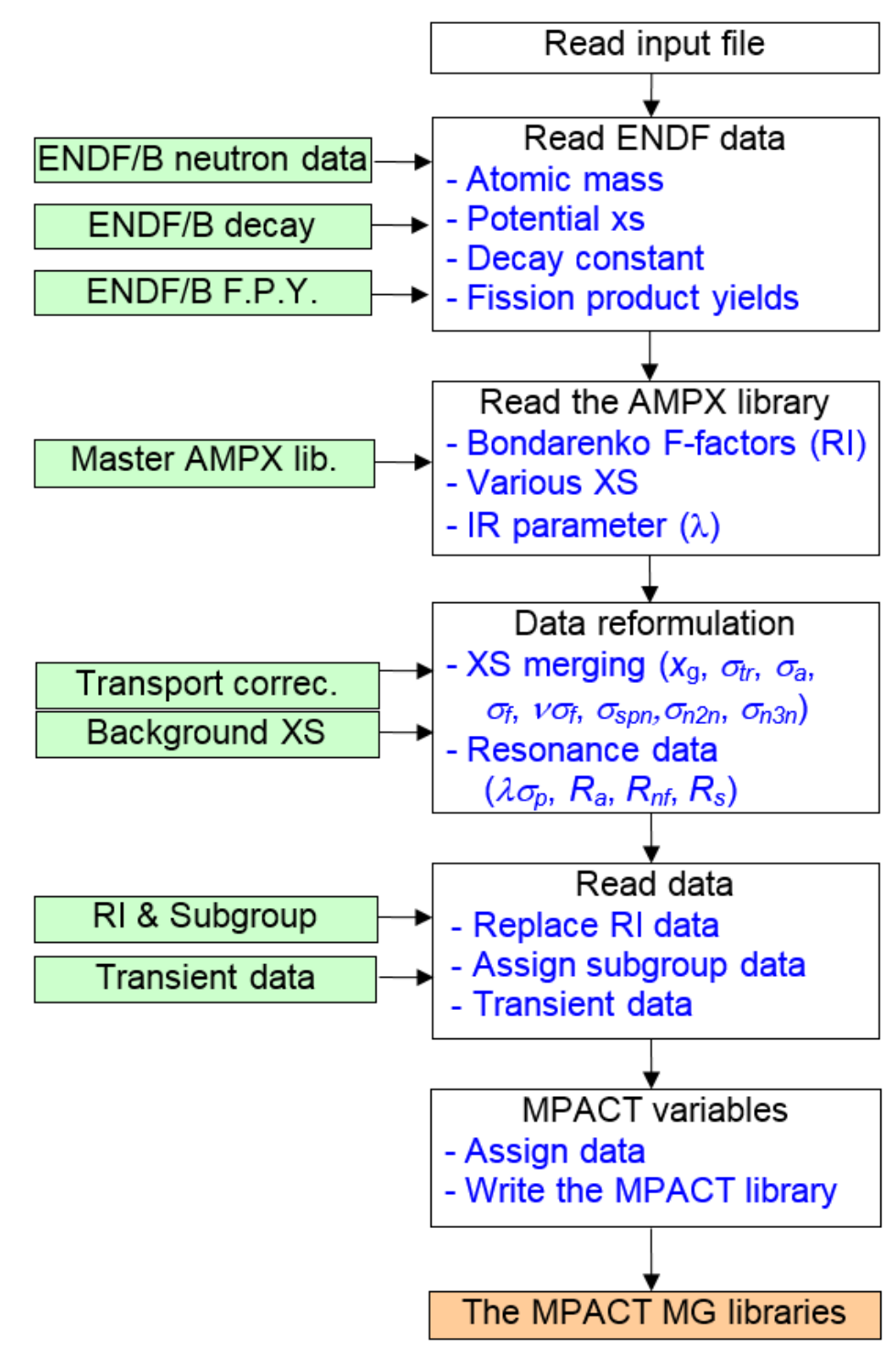

Figure 3.1. DECLIB Calculation Flow. 


\section{VERIFICATION AND VALIDATION}

\subsection{VERA CORE PHYSICS BENCHMARK PROGRESSION PROBLEMS}

\subsubsection{Characteristics of Benchmark Problems}

The VERA core physics benchmark progression problems were created to provide a method for developing and demonstrating increasing capabilities for reactor physics methods and software [God14]. The progression problems range from a simple 2D pin cell to the full cycle depletion and refueling of a 3D reactor core configuration with control rods and burnable poisons consistent with actual nuclear power plant designs. Most of the data are based on fuel and plant data from the initial core loading of Watts Bar Nuclear 1, a Westinghouse-designed $17 \times 17$ pressurized water reactor (PWR) of the common vintage built in the United States during the 1980s and 1990s.

Table 4.1. Details of the VERA Progression Problems

\begin{tabular}{|c|c|c|c|c|c|c|c|c|}
\hline \multirow{2}{*}{\multicolumn{2}{|c|}{ Problem }} & \multirow{2}{*}{ Description } & \multirow{2}{*}{ 235U w/o } & \multicolumn{3}{|c|}{ Temperature (K) } & \multicolumn{2}{|c|}{ Moderator } \\
\hline & & & & Mod & Clad & Fuel & $\mathrm{g} / \mathrm{cm}^{3}$ & PPM \\
\hline & $1 \mathrm{~A}$ & PWR pin & 3.1 & 565 & 565 & 565 & 0.743 & 1300 \\
\hline \multirow{4}{*}{ 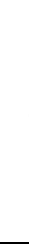 } & 1B & PWR pin & 3.1 & 600 & 600 & 600 & 0.661 & 1300 \\
\hline & $1 \mathrm{C}$ & PWR pin & 3.1 & 600 & 600 & 900 & 0.661 & 1300 \\
\hline & 1D & PWR pin & 3.1 & 600 & 600 & 1200 & 0.661 & 1300 \\
\hline & $1 \mathrm{E}$ & $\begin{array}{l}\text { PWR pin + integral fuel burnable absorber } \\
\text { (IFBA) }\end{array}$ & 3.1 & 600 & 600 & 600 & 0.743 & 1300 \\
\hline \multirow{17}{*}{2} & $2 A$ & PWR FA, no BP & 3.1 & 565 & 565 & 565 & 0.743 & 1300 \\
\hline & $2 B$ & PWR FA, no BP & 3.1 & 600 & 600 & 600 & 0.661 & 1300 \\
\hline & $2 \mathrm{C}$ & PWR FA, no BP & 3.1 & 600 & 600 & 900 & 0.661 & 1300 \\
\hline & $2 \mathrm{D}$ & PWR FA, no BP & 3.1 & 600 & 600 & 1200 & 0.661 & 1300 \\
\hline & $2 \mathrm{E}$ & PWR FA + 12 Pyrex & 3.1 & 600 & 600 & 600 & 0.743 & 1300 \\
\hline & $2 \mathrm{~F}$ & PWR FA + 24 Pyrex & 3.1 & 600 & 600 & 600 & 0.743 & 1300 \\
\hline & $2 \mathrm{G}$ & PWR FA + 24 AIC CR & 3.1 & 600 & 600 & 600 & 0.743 & 1300 \\
\hline & $2 \mathrm{H}$ & PWR FA + $24 \mathrm{~B}_{4} \mathrm{C} C \mathrm{CR}$ & 3.1 & 600 & 600 & 600 & 0.743 & 1300 \\
\hline & 21 & PWR FA + Instrument Thimble & 3.1 & 600 & 600 & 600 & 0.743 & 1300 \\
\hline & $2 \mathrm{~J}$ & PWR FA + Instrument Thimble + 24 Pyrex & 3.1 & 600 & 600 & 600 & 0.743 & 1300 \\
\hline & $2 \mathrm{~K}$ & PWR FA + Zoned enrichment + 24 Pyrex & $3.1 / 3.6$ & 600 & 600 & 600 & 0.743 & 1300 \\
\hline & $2 \mathrm{~L}$ & PWR FA + 80 IFBA & 3.1 & 600 & 600 & 600 & 0.743 & 1300 \\
\hline & $2 \mathrm{M}$ & PWR FA + 128 IFBA & 3.1 & 600 & 600 & 600 & 0.743 & 1300 \\
\hline & $2 \mathrm{~N}$ & PWR FA + 104 IFBA + 20 WABA & 3.1 & 600 & 600 & 600 & 0.743 & 1300 \\
\hline & 20 & PWR FA + 12 Gadolinia & $1.8 / 3.1$ & 600 & 600 & 600 & 0.743 & 1300 \\
\hline & $2 \mathrm{P}$ & PWR FA + 24 Gadolinia & $1.8 / 3.1$ & 600 & 600 & 600 & 0.743 & 1300 \\
\hline & $2 \mathrm{Q}$ & PWR FA + Zircaloy Spacer grid & 3.1 & 565 & 565 & 565 & 0.743 & 1300 \\
\hline \multirow{4}{*}{5} & $5 \mathrm{~A}-2 \mathrm{D}$ & PWR 2D core & $2.1 / 2.6 / 3.1$ & 565 & 565 & 565 & 0.743 & 1285 \\
\hline & $5 \mathrm{~B}-2 \mathrm{D}$ & PWR 2D core $\mathrm{B}_{4} \mathrm{C}$ Control rod & $2.1 / 2.6 / 3.1$ & 565 & 565 & 565 & 0.743 & 1285 \\
\hline & $5 \mathrm{C}-2 \mathrm{C}$ & PWR 2D core AIC Control rod & $2.1 / 2.6 / 3.1$ & 565 & 565 & 565 & 0.743 & 1285 \\
\hline & $5 A-3 D$ & PWR 3D core & $2.1 / 2.6 / 3.1$ & 565 & 565 & 565 & 0.743 & 1285 \\
\hline
\end{tabular}

The single-physics 2D benchmark problems were selected for the evaluating the neutron cross section library for the VERA neutronics simulator MPACT. Table 4.1 lists the selected VERA progression problems used for this benchmarking. Figure 4.1 provides layouts of the pins and assemblies. Godfrey [God14] provides detailed 


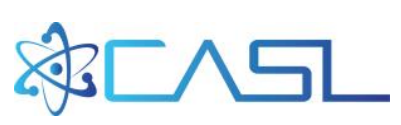

specifications of geometry and composition. The reference solutions were obtained using KENO with ENDF/B-VII.1 with and without the DBRC option.

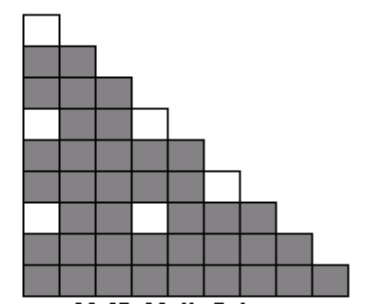

2A-2D, 2Q: Ho Poisons
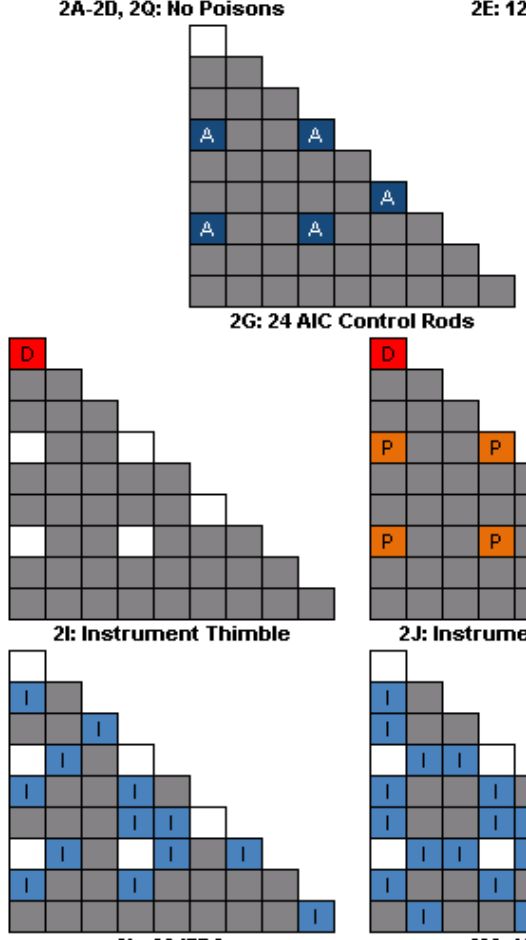

2L: 80 IFBA

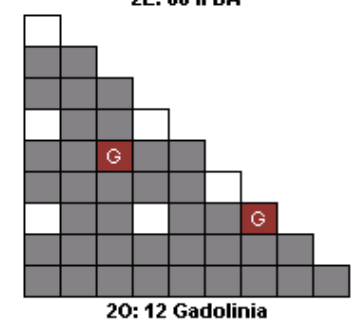

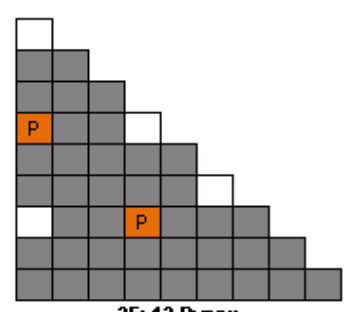

2E: 12 Pyтex
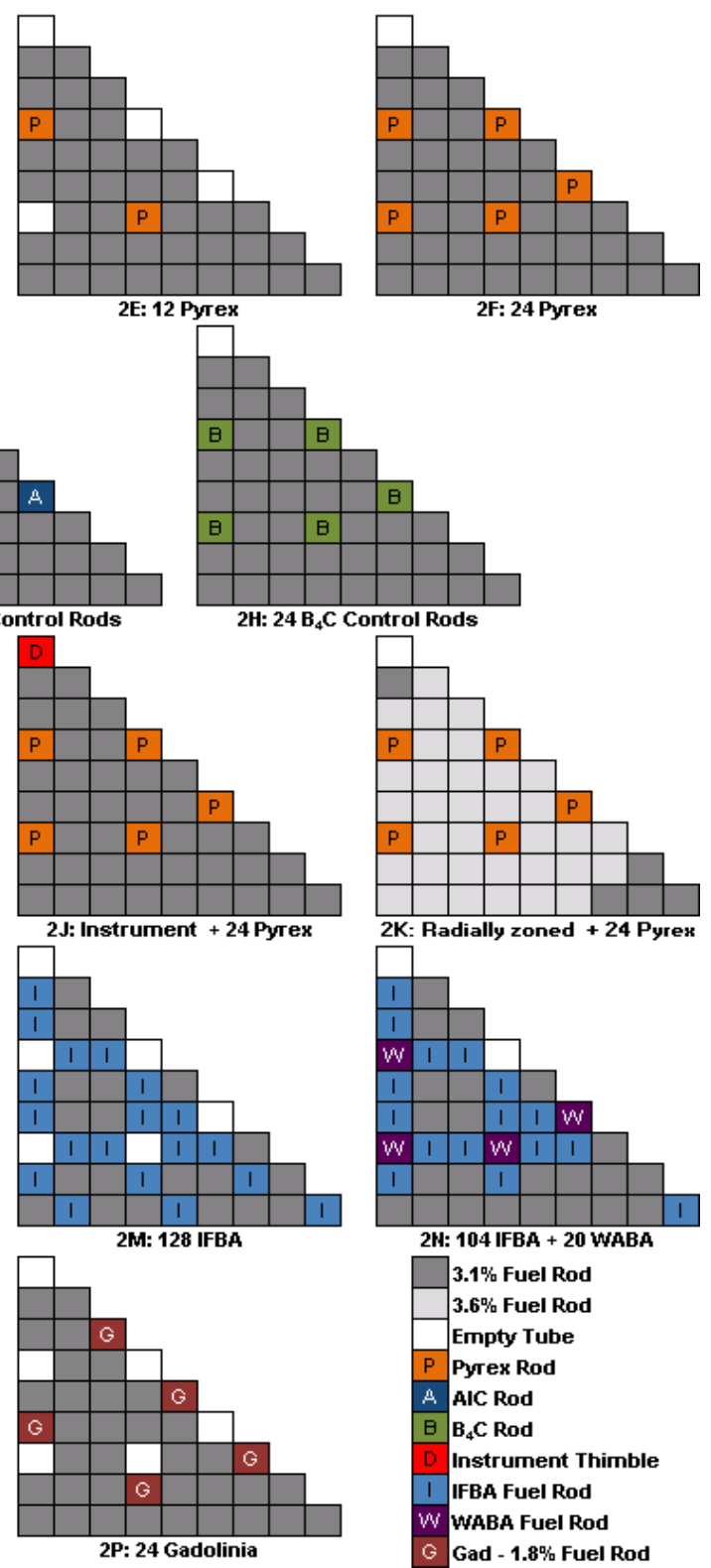

Figure 4.1. Problem 2 lattice Layouts (Octant Symmetry).

\subsubsection{Benchmark Results}

Benchmark calculations were performed by using the ENDF/B-VII.1 v4.3m1 MPACT 51group library with and without epithermal upscattering. Tables 4.1 and 4.2 provide benchmark results using the ENDF/B-7.1 MPACT 51-g library with and without considering epithermal upscattering. The benchmark results are summarized as follows: 
- All of the MPACT $P_{2}$ results satisfy the accuracy goals for prediction of multiplication factors $(<200 \mathrm{pcm} \Delta \rho$ or $\Delta \mathrm{k})$ and pin power distributions.

- ${ }^{238} \mathrm{U}$ epithermal upscattering resonance data (DBRC option in Monte Carlo) have been generated correctly.

- No temperature reactivity bias is not observed.

- Since the transport cross sections of ${ }^{1} \mathrm{H}$ have been generated to conserve neutron leakage for the whole core problems, there are some reactivity differences for single pin and assembly problems when performing transport-corrected $\mathrm{P}_{0}\left(\mathrm{TCP}_{0}\right)$ calculations.

- Cases $2 \mathrm{G}$ and $2 \mathrm{H}$ are control rod insertion cases which show significant keff differences when performing $\mathrm{TCP}_{0}$ calculations. The $\mathrm{TCP}_{0}$ calculation is not able to correctly simulate highly anisotropic neutron angular fluxes in and around control rods in single-lattice rodded problems, but these errors dissipate in fullcore calculations. Similar issues are observed for the burnable poison-bearing cases, even though keff differences are not significant.

- Prediction of the power distribution is good for all cases, regardless of the number of energy groups.

Table 4.2. Results with the ENDF/B-7.1 MPACT 51-g Library

\begin{tabular}{|c|c|c|c|c|c|c|c|c|c|c|c|c|c|c|}
\hline \multirow{4}{*}{ Case } & \multicolumn{7}{|c|}{ Epithermal upscattering } & \multicolumn{7}{|c|}{ No epithermal upscattering } \\
\hline & \multirow{3}{*}{$\frac{\text { KENO }}{k_{\text {eff }}}$} & \multicolumn{3}{|c|}{ MPACT $\mathrm{P}_{2}{ }^{\mathrm{b}}$} & \multicolumn{3}{|c|}{ MPACT TCPO } & \multirow{3}{*}{$\frac{\text { KENO }}{k_{\text {eff }}}$} & \multicolumn{3}{|c|}{ MPACT $P_{2}{ }^{b}$} & \multicolumn{3}{|c|}{ MPACT TCP ${ }^{c}$} \\
\hline & & \multirow{2}{*}{$\begin{array}{c}\Delta \mathrm{k} \\
\mathrm{pcm}\end{array}$} & \multicolumn{2}{|c|}{ Pin power \% } & \multirow{2}{*}{$\begin{array}{c}\Delta \mathrm{k} \\
\mathrm{pcm}\end{array}$} & \multicolumn{2}{|c|}{ Pin power \% } & & \multirow{2}{*}{$\begin{array}{c}\Delta \mathrm{k} \\
\mathrm{pcm}\end{array}$} & \multicolumn{2}{|c|}{ Pin power \% } & \multirow{2}{*}{$\begin{array}{c}\Delta \mathrm{k} \\
\mathrm{pcm}\end{array}$} & \multicolumn{2}{|c|}{ Pin power \% } \\
\hline & & & SD & Max. & & SD & Max. & & & \begin{tabular}{|l} 
SD \\
\end{tabular} & Max. & & SD & Max. \\
\hline $1 \mathrm{~A}$ & 1.18569 & -27 & 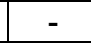 & - & -45 & 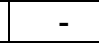 & 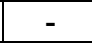 & 1.18700 & -24 & & & -45 & & \\
\hline 1B & 1.18065 & -14 & - & - & -51 & - & - & 1.18214 & -12 & & & -52 & & \\
\hline $1 \mathrm{C}$ & 6005 & -5 & 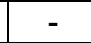 & - & -49 & - & 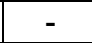 & 1.17 & -22 & & & -68 & & \\
\hline 1D & 15885 & -3 & - & - & -53 & - & - & 1.16258 & -23 & & & -76 & & \\
\hline $1 \mathrm{E}$ & .77082 & -168 & - & - & -141 & - & - & 0.77127 & -204 & & & -177 & & \\
\hline $2 \mathrm{~A}$ & .18081 & -76 & 0.12 & 0.33 & -48 & 0.12 & -0.30 & 1.18187 & -85 & 0.12 & 0.25 & -59 & 0.12 & 0.26 \\
\hline $2 \mathrm{~B}$ & 1.18190 & -38 & 0.11 & 0.21 & -30 & 0.11 & -0.23 & 1.1 & -37 & 0.13 & 0.31 & -32 & 0.14 & 0.32 \\
\hline $2 \mathrm{C}$ & 1.17125 & -31 & 0.13 & 0.29 & -29 & 0.12 & 0.30 & 1.1 & -34 & 0.12 & -0.23 & -34 & 0.13 & 0.29 \\
\hline $2 \mathrm{D}$ & 16189 & -45 & .11 & 0.34 & -48 & 0.11 & 0.36 & 1.1 & -34 & 0.13 & 0.37 & -39 & 0.13 & 0.32 \\
\hline $2 \mathrm{E}$ & 1.06829 & -71 & 0.14 & -0.25 & -120 & 0.10 & -0.23 & 1.06 & -58 & 0.15 & -0.44 & -109 & 0.13 & -0.40 \\
\hline $2 \mathrm{~F}$ & 0.97462 & -96 & 0.18 & 0.43 & -175 & 0.17 & -0.46 & 0.97 & -92 & 0.16 & 0.41 & -173 & 0.15 & 0.43 \\
\hline $2 \mathrm{G}$ & 0.84674 & -140 & 0.22 & -0.45 & -375 & 0.25 & -0.58 & 0.84766 & -135 & 0.23 & 0.47 & -372 & 0.26 & -0.66 \\
\hline $2 \mathrm{H}$ & 0.78705 & -145 & 0.23 & 0.58 & -494 & 0.27 & 0.70 & 0.78793 & -136 & 0.24 & -0.67 & -486 & 0.30 & -0.90 \\
\hline 21 & 1.17865 & -65 & 0.12 & 0.29 & -40 & 0.13 & 0.29 & 1.17962 & -90 & 0.14 & 0.33 & -67 & 0.14 & 0.30 \\
\hline $2 \mathrm{~J}$ & 0.97378 & -104 & 0.14 & -0.33 & -183 & 0.14 & 0.33 & 0.97496 & -89 & 0.17 & -0.44 & -170 & 0.16 & -0.42 \\
\hline $2 \mathrm{~K}$ & 1.01864 & -115 & 0.17 & 0.34 & -189 & 0.17 & -0.38 & 1.01977 & -108 & 0.14 & 0.36 & -183 & 0.14 & 0.31 \\
\hline $2 \mathrm{~L}$ & 1.01760 & -153 & 0.15 & -0.37 & -132 & 0.15 & -0.40 & 1.01868 & -148 & 0.13 & 0.37 & -128 & 0.13 & 0.34 \\
\hline $2 \mathrm{M}$ & 0.93778 & -152 & 0.12 & -0.25 & -123 & 0.14 & -0.33 & 0.93855 & -168 & 0.15 & 0.32 & -141 & 0.16 & -0.41 \\
\hline $2 \mathrm{~N}$ & 0.86840 & -129 & 0.19 & 0.44 & -166 & 0.13 & -0.30 & 0.86944 & -113 & 0.22 & 0.64 & -151 & 0.16 & 0.51 \\
\hline 20 & 1.04613 & -91 & 0.16 & -0.39 & -183 & 0.16 & -0.42 & 1.04717 & -93 & 0.18 & 0.43 & -188 & 0.17 & 0.44 \\
\hline $2 P$ & 0.92566 & -117 & 0.23 & -0.51 & -284 & 0.21 & 0.47 & 0.92670 & -104 & 0.21 & -0.46 & -273 & 0.19 & -0.46 \\
\hline
\end{tabular}

a SD: standard deviation

b P2: $\mathrm{P}_{2}$ scattering

c TCP0: transport correct $\mathrm{P}_{0}$ scattering 


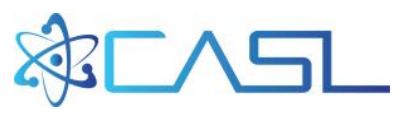

Table 4.3 and Figure 4.2 provide benchmark results for the VERA progression 5A-2D, 5B-2D and 5C-2D quarter core problems by using the v4.3m1 MPACT and 51-group library. The reference solutions were obtained by using CE-KENO with the ENDF/B-7.1 nuclear data with and without considering epithermal upscattering. The benchmark results are very consistent with the reference CE-KENO result for both multiplication factors and pin power distributions.

Table 4.3. Results for 2D Core Problems with the ENDF/B-7.1 Library.

\begin{tabular}{|c|c|c|c|c|c|c|c|c|}
\hline \multirow{3}{*}{$\begin{array}{l}\text { Epithermal } \\
\text { upscattering }\end{array}$} & \multirow{3}{*}{ Case } & \multirow{3}{*}{$\begin{array}{c}\text { KENO* } \\
\mathrm{k}_{\mathrm{eff}}\end{array}$} & \multicolumn{3}{|c|}{ MPACT $P_{2}$} & \multicolumn{3}{|c|}{ MPACT TCP 0} \\
\hline & & & \multirow{2}{*}{$\Delta \mathrm{k}_{\mathrm{eff}}(\mathrm{pcm})$} & \multicolumn{2}{|c|}{ pin power diff. (\%) } & \multirow{2}{*}{$\begin{array}{c}\Delta \mathrm{k}_{\text {eff }} \\
(\mathrm{pcm})\end{array}$} & \multicolumn{2}{|c|}{ pin power diff. (\%) } \\
\hline & & & & Max. & RMS & & Max. & RMS \\
\hline \multirow{3}{*}{ No } & $5 A-2 D$ & 1.00370 & -86 & 1.78 & 0.76 & -97 & 1.10 & 0.45 \\
\hline & $5 B-2 D$ & 0.99113 & -89 & 2.00 & 0.94 & -101 & 1.23 & 0.47 \\
\hline & $5 C-2 D$ & 0.98979 & -71 & 2.29 & 0.98 & -106 & 1.21 & 0.47 \\
\hline \multirow{3}{*}{ Yes } & $5 A-2 D$ & 1.00273 & -83 & - & - & -91 & - & - \\
\hline & $5 B-2 D$ & 0.99013 & -89 & - & - & -100 & - & - \\
\hline & $5 C-2 D$ & 0.98893 & -81 & - & - & -91 & - & - \\
\hline
\end{tabular}

*S.D. $<0.00005$

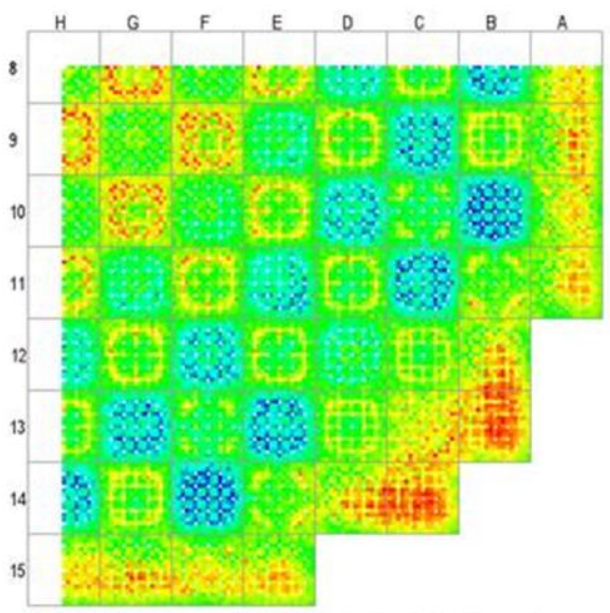

(a) Epithermal upscattering

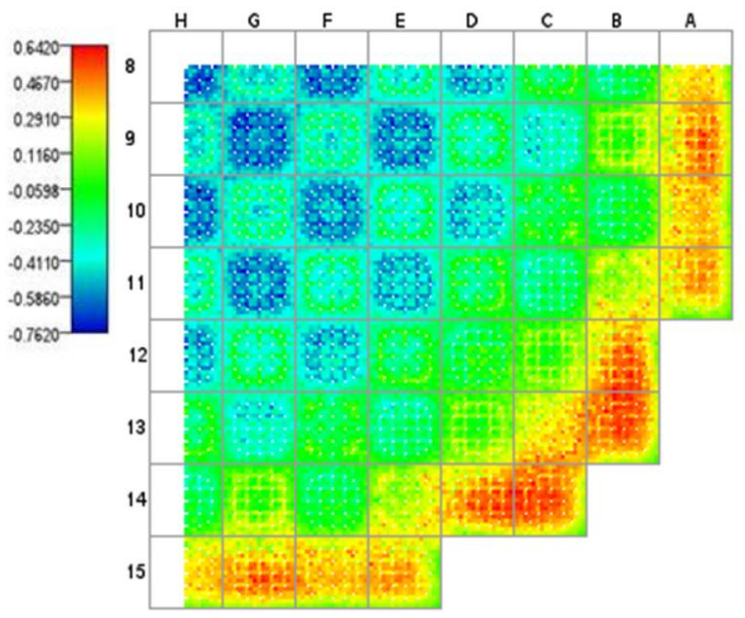

(b) No epithermal upscattering

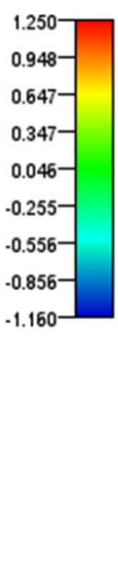

Figure 4.2. Pin Power Comparisons for Problem 5A-2D. 


\subsection{EXTENDED VERA BENCHMARK PROGRESSION PROBLEMS}

\subsubsection{Characteristics of Problems}

Since the VERA core physics benchmark progression problems do not include various ${ }^{235} \mathrm{U}$ enrichment and burnup compositions, additional benchmark problems have been developed to determine the sensitivities of the libraries to ${ }^{235} \mathrm{U}$ enrichment, burnup, and the number of radial fuel rings. These benchmark problems are based on VERA progression problems $1 \mathrm{~B}$ and $1 \mathrm{C}$. Table 4.4 provides a list of new extended VERA benchmark problems. Cases $1 \mathrm{C}-10-1 \mathrm{~h}$ through $1 \mathrm{C}-60-1 \mathrm{~h}$ include only heavy nuclides and exclude fission product isotopes.

Table 4.4. Extended VERA Benchmark Problems

\begin{tabular}{|c|c|c|c|c|c|c|c|c|}
\hline \multirow{2}{*}{ Case } & \multirow{2}{*}{ Description } & \multirow{2}{*}{${ }^{235} \mathrm{U} w / 0$} & \multirow{2}{*}{$\begin{array}{c}\text { Burnup } \\
\text { (MWD/kgU) }\end{array}$} & \multicolumn{3}{|c|}{ Temperature (K) } & \multicolumn{2}{|c|}{ Moderator } \\
\hline & & & & Mod. & Clad & Fuel & $\mathrm{g} / \mathrm{cm}^{3}$ & PPM \\
\hline $1 \mathrm{~B}-21$ & PWR pin ${ }^{235} \mathrm{U} 2.1 \mathrm{w} / \mathrm{o}$ & 2.1 & 0 & 600 & 600 & 600 & 0.661 & 1300 \\
\hline 1B-26 & PWR pin ${ }^{235} \mathrm{U} 2.6 \mathrm{w} / \mathrm{o}$ & 2.6 & 0 & 600 & 600 & 600 & 0.661 & 1300 \\
\hline 1B-31 & PWR pin ${ }^{235} \mathrm{U} 3.1 \mathrm{w} / \mathrm{o}$ & 3.1 & 0 & 600 & 600 & 600 & 0.661 & 1300 \\
\hline 1B-36 & PWR pin ${ }^{235} \mathrm{U} 3.6 \mathrm{w} / \mathrm{o}$ & 3.6 & 0 & 600 & 600 & 600 & 0.661 & 1300 \\
\hline 1B-41 & PWR pin ${ }^{235} \mathrm{U} 4.1 \mathrm{w} / \mathrm{o}$ & 4.1 & 0 & 600 & 600 & 600 & 0.661 & 1300 \\
\hline 1B-46 & PWR pin ${ }^{235} \mathrm{U} 4.6 \mathrm{w} / \mathrm{o}$ & 4.6 & 0 & 600 & 600 & 600 & 0.661 & 1300 \\
\hline $1 \mathrm{C}-00-3 \mathrm{a}$ & PWR pin 3-ring, full isotopes & 3.1 & 0 & 600 & 600 & 900 & 0.661 & 1300 \\
\hline $1 \mathrm{C}-10-3 a$ & PWR pin 3-ring, full isotopes & 3.1 & 10 & 600 & 600 & 900 & 0.661 & 1300 \\
\hline $1 \mathrm{C}-20-3 a$ & PWR pin 3-ring, full isotopes & 3.1 & 20 & 600 & 600 & 900 & 0.661 & 1300 \\
\hline $1 \mathrm{C}-40-3 a$ & PWR pin 3-ring, full isotopes & 3.1 & 40 & 600 & 600 & 900 & 0.661 & 1300 \\
\hline $1 \mathrm{C}-60-3 a$ & PWR pin 3-ring, full isotopes & 3.1 & 60 & 600 & 600 & 900 & 0.661 & 1300 \\
\hline $1 \mathrm{C}-10-1 \mathrm{~h}$ & PWR pin 1-ring, heavy isotopes & 3.1 & 10 & 600 & 600 & 900 & 0.661 & 1300 \\
\hline $1 \mathrm{C}-20-1 \mathrm{~h}$ & PWR pin 1-ring, heavy isotopes & 3.1 & 20 & 600 & 600 & 900 & 0.661 & 1300 \\
\hline $1 \mathrm{C}-40-1 \mathrm{~h}$ & PWR pin 1-ring, heavy isotopes & 3.1 & 40 & 600 & 600 & 900 & 0.661 & 1300 \\
\hline $1 \mathrm{C}-60-1 \mathrm{~h}$ & PWR pin 1-ring, heavy isotopes & 3.1 & 60 & 600 & 600 & 900 & 0.661 & 1300 \\
\hline
\end{tabular}

\subsubsection{Benchmark Results}

Benchmark calculations have been performed using the ENDF/B-VII.1 MPACT 51group library with and without considering epithermal upscattering. The benchmark results can be summarized as follows:

- As shown in the benchmark results in Section 4.1, there is a difference of about 40 pcm between $\mathrm{P}_{2}$ and $T C \mathrm{P}_{0}$ for fresh single pin problems. However, very large keff differences are observed for high burnup fuel cases such as $1 \mathrm{C}-40 \_1 \mathrm{~h}$ and 1C-60_1h.

- There is no ${ }^{235} \mathrm{U}$ enrichment reactivity bias. 


\section{严人كட}

Table 4.5. Benchmark Result with the ENDF/B-7.1 MPACT 51-g Library

\begin{tabular}{|c|c|c|c|c|c|c|}
\hline \multirow{3}{*}{ Case } & \multicolumn{3}{|c|}{ Epithermal Upscattering } & \multicolumn{3}{|c|}{ No epithermal Upscattering } \\
\hline & \multirow{2}{*}{$\begin{array}{c}\text { KENO } \\
\text { Kinf }_{\text {inf }}\end{array}$} & \multicolumn{2}{|c|}{ KENO-MPACT (pcm) } & \multirow{2}{*}{$\begin{array}{c}\text { KENO } \\
\mathrm{k}_{\text {inf }}\end{array}$} & \multicolumn{2}{|c|}{ KENO-MPACT (pcm) } \\
\hline & & $\mathrm{P}_{2}$ & $\mathrm{TCP}_{0}$ & & $\mathrm{P}_{2}$ & $\mathrm{TCP}_{0}$ \\
\hline $1 \mathrm{C}-21$ & 1.06871 & -21 & -50 & 1.07002 & -30 & -62 \\
\hline $1 \mathrm{C}-26$ & 1.13385 & -17 & -51 & 1.13548 & 0 & -36 \\
\hline 1C-31 & 1.18048 & -30 & -68 & 1.18211 & -15 & -55 \\
\hline $1 \mathrm{C}-36$ & 1.21951 & -19 & -60 & 1.22096 & -23 & -66 \\
\hline $1 \mathrm{C}-41$ & 1.25125 & 2 & -42 & 1.25244 & -28 & -74 \\
\hline $1 \mathrm{C}-46$ & 1.27712 & -25 & -71 & 1.27871 & -15 & -63 \\
\hline 1C-00-3a & 1.24435 & 54 & -3 & 1.24720 & 64 & 5 \\
\hline $1 \mathrm{C}-10-3 a$ & 1.08484 & -113 & -174 & 1.08738 & -94 & -158 \\
\hline 1C-20-3a & 1.00059 & -35 & -129 & 1.00297 & -11 & -107 \\
\hline $1 \mathrm{C}-40-3 \mathrm{a}$ & 0.88112 & 38 & -80 & 0.88297 & 41 & -80 \\
\hline 1C-60-3a & 0.80711 & 16 & -106 & 0.80869 & 12 & -112 \\
\hline 1C-10-1h & 1.17128 & -64 & -133 & 1.17394 & -57 & -128 \\
\hline 1C-20-1h & 1.11417 & 62 & -44 & 1.11647 & 46 & -63 \\
\hline 1C-40-1h & 1.03382 & 161 & 25 & 1.03614 & 166 & 27 \\
\hline 1C-60-1h & 0.98625 & 194 & 51 & 0.98849 & 204 & 58 \\
\hline
\end{tabular}




\subsection{VERA DEPLETION BENCHMARK PROBLEMS}

\subsubsection{Characteristics of Problems}

The VERA depletion benchmark problems [Kim16a] have been developed based on the VERA progression problems [God14]. Kim [Kim16a] provides the detailed geometrical and material data for the benchmark problems from VERA progression problems \#1 and \#2. The depletion benchmark suite includes 8 single pin problems and 16 fuel assembly problems with various fuel temperatures, ${ }^{235} \mathrm{U}$ enrichments, control rods, and burnable poisons, as shown in Table 4.6. The pin configurations of fuel rods, guide/instrument tubes, and burnable poisons are shown in Figure 4.6.

Table 4.6. Single Pin and Assembly Depletion Benchmark Problems

\begin{tabular}{|c|c|c|c|c|c|c|c|}
\hline \multirow{2}{*}{ Case } & \multirow{2}{*}{ Description } & \multicolumn{3}{|c|}{ Temperature (K) } & \multirow{2}{*}{$\begin{array}{l}\text { Moderator } \\
\text { Density } \\
\text { (g/cc) }\end{array}$} & \multirow{2}{*}{$\begin{array}{l}{ }^{235} U \\
w / 0\end{array}$} & \multirow{2}{*}{$\begin{array}{l}\text { Power } \\
\text { density } \\
\text { (w/gU) }\end{array}$} \\
\hline & & Moderator & Clad & Fuel & & & \\
\hline $1 \mathrm{~A}$ & Pin $3.1 \mathrm{w} / \mathrm{o} \mathrm{T}_{\mathrm{F}}=565 \mathrm{~K}$ & 565 & 565 & 565 & 0.743 & 3.1 & 40.0 \\
\hline $1 \mathrm{~B}$ & Pin $3.1 \mathrm{w} / \mathrm{o} \mathrm{T}_{\mathrm{F}}=600 \mathrm{~K}$ & 600 & 600 & 600 & 0.700 & 3.1 & 40.0 \\
\hline $1 \mathrm{C}$ & Pin $3.1 \mathrm{~W} / 0 \mathrm{~T}_{\mathrm{F}}=900 \mathrm{~K}$ & 600 & 600 & 900 & 0.700 & 3.1 & 40.0 \\
\hline 1D & Pin $3.1 \mathrm{w} / 0 \mathrm{~T}_{\mathrm{F}}=1200 \mathrm{~K}$ & 600 & 600 & 1,200 & 0.700 & 3.1 & 40.0 \\
\hline $1 \mathrm{E}$ & Pin IFBA $3.1 \mathrm{w} / \mathrm{o} \mathrm{T}_{\mathrm{F}}=600 \mathrm{~K}$ & 600 & 600 & 900 & 0.700 & 3.1 & 40.0 \\
\hline $1 \mathrm{~F}$ & Pin $2.1 \mathrm{w} / \mathrm{o} \mathrm{T}_{\mathrm{F}}=900 \mathrm{~K}$ & 600 & 600 & 900 & 0.700 & 2.1 & 40.0 \\
\hline $1 \mathrm{G}$ & Pin $3.6 \mathrm{~W} / \mathrm{o} \mathrm{T}_{\mathrm{F}}=900 \mathrm{~K}$ & 600 & 600 & 900 & 0.700 & 3.6 & 40.0 \\
\hline $1 \mathrm{H}$ & Pin $4.6 \mathrm{w} / \mathrm{o} \mathrm{T}_{\mathrm{F}}=900 \mathrm{~K}$ & 600 & 600 & 900 & 0.700 & 4.6 & 40.0 \\
\hline $2 \mathrm{~A}$ & FA No Poisons $T_{F}=565 K$ & 565 & 565 & 565 & 0.743 & 3.1 & 40.0 \\
\hline $2 B$ & FA No Poisons $T_{F}=600 \mathrm{~K}$ & 600 & 600 & 600 & 0.700 & 3.1 & 40.0 \\
\hline $2 \mathrm{C}$ & FA No Poisons $T_{F}=900 \mathrm{~K}$ & 600 & 600 & 900 & 0.700 & 3.1 & 40.0 \\
\hline $2 \mathrm{D}$ & FA No Poisons $T_{F}=1200 K$ & 600 & 600 & 1,200 & 0.700 & 3.1 & 40.0 \\
\hline $2 \mathrm{E}$ & FA 12 Pyrex & 600 & 600 & 900 & 0.700 & 3.1 & 40.0 \\
\hline $2 \mathrm{~F}$ & FA 24 Pyrex & 600 & 600 & 900 & 0.700 & 3.1 & 40.0 \\
\hline $2 \mathrm{G}$ & FA 24 AIC & 600 & 600 & 900 & 0.700 & 3.1 & 40.0 \\
\hline $2 \mathrm{H}$ & FA 24 B4C & 600 & 600 & 900 & 0.700 & 3.1 & 40.0 \\
\hline 21 & FA Instrument Thimble & 600 & 600 & 900 & 0.700 & 3.1 & 40.0 \\
\hline $2 \mathrm{~J}$ & FA Instrument + 24 Pyrex & 600 & 600 & 900 & 0.700 & 3.1 & 40.0 \\
\hline $2 \mathrm{~K}$ & FA Zoned + 24 Pyrex & 600 & 600 & 900 & 0.700 & $3.1 / 3.6$ & 40.0 \\
\hline $2 \mathrm{~L}$ & FA 80 IFBA & 600 & 600 & 900 & 0.700 & 3.1 & 40.0 \\
\hline $2 \mathrm{M}$ & FA 128 IFBA & 600 & 600 & 900 & 0.700 & 3.1 & 40.0 \\
\hline $2 \mathrm{~N}$ & FA 104 IFBA + 20 WABA & 600 & 600 & 900 & 0.700 & 3.1 & 40.0 \\
\hline 20 & FA 12 Gadolinia & 600 & 600 & 900 & 0.700 & $3.1 / 1.8$ & 40.0 \\
\hline $2 \mathrm{P}$ & FA 24 Gadolinia & 600 & 600 & 900 & 0.700 & $3.1 / 1.8$ & 40.0 \\
\hline
\end{tabular}

The computational results of the depletion calculations would depend on user options and libraries. Therefore, to minimize differences due to the user and library options, the following options should be used in the calculations.

- Xenon option: Non-equilibrium for all cases 
- Power density: Table 4.6 provides the specific power density for each case $(40.0 \mathrm{w} / \mathrm{gU})$.

- Library: ENDF/B-VII.1

- Epithermal upscattering: Both with and without considering epithermal upscattering

- Number of depletion zones

- $\mathrm{UO}_{2}$ pellet: 3 equivolumetric zones

- $\mathrm{UO}_{2}+\mathrm{Gd}_{2} \mathrm{O}_{3}$ Gadolinia rod: 5 equivolumetric zones

- WABA \& PYREX: 3 equivolumetric zones

\subsubsection{Benchmark Results}

The benchmark calculations have been performed by using VERA (MPACT+ORIGEN) with the ENDF/B-VII.1 v4.3m1 MPACT 51-group library with and without considering epithermal upscattering and by using the $\mathrm{P}_{2}$ and $\mathrm{TCP}_{0}$ scattering options. Reference solutions have been obtained by using the continuous energy Monte Carlo code SERPENT [Lep13] using ENDF/B-VII.1 data. Since SERPENT does not support ENDF/B-VII.1 ACE format library, the Monte Carlo N-Particle (MCNP)-6.1 ACE format library was used with some modification except for on the water $S(\alpha, \beta)$ data.

Since multiplication factors obtained as a function of burnup are sensitive to neutron flux levels, the same values of recoverable energies per fission have been used for all three codes [Kim16a]. Since there is additional computational burden when using the full ORIGEN burnup chain tracking over 2,200 isotopes, a simplified burnup chain with 255 isotopes was developed to minimize errors in multiplication factors [Kim16a]. Sensitivity calculations were performed using full and simplified burnup chains for all VERA depletion problems. Figure 4.3 provides differences of the multiplication factors in $\mathrm{pcm}$ for representative cases. All results with simplified burnup chains except for gadolinia rods are very consistent with those with the full burnup chains, within $50 \mathrm{pcm}$ at all burnup points. Even though the gadolinia rods are the most extreme case showing the largest difference, fuel assemblies with gadolinia rods also show good consistency.

Figures 4.4-4.6 provide comparisons of multiplication factors and pin power distributions as a function of burnup for all benchmark cases considering epithermal upscattering. The VERA calculations have been performed using both $\mathrm{P}_{2}$ and TCP 0 scattering options. The VERA-CS results with the $\mathrm{P}_{2}$ scattering option are very consistent with the SERPENT results, within $200 \mathrm{pcm} \Delta \mathrm{K}_{\text {eff }}$ at all burnup points, and with $0.5 \%$ RMS and $1.0 \%$ maximum power difference. The VERA-CS results with the TCP0 scattering option introduce $>200 \mathrm{pcm} \Delta \mathrm{k}_{\text {eff }}$ for cases that include control rod insertion and gadolinia burnable poison due to the very anisotropic angular fluxes around very strong neutron absorbers. Figures 4.7-4.9 provide comparisons of multiplication factors and pin power distributions as a function of burnup for all benchmark cases without considering epithermal upscattering. The results are very similar to the benchmark results considering epithermal upscattering. 
To see a difference between the ENDF/B-VII.0 and VII.1 libraries for burnup, a sensitivity calculation was performed using SERPENT without considering epithermal upscattering. As shown in Figure 4.10, the ENDF/B-VII.1 library is overestimating the multiplication factors at 30-40 MWD/kgU burnup points by about $100 \mathrm{pcm} \Delta \mathrm{k}_{\text {eff. }}$.

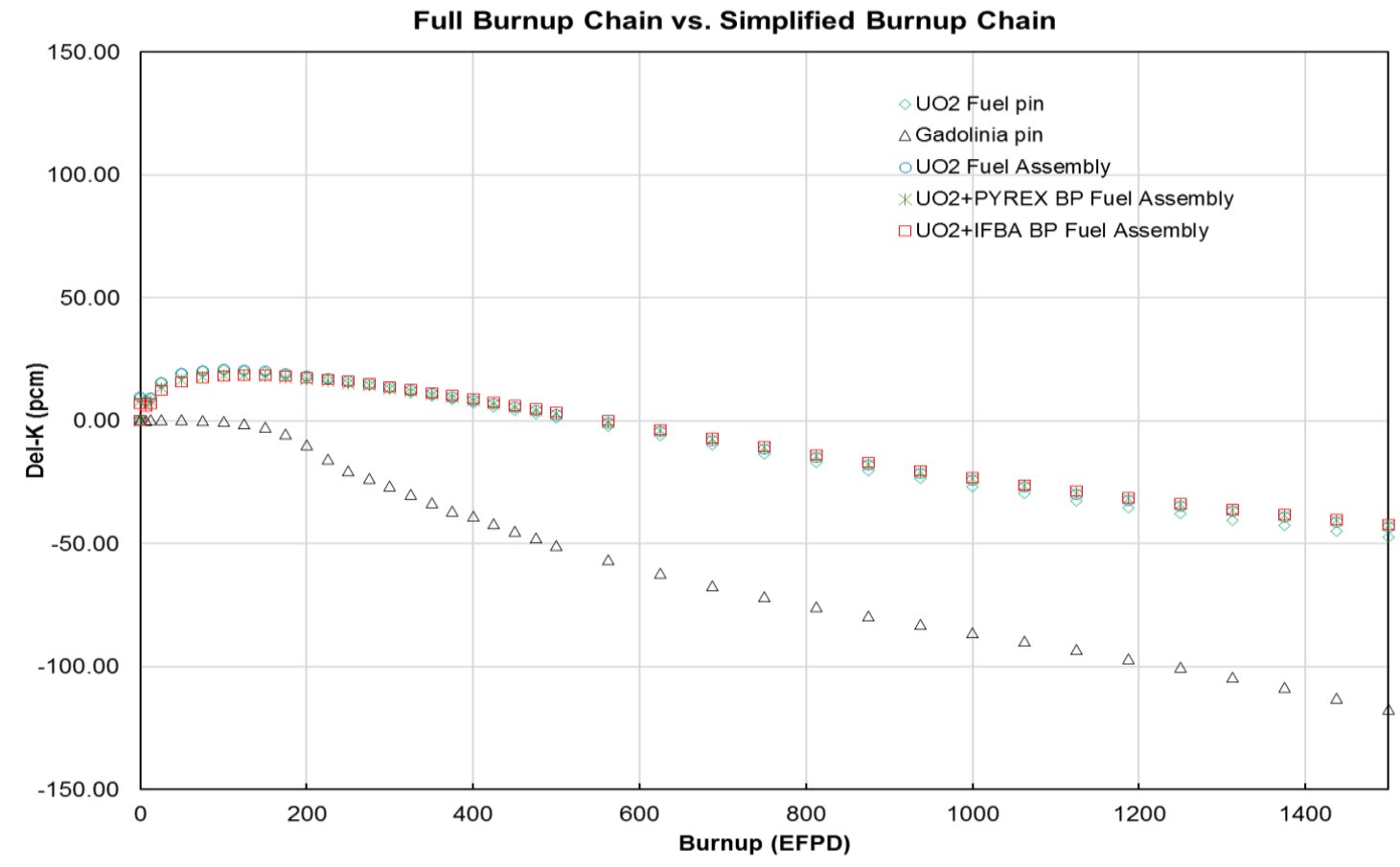

Figure 4.3. Comparison of Simplified Burnup Chain to Full Burnup Chain. 


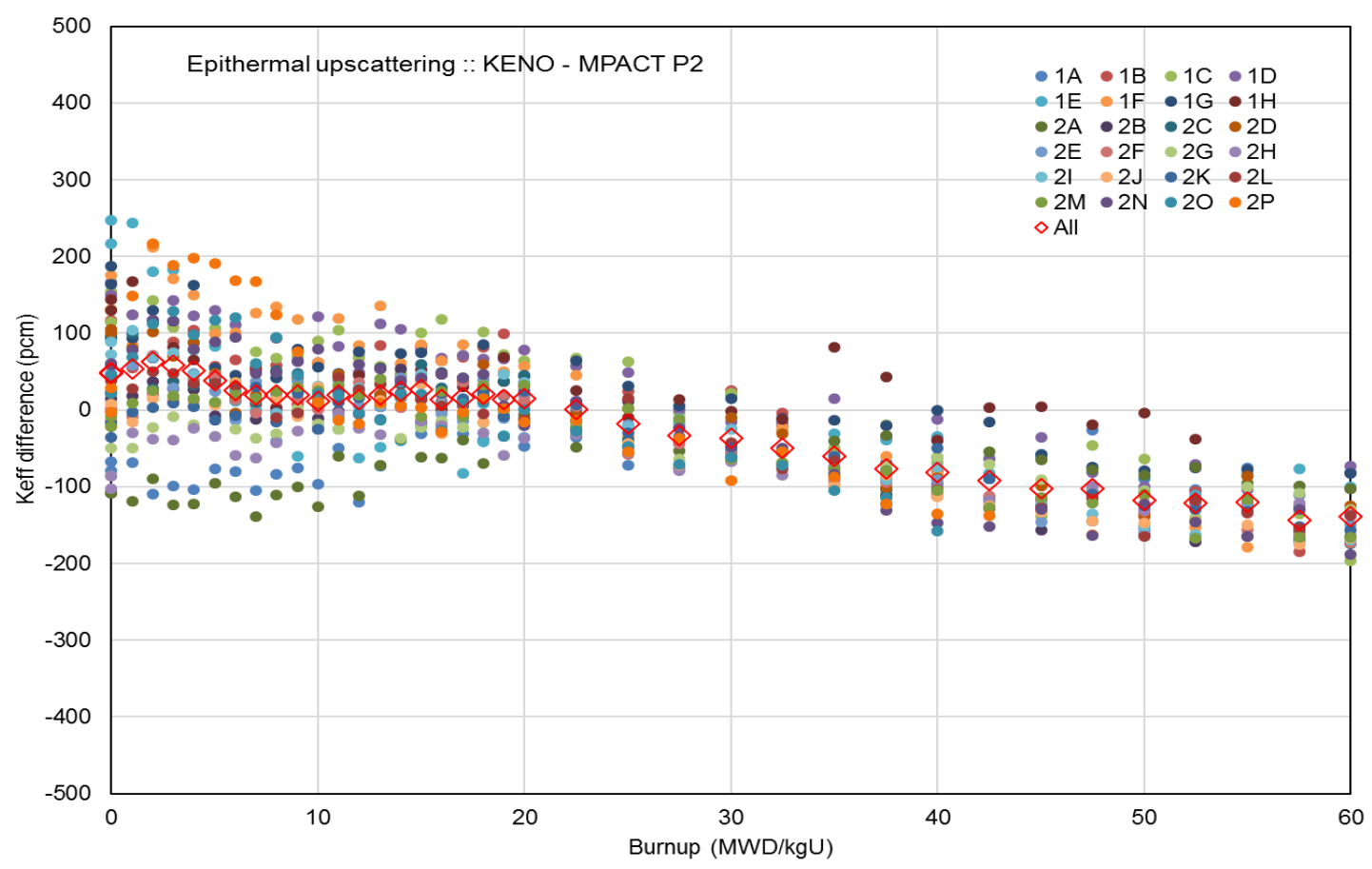

Figure 4.4. Comparison of Multiplication Factors between KENO and MPACT $P_{2}$ with Epithermal Upscattering.

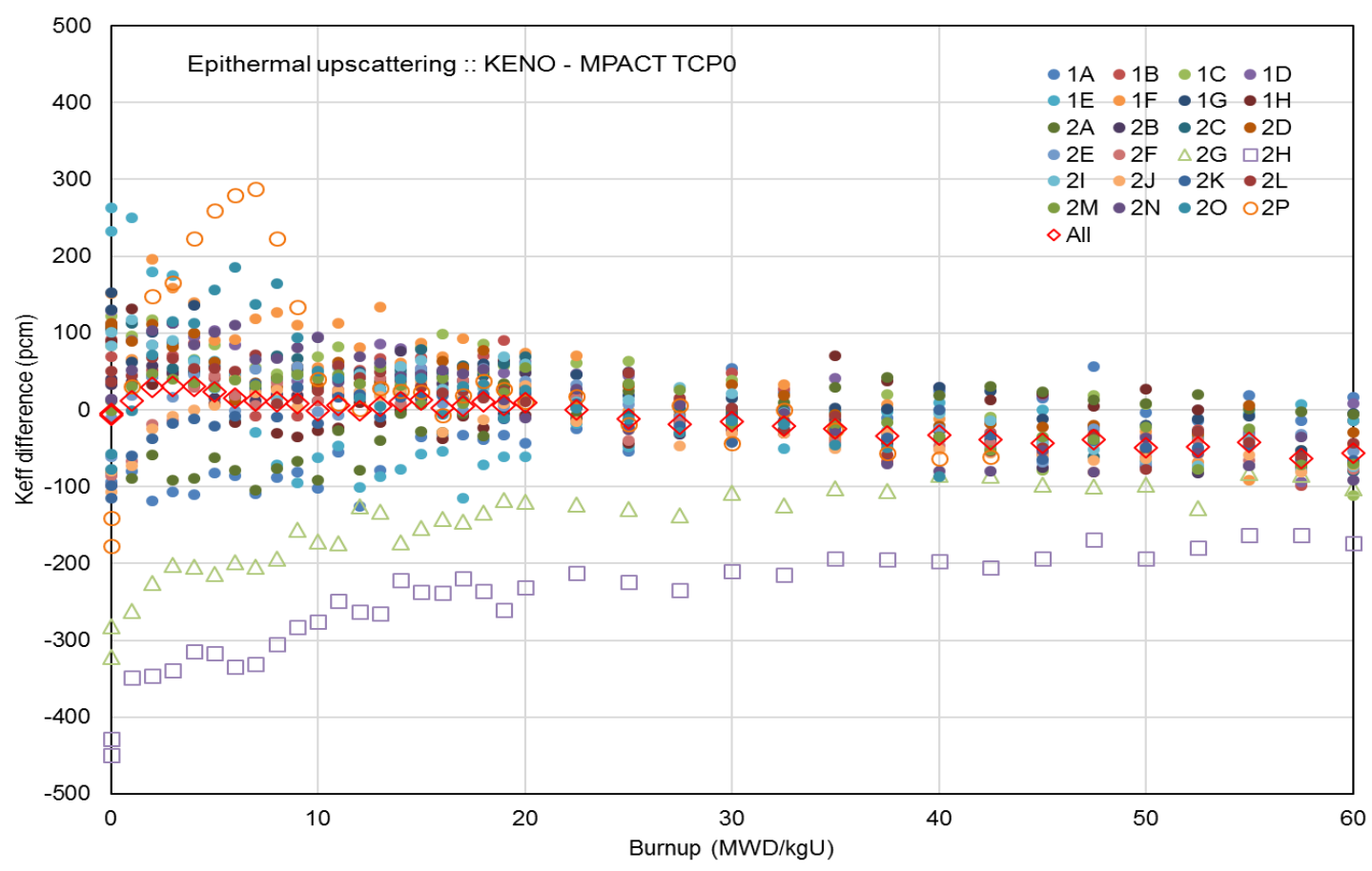

Figure 4.5. Comparison of Multiplication Factors between KENO and MPACT TCP 0 with Epithermal Upscattering. 


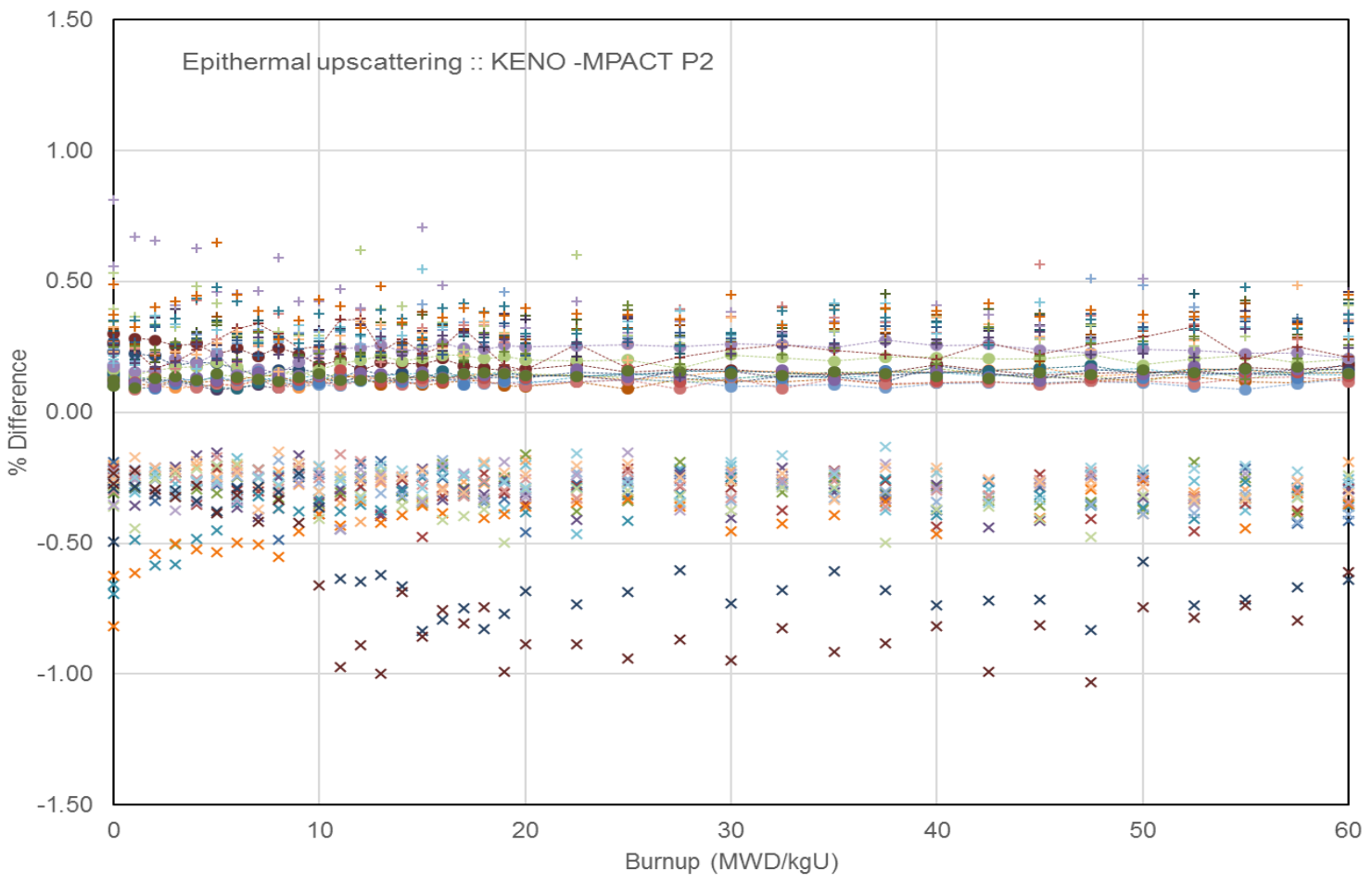

Figure 4.6. Comparison of Pin Powers between KENO and MPACT $\mathrm{P}_{2}$ with Epithermal Upscattering.

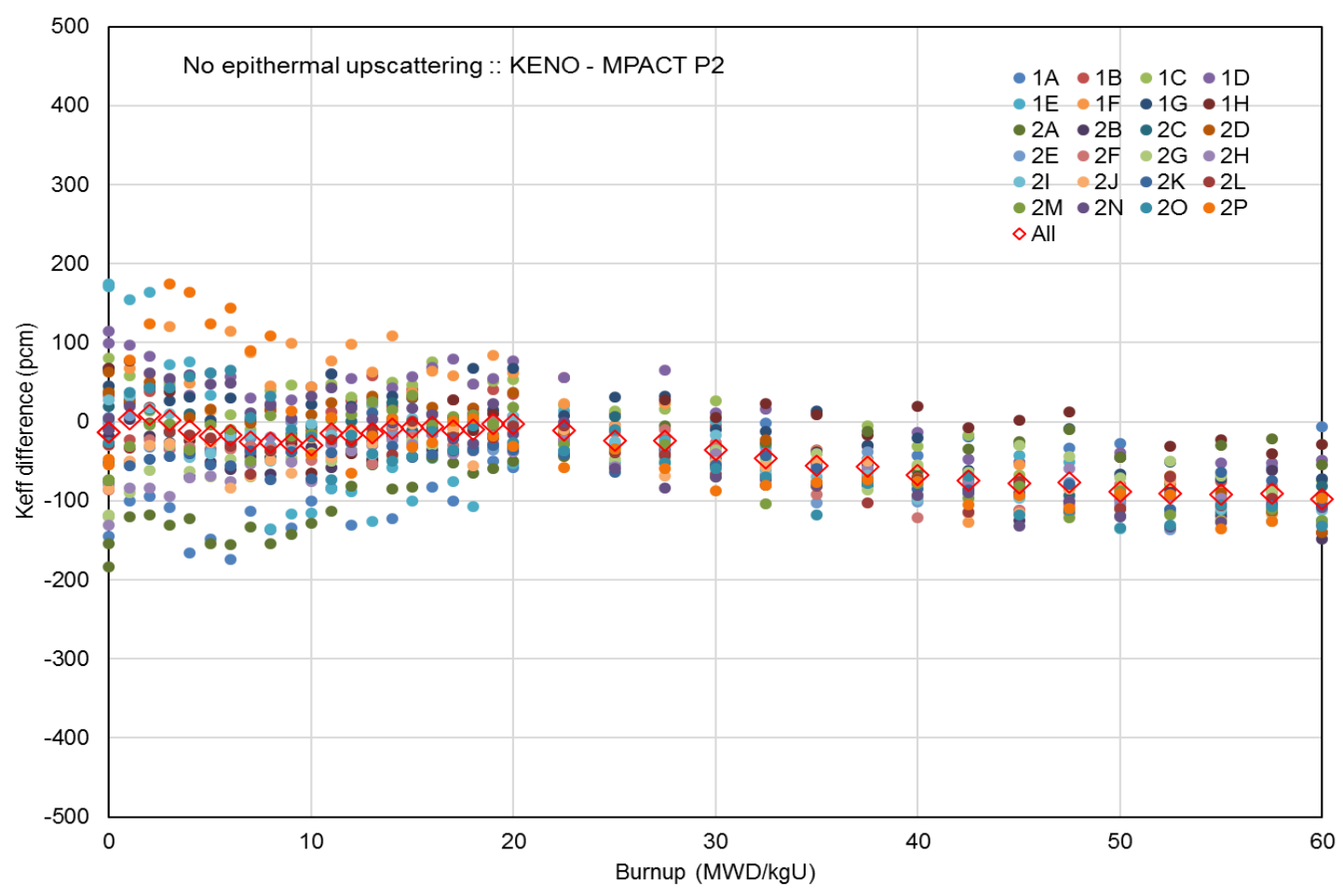

Figure 4.7. Comparison of Multiplication Factors between KENO and MPACT $P_{2}$ without Epithermal Upscattering. 


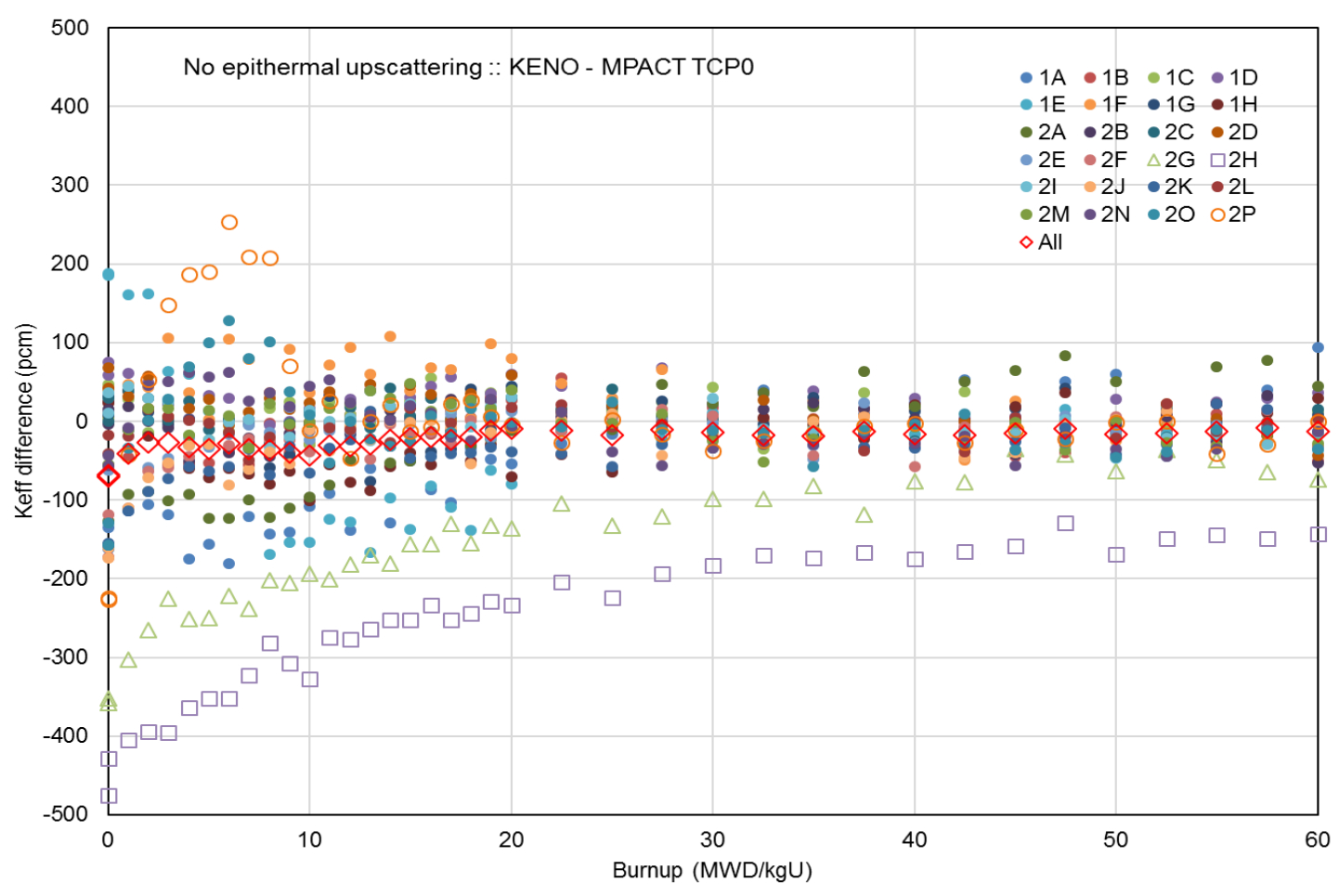

Figure 4.8. Comparison of Multiplication Factors between KENO and MPACT $P_{2}$ without Epithermal Upscattering.

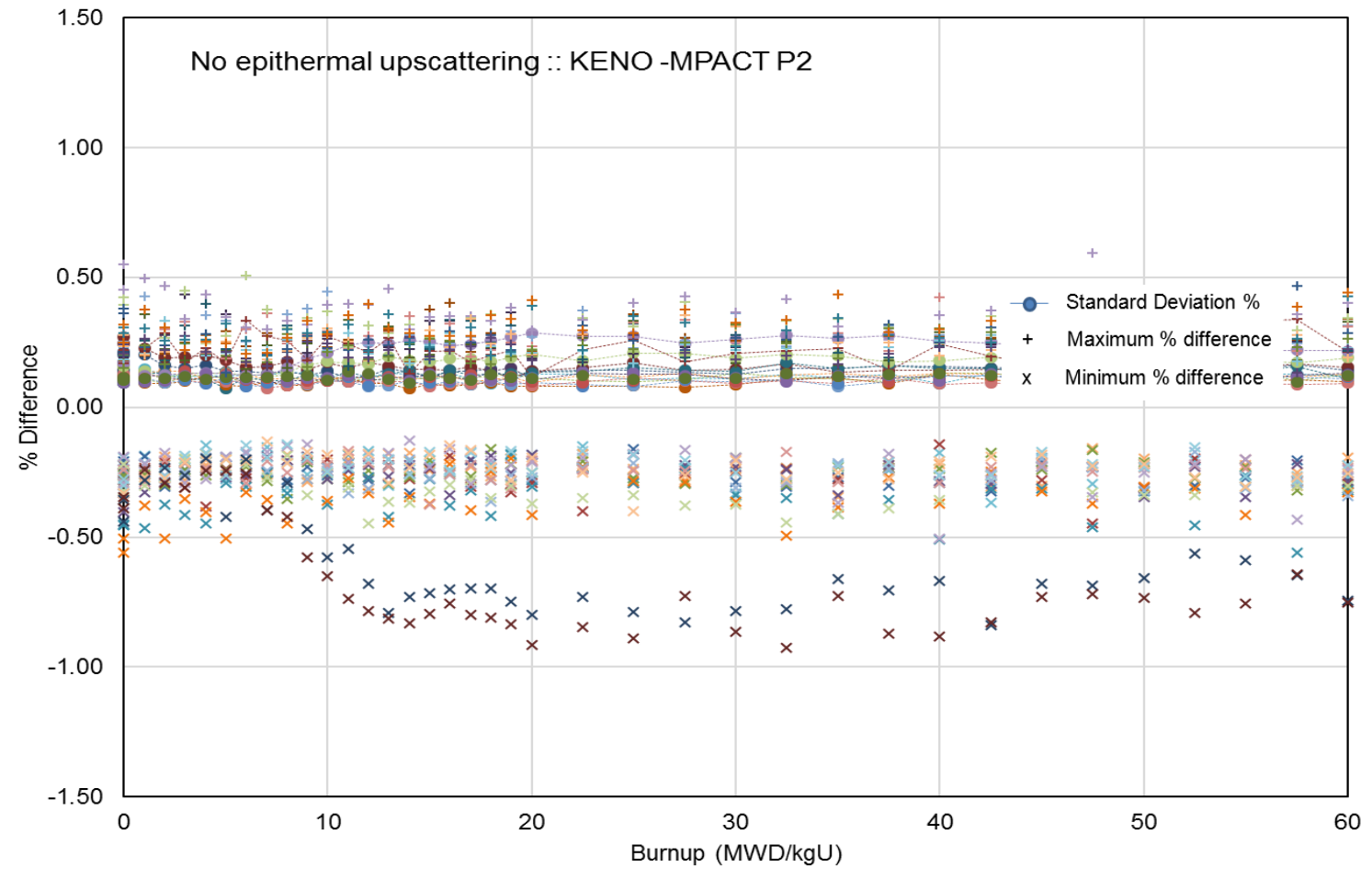

Figure 4.9. Comparison of Pin Powers between KENO and MPACT $P_{2}$ without Epithermal Upscattering. 
象口ヘكட

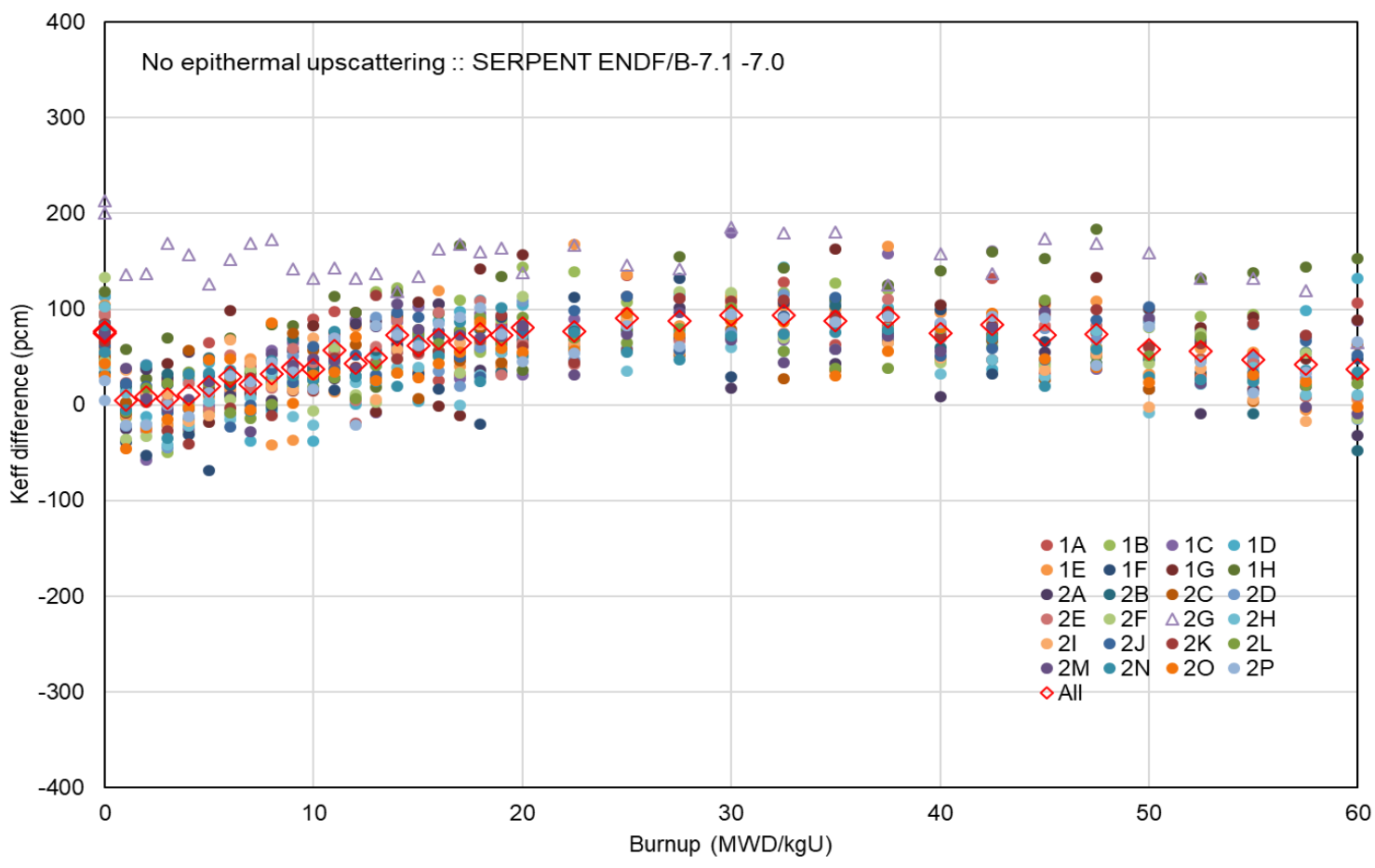

Figure 4.10. Comparison of Multiplication Factors between ENDF/B-VII.0 and ENDF/B-VII.1 using SERPENT without Epithermal Upscattering. 


\subsection{EXTENSIVE PWR PIN AND ASSEMBLY BENCHMARK PROBLEMS}

\subsubsection{Characteristics of Problems}

Extensive benchmark problems for PWR fuel pins and fuel assemblies have been developed to determine how well the MPACT MG library agrees with continuous-energy Monte Carlo results [Pal17a, Pal17b]. The PWR fuel pin cases consist of:

- $\quad 3{ }^{235} \mathrm{U}$ enrichments $(2.1 \%, 3.1 \%$, and $4.1 \%)$,

- 4 rod sizes corresponding to Watts Bar (WB) Unit 1 Cycle $1(17 \times 17)$, BEAVRS Cycle $1(17 \times 17)$, Surry Cycle $1(15 \times 15)$, and Krsko $(16 \times 16)$,

- 3 hot coolant densities corresponding to typical inlet, average, and outlet conditions,

- 3 hot fuel temperatures $(600,900$, and $1200 K)$,

- cold cases at room temperature, and

- 3 boron concentrations (0,600, and 1300 ppm).

There are a total of 360 cases: $324(3 \times 4 \times 3 \times 3 \times 3)$ hot cases and $36(3 \times 4 \times 3)$ cold cases. The PWR pin cells were modeled as 3 concentric rings of fuel, helium gap, and zirconium surrounded by a square region of coolant. The moderator densities correspond to typical PWR conditions at the core inlet, the core average, and the core outlet. The hot densities are calculated from subcooled steam tables at 2,250 psia. The cold density is at room conditions. Table 4.7 provides moderator temperatures and densities based on various reactor conditions. Table 4.8 provides pin cell dimensions and fuel-to-coolant volume ratios for fuel types. All fuel had a stack density of $10.257 \mathrm{~g} / \mathrm{cc}$, and the ${ }^{235} \mathrm{U}$ enrichments are $2.1,3.1$, and $4.1 \%$. The same number densities are used in all rod geometries. In terms of fuel-to-moderator ratios, the BEAVRS rod is the "wettest" configuration, and Krsko is the "driest" configuration.

Table 4.7. Moderator Temperatures and Densities

\begin{tabular}{|c|c|c|c|}
\hline Reactor Condition & Nomenclature & Temperature (K) & Density (g/cc) \\
\hline Cold & den0 & 293.6 & 1.000000 \\
\hline Hot Inlet & den1 & 566.0 & 0.740816 \\
\hline Hot Average & den2 & 583.9 & 0.703158 \\
\hline Hot Outlet & den3 & 601.7 & 0.655986 \\
\hline
\end{tabular}

Table 4.8. Pin Cell Dimensions

\begin{tabular}{|c|c|c|c|c|}
\hline Fuel Type & WB & BEAVRS & Surry & Krsko \\
$\mathbf{1 7} \times \mathbf{1 7}$ & $\mathbf{1 7}$ & $\mathbf{1 5} \times \mathbf{1 5}$ & $\mathbf{1 6}$ \\
\hline Pin Pitch $(\mathrm{cm})$ & 1.2600 & 1.2600 & 1.4300 & 1.2319 \\
\hline Fuel Outer Radius $(\mathrm{cm})$ & 0.4096 & 0.39218 & 0.4647 & 0.4096 \\
\hline Clad Inner Radius (cm) & 0.4180 & 0.40005 & 0.4742 & 0.4180 \\
\hline Clad Outer Radius (cm) & 0.4750 & 0.4572 & 0.5359 & 0.4750 \\
\hline Fuel-to-Coolant Ratio & 0.6000 & 0.5190 & 0.5940 & 0.6520 \\
\hline
\end{tabular}

Additional benchmark problems have been developed for fourteen different PWR assembly types, including $15 \times 15,16 \times 16$, and $17 \times 17$ designs by different fuel 
vendors, with many different state point conditions encountered in a reactor. The complete set of assembly geometries is listed in Table 4.9. Each assembly type includes 90 different state points, as follows:

- $\quad 3{ }^{235} \mathrm{U}$ enrichments $(2.1 \%, 3.1 \%$, and $4.1 \%)$

- 3 hot coolant densities corresponding to typical inlet, average, and outlet conditions

- 3 hot fuel temperatures $(600,900$, and $1200 \mathrm{~K})$

- 1 cold case at standard room temperature and density

- 3 boron concentrations (0,600, and 1300 ppm)

There are a total of 81 hot cases $(3 \times 3 \times 3 \times 3)$ and 9 cold cases $(3 \times 3)$ per assembly, for a total of 1,260 cases. The Watts Bar assemblies are slightly modified. The modifications include:

- The cladding material is natural zirconium to reduce the number of isotopes in the MCNP model,

- The enrichment, boron, fuel temperatures, and moderator densities are set by the case matrix (described below), and

- The moderator density inside the guide tubes (GTs) and instrument tube (IT) are set to the core inlet conditions.

The assembly geometry descriptions are given in Table 4.10.

Table 4.9. Assembly Geometry Descriptions

\begin{tabular}{|c|c|}
\hline Geometry & Description \\
\hline ce16 & CE $16 \times 16$ Assembly with large water rods \\
\hline krsko & Krško Westinghouse $16 \times 16$ \\
\hline surry & Surry Westinghouse $15 \times 15$ \\
\hline tmi1 & TMI B\&W $15 \times 15$ with 4 gad rods \\
\hline tmi2 & TMI B\&W $15 \times 15$ with no gad \\
\hline wb2a & Watts Bar $2 \mathrm{~A} 17 \times 17$ \\
\hline wb2e & Watts Bar 2E $17 \times 1712$ Pyrex \\
\hline wb2f & Watts Bar 2F $17 \times 1724$ Pyrex \\
\hline wb2l & Watts Bar $2 \mathrm{~L} 17 \times 1780$ IFBA rods \\
\hline wb2m & Watts Bar 2 M $17 \times 17128$ IFBA rods \\
\hline wb2o & Watts Bar $2017 \times 1712$ gad rods \\
\hline wb2p & Watts Bar 2P $17 \times 1724$ gad rods \\
\hline wb2w & Watts Bar 2 W $17 \times 17$ thermally expanded \\
\hline wb2x & Watts Bar 2 X $17 \times 17$ thermally expanded + zone enrichment \\
\hline
\end{tabular}




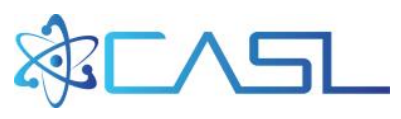

Table 4.10. Assembly dimensions

\begin{tabular}{|c|c|c|c|c|c|c|c|c|c|}
\hline \multirow{2}{*}{ Type } & \multicolumn{3}{|c|}{ Fuel Rod (cm) } & \multicolumn{3}{c|}{ Guide Tube $(\mathbf{c m})$} & \multicolumn{2}{c|}{ Instrument Tube (cm) } \\
\cline { 2 - 10 } & Pin Pitch & FA pitch & $\mathbf{R}_{\text {fuel }}$ & $\mathbf{R}_{\text {gap }}$ & $\mathbf{R}_{\text {clad }}$ & $\mathbf{R}_{\text {in }}$ & $\mathbf{R}_{\text {out }}$ & $\mathbf{R}_{\text {in }}$ & $\mathbf{R}_{\text {out }}$ \\
\hline CE16 & 1.28524 & 20.6400 & 0.41339 & 0.42164 & 0.48514 & 1.14300 & 1.24460 & 1.14300 & 1.24460 \\
\hline KRSKO & 1.23200 & 19.7180 & 0.40960 & 0.41800 & 0.47500 & 0.55250 & 0.59800 & 0.55250 & 0.59800 \\
\hline SURRY & 1.43000 & 21.5036 & 0.46469 & 0.47422 & 0.53594 & 0.61392 & 0.69012 & 0.61392 & 0.69012 \\
\hline TMI1 & 1.44270 & 21.8110 & 0.46950 & 0.47880 & 0.54610 & 0.63245 & 0.67310 & 0.56005 & 0.62610 \\
\hline TMI2 & 1.44270 & 21.8110 & 0.46950 & 0.47880 & 0.54610 & 0.63245 & 0.67310 & 0.56005 & 0.62610 \\
\hline WB2A & 1.26000 & 21.5000 & 0.40960 & 0.41800 & 0.47500 & 0.56100 & 0.60200 & 0.55900 & 0.60500 \\
\hline WB2E & 1.26000 & 21.5000 & 0.40960 & 0.41800 & 0.47500 & 0.56100 & 0.60200 & 0.55900 & 0.60500 \\
\hline WB2F & 1.26000 & 21.5000 & 0.40960 & 0.41800 & 0.47500 & 0.56100 & 0.60200 & 0.55900 & 0.60500 \\
\hline WB2L & 1.26000 & 21.5000 & 0.40960 & 0.41800 & 0.47500 & 0.56100 & 0.60200 & 0.55900 & 0.60500 \\
\hline WB2M & 1.26000 & 21.5000 & 0.40960 & 0.41800 & 0.47500 & 0.56100 & 0.60200 & 0.55900 & 0.60500 \\
\hline WB2O & 1.26000 & 21.5000 & 0.40960 & 0.41800 & 0.47500 & 0.56100 & 0.60200 & 0.55900 & 0.60500 \\
\hline WB2P & 1.26000 & 21.5000 & 0.40960 & 0.41800 & 0.47500 & 0.56100 & 0.60200 & 0.55900 & 0.60500 \\
\hline WB2W & 1.26260 & 21.6050 & 0.41208 & 0.41894 & 0.47607 & 0.56226 & 0.60335 & 0.56226 & 0.60335 \\
\hline WB2X & 1.26260 & 21.6050 & 0.41208 & 0.41894 & 0.47607 & 0.56226 & 0.60335 & 0.56226 & 0.60335 \\
\hline
\end{tabular}

\subsubsection{Benchmark Results}

\section{Pin cell cases}

Tables 4.11 and 4.12 summarize the PWR pin cell eigenvalue comparisons between MPACT and KENO with ENDF/B-VII.1, with and without considering epithermal upscattering. The $\mathrm{P}_{2}$ scattering option was used in Table 4.11, and the TCP $\mathrm{P}_{0}$ scattering option was used in Table 4.12. All results show the differences between the KENO and MPACT eigenvalues in pcm. Overall, the PWR pin results are acceptable. The average of all 324 hot cases was $1 \mathrm{pcm}$, with a standard deviation of $63 \mathrm{pcm}$ for the $\mathrm{P}_{2}$ scattering and $-32 \mathrm{pcm}$ with a standard deviation of $65 \mathrm{pcm}$ for the TCP 0 scattering. All of the hot cases were between -138 and +138 pcm for the $P_{2}$ scattering and between -167 pcm and +84 pcm for the TCP 0 scattering. The cold cases had a bias of approximately 20-30 pcm compared with the hot cases. The PWR pin cell results are depicted as a histogram in Figures 4.11 and 4.12, which shows that the results closely match a normal distribution.

Table 5.6.5 also shows the hot and cold results averaged over individual parameter subgroups (type, enrichment, boron, moderator density, and fuel temperature). A subgroup is defined as a group in which all the cases that have a particular parameter. The averages over subgroups show trends in parameters. When using a criterion of 100 pcm between subgroup differences to define a trend, no trends are observed in geometry, enrichment, boron concentration, or moderator density. A trend was observed in the fuel temperature (a 126 pcm difference from 600-1,200K). There is a $-58 \mathrm{pcm}$ bias between hot and cold cases and a $156 \mathrm{pcm}$ trend observed in cold boron cases.

Table 5.6.7 summarizes the PWR pin-cell eigenvalue results for MPACT with the ENDF/B-7.1 v5.0m0 SAMPX 51-g library and MCNP with ENDF/B VII.1. 
All results show the differences between the MCNP and MPACT eigenvalues in pcm. The average of all 324 hot cases was $15 \mathrm{pcm}$, with a standard deviation of $85 \mathrm{pcm}$. Compared to the MPACT 51-g library, the average has been decreased to $15 \mathrm{pcm}$ from 44 , but the standard deviation has been increased by $16 \mathrm{pcm}$. Even though some of eigenvalue differences are over 200 pcm, reactivity differences are still less than 200 pcm. Cold cases show much better agreement between MCNP and MPACT.

Table 4.11. Benchmark Result for Pin Cell Problems $\left(P_{2}\right)$

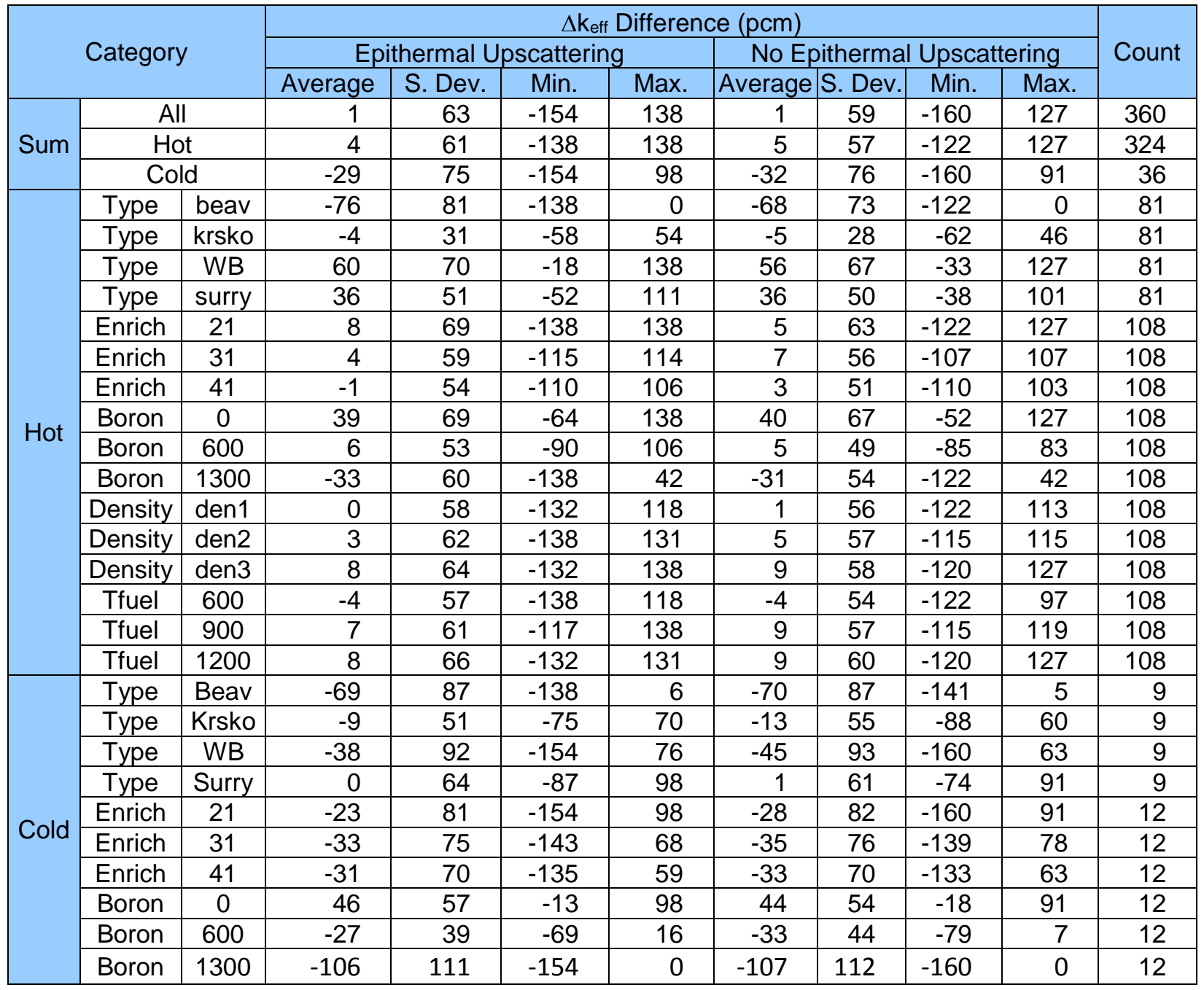




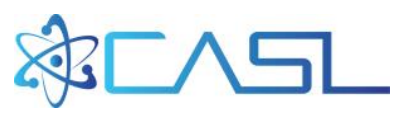

Table 4.12. Benchmark Result for Pin Cell Problems ( $\left.T \mathrm{CP}_{0}\right)$

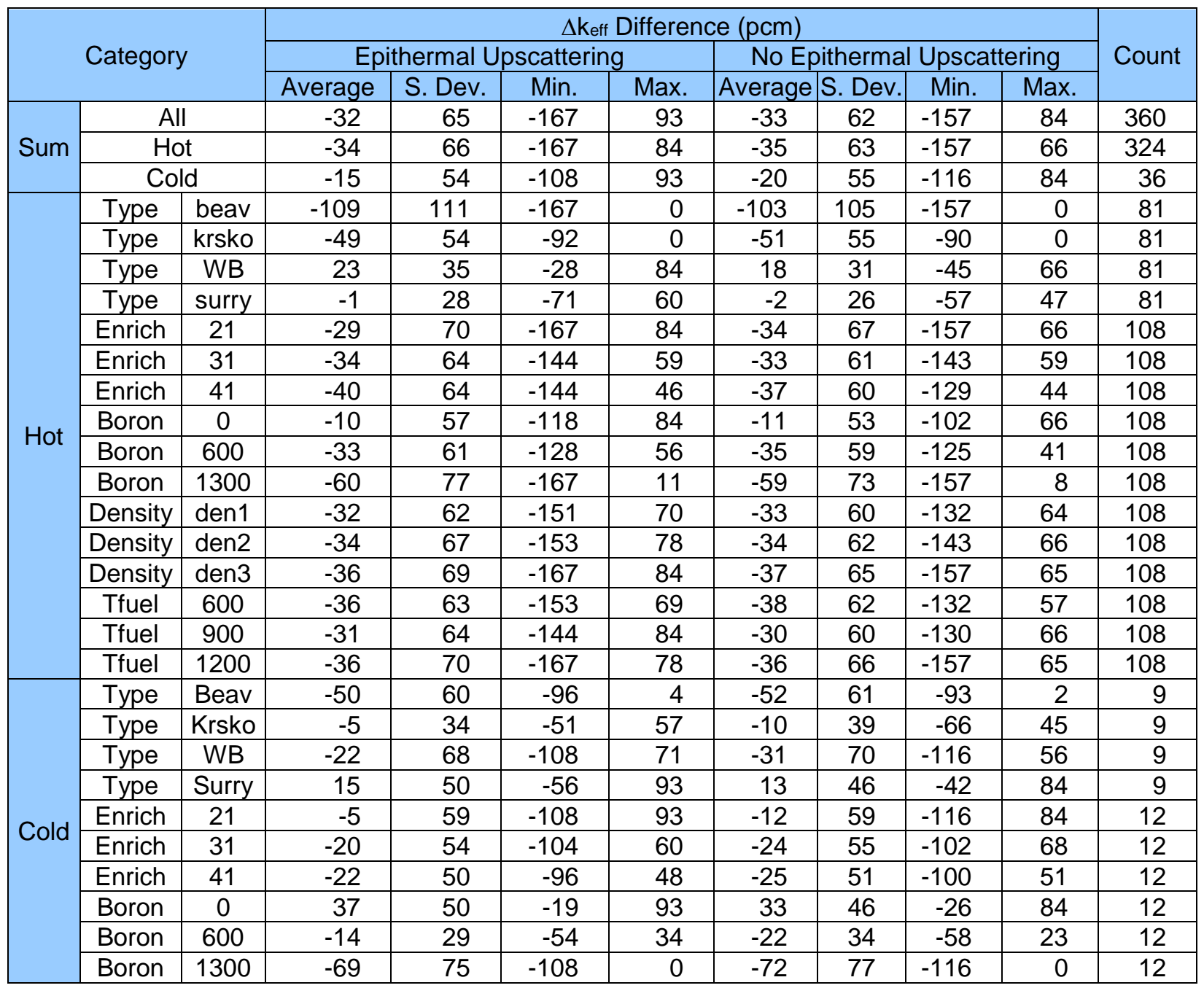


末ㄷㄴ

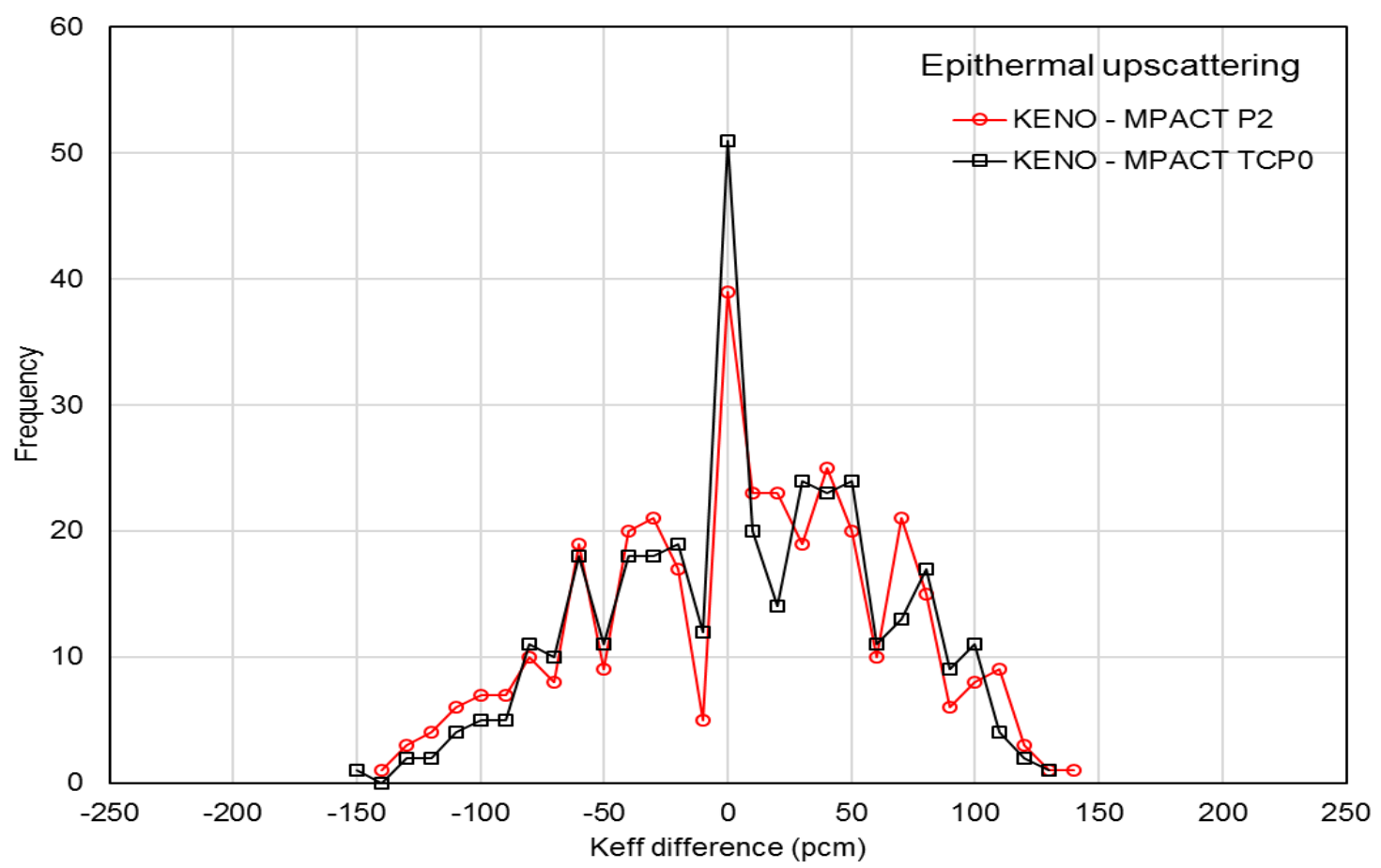

Figure 4.11. Pin $k_{\text {eff }}$ Difference Distribution with Epithermal Upscattering.

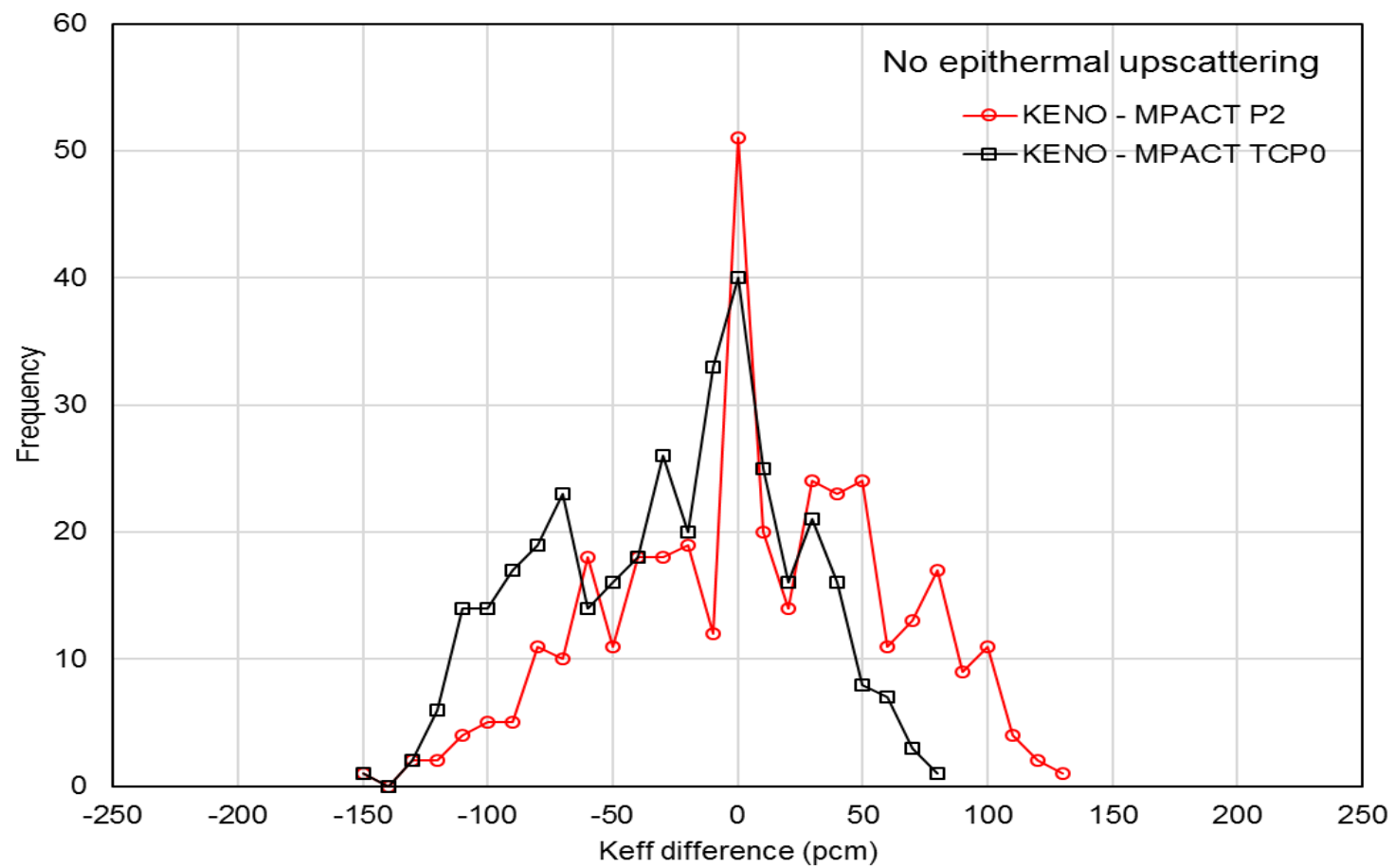

Figure 4.12. Pin $\mathrm{K}_{\mathrm{eff}}$ Difference Distribution without Epithermal Upscattering. 


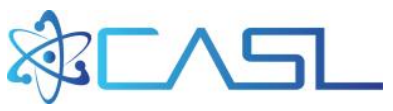

\section{Assembly cases}

Tables 4.13 and 4.14 summarize PWR assembly benchmark results with and without considering epithermal upscattering and with the $\mathrm{P}_{2}$ scattering. Overall, the eigenvalue results are acceptable. The averages of all 1,134 hot cases are $-7 \mathrm{pcm}$, with a standard deviation of $54 \mathrm{pcm}$ for the epithermal upscattering and $-6 \mathrm{pcm}$ with a standard deviation of $52 \mathrm{pcm}$ without epithermal upscattering.

All of the hot cases are between -192 and +126 pcm for the epithermal upscattering and between $-180 \mathrm{pcm}$ and $118 \mathrm{pcm}$ without epithermal upscattering. A reasonable goal is to have all eigenvalue differences between $+/-200 \mathrm{pcm}$. Standard deviations of the cold cases are about $140 \mathrm{pcm}$ for both cases, which are much larger compared to the hot cases. The hot pin power results look very good. All of the hot assemblies have a maximum pin power less than $0.5 \%$. The cold pin power results are not as good, and the maximum error is almost $1 \%$. Additional coolant rings may need to be included in the cold cases to reduce the maximum pin power errors.

Some cases have very large cold eigenvalue differences. For example, the high gad case (wb2p) at low enrichments has a maximum eigenvalue difference of $-568 \mathrm{pcm}$. This large maximum is not observable in the hot cases. The largest cold pin power differences are in the CE16 assemblies, which have the large water rods. The larger pin power differences in cold cases may be due to not modeling enough rings (at source regions) in the coolant. This is more important for cold cases, which have higher moderator densities than the hot cases. The eigenvalue results over all cases are shown as histograms in Figures 4.13 and 4.14.

\section{Reference solution and scattering order}

The reference solutions for this benchmark suite were obtained using KENO and MCNP. However, the MPACT MG libraries have been developed to be consistent with the CE-KENO results, for which the SPH factors were obtained by performing the CE-KENO calculations. Figure 4.14 shows an intrinsic difference between MCNP and CE-KENO, for which the keff differences are between $-180 \mathrm{pcm}$ and $160 \mathrm{pcm}$.

In these benchmark calculations, the MPACT calculations were also performed by the TCPO option, which is a default option for power plant simulation. The ${ }^{1} \mathrm{H}$ transport cross sections were developed to accurately consider neutron leakage for large size problems. Therefore, when developing the cross section library and performing the small size problem, a high order scattering $\left(\geq P_{2}\right)$ calculation would be more reasonable. The $T C P_{0}$ results get closer to the $P_{2}$ results as the problem size increases. 
象口へらட

Table 4.13 Benchmark Result for Assembly Problems with Epithermal Upscattering

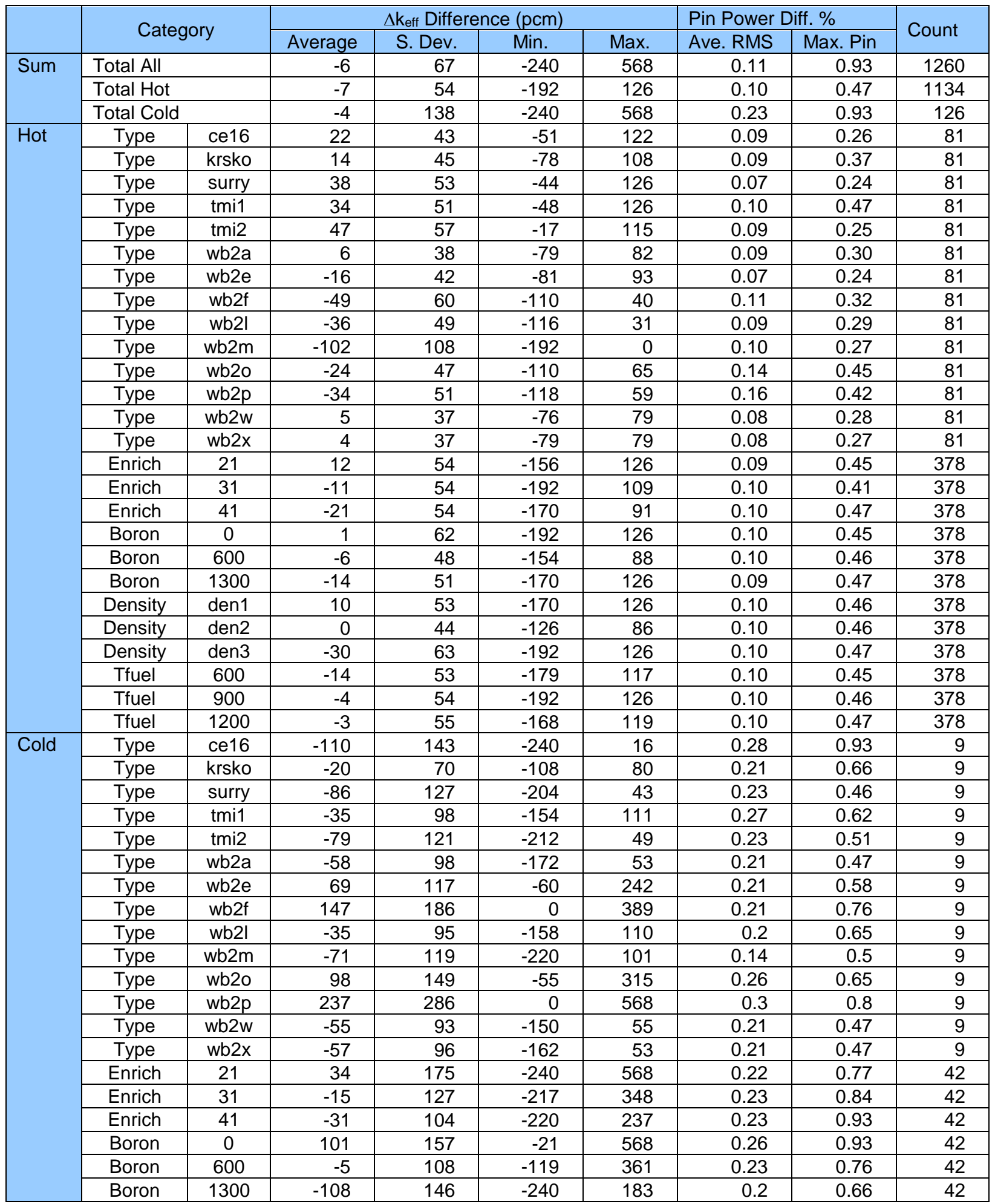




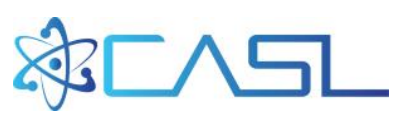

Table 4.14 Benchmark Result for Assembly Problems without Epithermal Upscattering

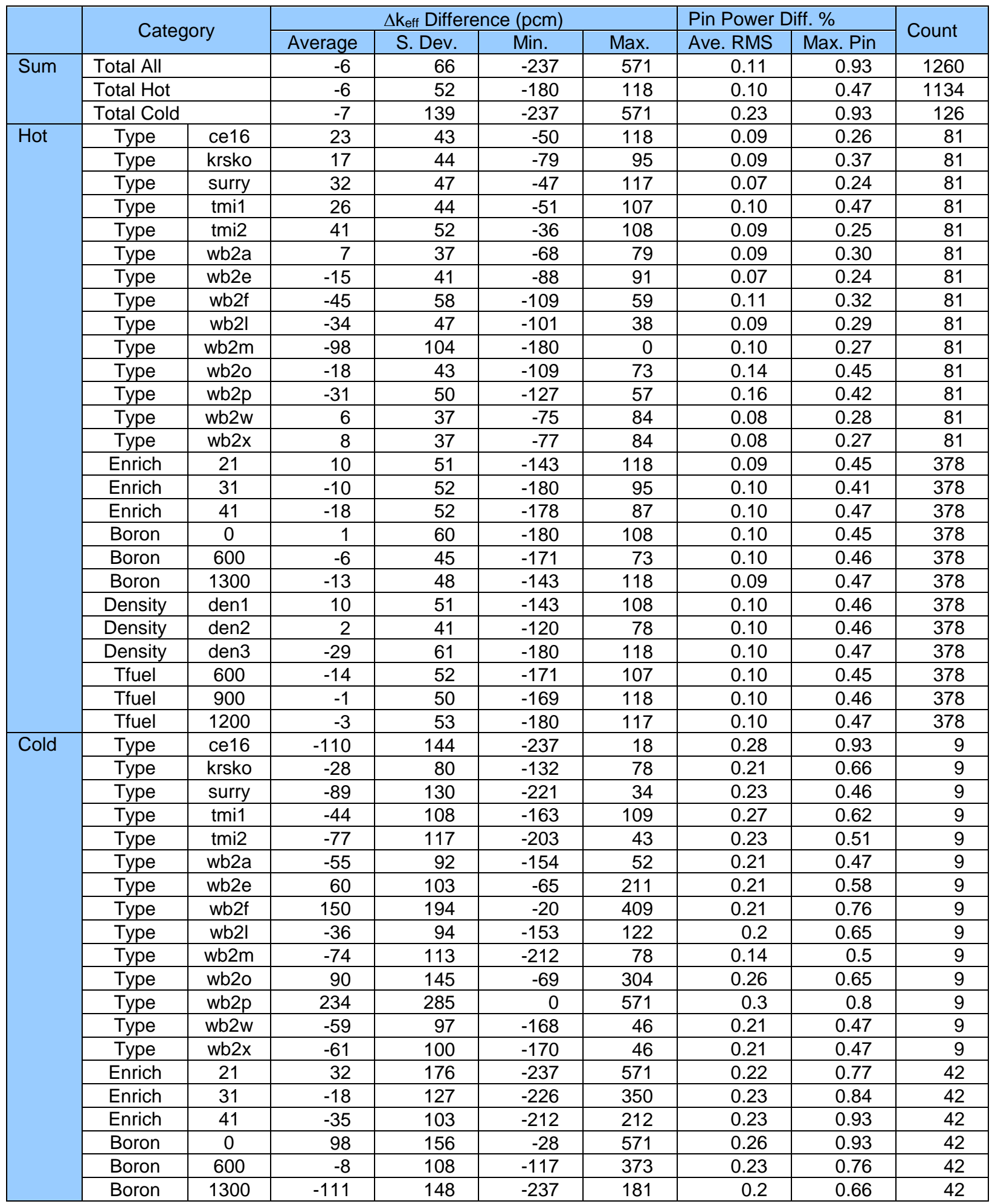


末ㄷㄴ

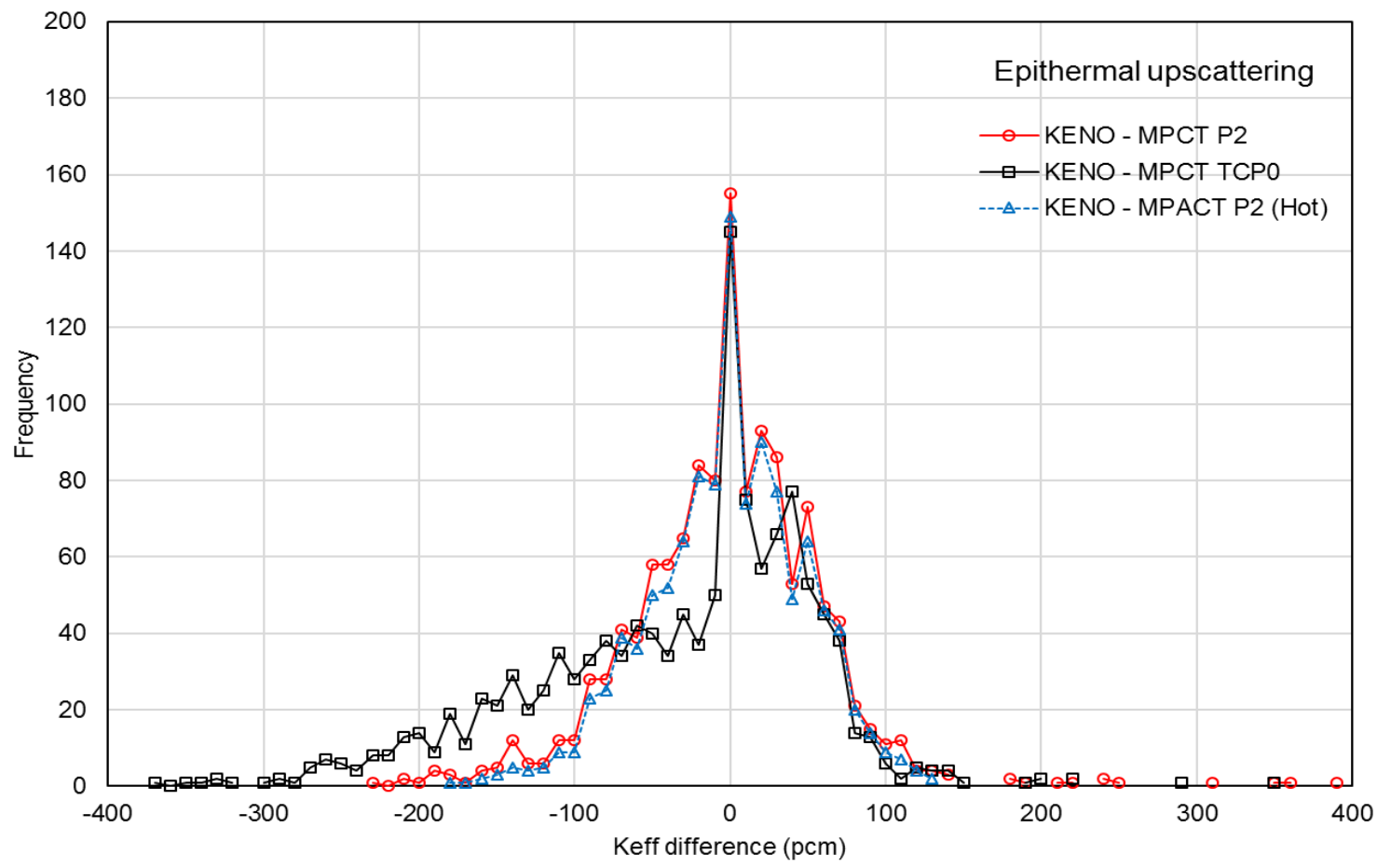

Figure 4.13. Assembly $k_{\text {eff }}$ Difference Distribution with Epithermal Upscattering.

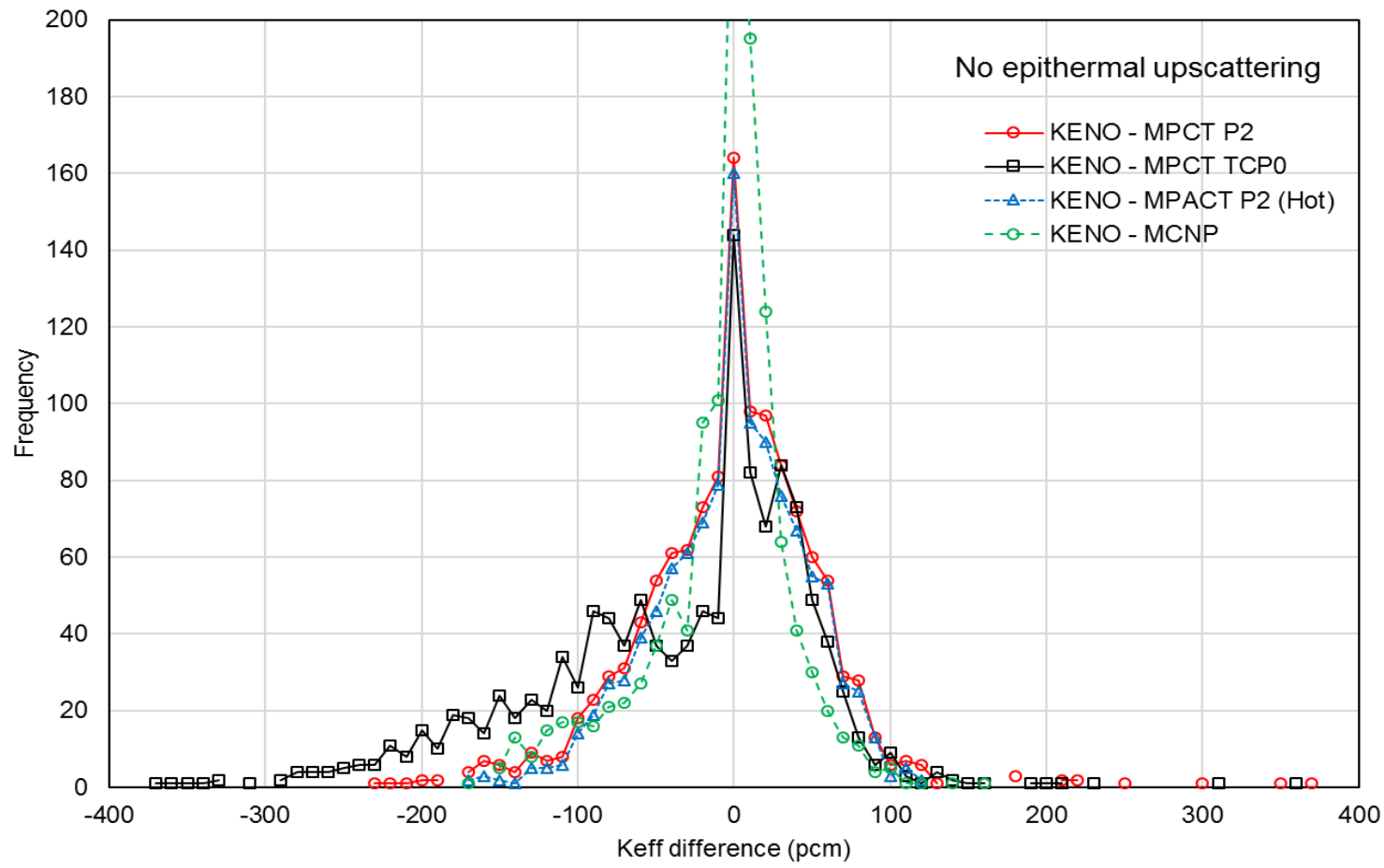

Figure 4.14. Assembly $k_{\text {eff }}$ Difference Distribution without Epithermal Upscattering. 


\subsection{NONUNIFORM FUEL TEMPERATURE BENCHMARK PROBLEMS}

\subsubsection{Characteristics of Problems}

Seoul National University (SNU) has developed a benchmark suite for the intra-pellet nonuniform temperature distribution cases [Joo05]. Table 4.15 and Figure 4.16 provide the geometrical specifications, including five equivolume subzones in the fuel pellet, gap, cladding, and moderator. Table 4.16 provides the compositional specification, including nuclides and atomic number densities.

Nonuniform temperature profiles as a function of power and average fuel temperatures are shown in Table 4.17 and Figure 4.15. Benchmark calculations are performed by using both nonuniform and uniform temperature profiles.

Table 4.15. Geometrical Data

\begin{tabular}{|c|c|c|c|}
\hline Region & \multicolumn{3}{|c|}{ Dimensions } \\
\hline \multirow{6}{*}{ Fuel } & \multicolumn{2}{|c|}{ Outer Radius (cm) } & 0.4127 \\
\hline & \multirow{5}{*}{$\begin{array}{l}\text { Sub-pellet annular ring radius } \\
\qquad(\mathrm{cm})\end{array}$} & 1 & 0.1846 \\
\hline & & 2 & 0.2610 \\
\hline & & 3 & 0.3197 \\
\hline & & 4 & 0.3692 \\
\hline & & 5 & 0.4127 \\
\hline \multicolumn{4}{|l|}{ Gap } \\
\hline \multirow{2}{*}{ Clad } & \multicolumn{2}{|c|}{ Inner Radius (cm) } & 0.4203 \\
\hline & \multicolumn{2}{|c|}{ Outer Radius (cm) } & 0.4862 \\
\hline Coolant & \multicolumn{2}{|c|}{ Cell Pitch $(\mathrm{cm})$} & 1.2870 \\
\hline
\end{tabular}

Table 4.16. Composition Data

\begin{tabular}{|c|c|c|c|}
\hline \multirow{2}{*}{ Composition } & \multicolumn{2}{|c|}{ Nuclides } & $\begin{array}{c}\text { Atomic Number Density } \\
\text { (atoms/barn-cm) }\end{array}$ \\
\hline \multirow{3}{*}{$3.0 \% \mathrm{UO}_{2}$} & ${ }^{235} \mathrm{U}$ & 92,235 & $7.13479 \mathrm{E}-04$ \\
\cline { 2 - 4 } & ${ }^{238} \mathrm{U}$ & 92,238 & $2.27778 \mathrm{E}-02$ \\
\cline { 2 - 4 } & ${ }^{16} \mathrm{O}$ & 8,016 & $4.69825 \mathrm{E}-02$ \\
\hline \multirow{3}{*}{ Gap } & $16 \mathrm{O}$ & 8,016 & $1.00000 \mathrm{E}-08$ \\
\hline \multirow{3}{*}{ Clad } & $90 \mathrm{Zr}$ & 40,090 & $2.22157 \mathrm{E}-02$ \\
\cline { 2 - 4 } & ${ }^{91} \mathrm{Zr}$ & 40,091 & $4.79136 \mathrm{E}-03$ \\
\cline { 2 - 4 } & $92 \mathrm{Zr}$ & 40,092 & $7.24405 \mathrm{E}-03$ \\
\cline { 2 - 4 } & ${ }^{94} \mathrm{Zr}$ & 40,094 & $7.18475 \mathrm{E}-03$ \\
\cline { 2 - 4 } & $96 \mathrm{Zr}$ & 40,096 & $1.13334 \mathrm{E}-03$ \\
\hline \multirow{2}{*}{ Coolant } & ${ }^{1} \mathrm{H}$ & 1,001 & $4.65690 \mathrm{E}-02$ \\
\cline { 2 - 4 } & ${ }^{16} \mathrm{O}$ & 8,016 & $2.32840 \mathrm{E}-02$ \\
\hline
\end{tabular}


Table 4.17. Nonuniform Temperature Profiles as a Function Power

\begin{tabular}{|c|c|c|c|c|c|c|c|c|}
\hline \multirow{3}{*}{\multicolumn{2}{|c|}{ Region }} & \multicolumn{7}{|c|}{ Temperature (K) } \\
\hline & & \multicolumn{7}{|c|}{ Power Level (\%) } \\
\hline & & 50 & 75 & 100 & 125 & 150 & 175 & 200 \\
\hline \multirow{6}{*}{ Pellet } & 1 & 787.4 & 897.7 & 1017.9 & 1148.2 & 1288.2 & 1437.7 & 1596.3 \\
\hline & 2 & 754.7 & 843.7 & 939.3 & 1041.7 & 1150.6 & 1266.0 & 1387.5 \\
\hline & 3 & 723.1 & 792.2 & 865.1 & 942.0 & 1022.7 & 1107.3 & 1195.6 \\
\hline & 4 & 683.0 & 728.3 & 774.9 & 823.2 & 873.0 & 924.3 & 977.1 \\
\hline & 5 & 669.2 & 708.3 & 748.4 & 789.4 & 831.4 & 874.3 & 918.2 \\
\hline & Avg. & 723.5 & 794.0 & 869.1 & 948.9 & 1033.2 & 1121.9 & 1214.9 \\
\hline \multicolumn{2}{|c|}{ Gap } & 606.1 & 610.2 & 614.0 & 617.7 & 621.2 & 624.7 & 628.1 \\
\hline \multicolumn{2}{|c|}{ Clad } & 606.1 & 610.2 & 614.0 & 617.7 & 621.2 & 624.7 & 628.1 \\
\hline \multicolumn{2}{|c|}{ Coolant } & 586.7 & 586.7 & 586.7 & 586.7 & 586.7 & 586.7 & 586.7 \\
\hline
\end{tabular}

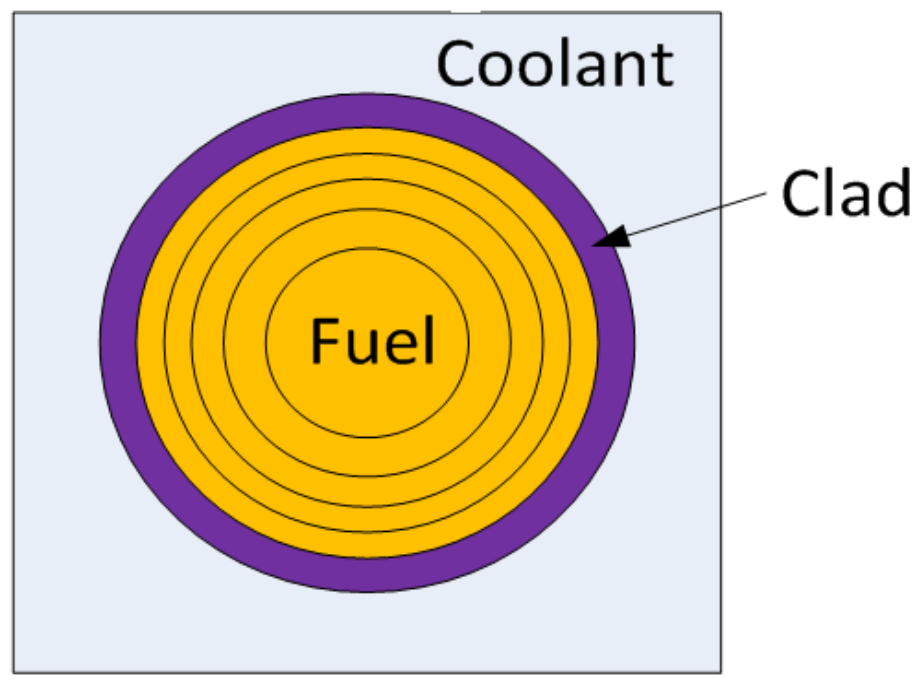

Figure 4.15. Geometrical Configuration.

\subsubsection{Benchmark Results}

Benchmark calculations were performed using the continuous-energy Monte Carlo code KENO using the ENDF/B-VII.1 nuclear data and the VERA-CS MPACT using the ENDF/B-VII.1 v4.3m1 MPACT 51-group library. SCALE-6.2 with CE-KENO includes a new capability to interpolate continuous-energy cross sections for any specified temperature based on the reference temperatures for base cross sections.

Figure 4.16 provides a comparison of reactivities between nonuniform and uniform temperature profile results obtained by KENO. This comparison indicates that the slopes of nonuniform and uniform temperature profiles, which determine the fuel temperature reactivity coefficient, are different. In other words, the fuel temperature coefficient of the nonuniform temperature is less negative than that of the uniform temperature. Therefore, when performing whole core calculations with thermal/hydraulic 
$(\mathrm{T} / \mathrm{H})$ feedback, nonuniform temperature profiles must be considered properly in estimating resonance self-shielded cross sections by performing subgroup calculations.

Figure 4.17 provides the benchmark results for the uniform temperature cases. There are very good agreements between the KENO and the MPACT results, with both $\mathrm{P}_{2}$ and $\mathrm{TCP}_{0}$ scatterings in the reactivities for all temperatures. Figure 4.18 provides the benchmark results for the nonuniform temperature cases. There are very good agreements between the KENO and the MPACT results, with both $\mathrm{P}_{2}$ and TCP0 scatterings in the reactivities for all temperatures.

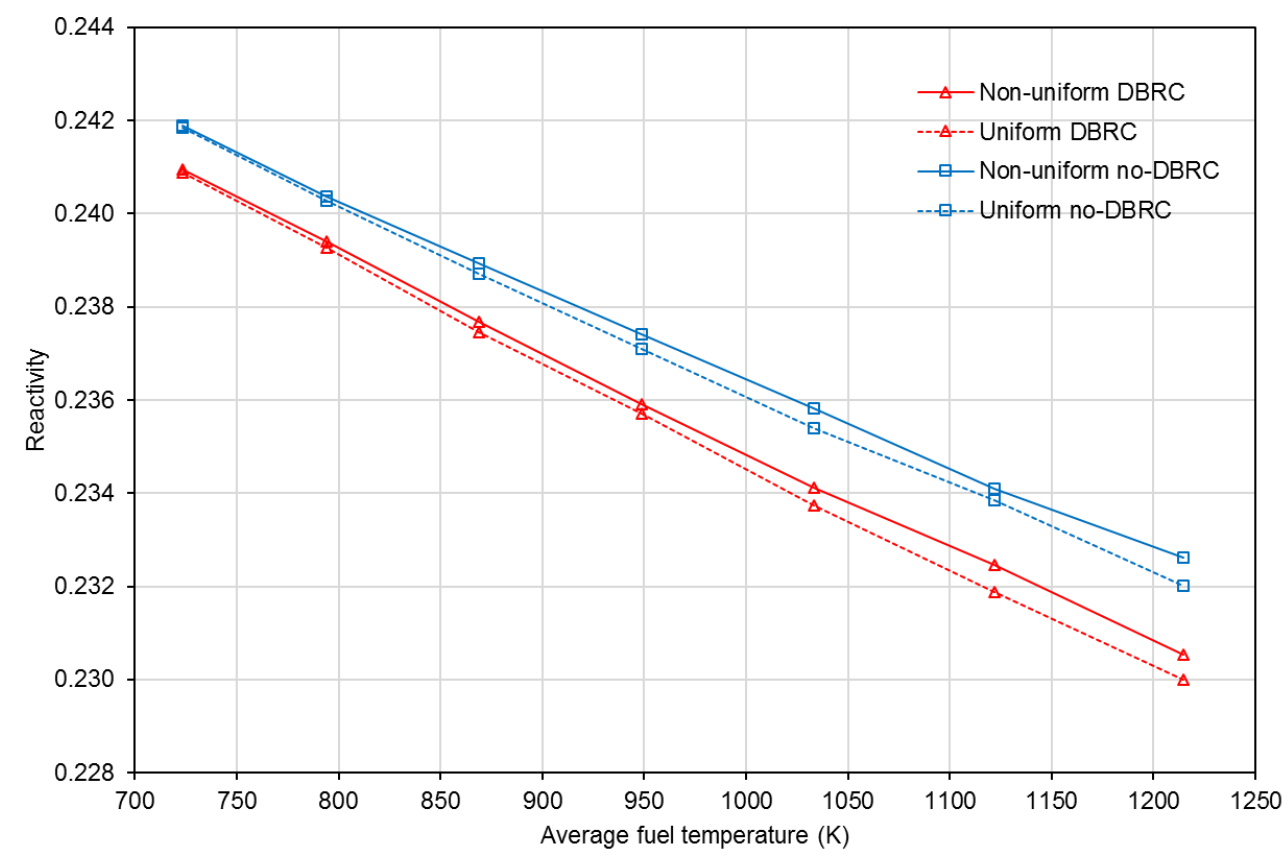

Figure 4.16. Comparison of Reactivities between Nonuniform and Uniform Temperature Distributions. (KENO). 
䩖口ヘكட
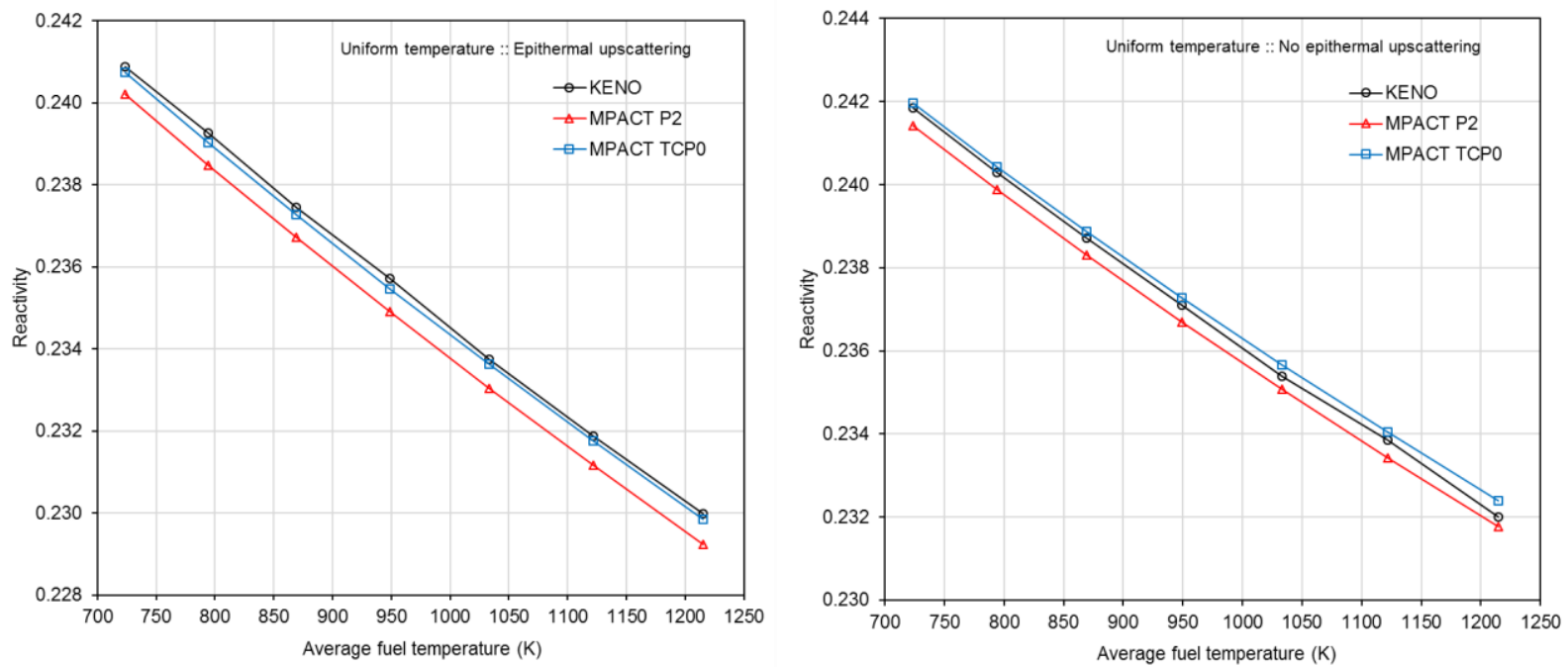

\begin{tabular}{|c|c|c|c|c|}
\hline \multirow{2}{*}{ Code } & \multicolumn{2}{|c|}{ Epithermal Upscattering } & \multicolumn{2}{c|}{ No Epithermal Upscattering } \\
\cline { 2 - 5 } & $\mathrm{FTC}(\mathrm{pcm} / \mathrm{K})$ & $\Delta \mathrm{FTC}(\mathrm{pcm} / \mathrm{K})$ & $\mathrm{FTC}(\mathrm{pcm} / \mathrm{K})$ & $\Delta \mathrm{FTC}(\mathrm{pcm} / \mathrm{K})$ \\
\hline $\mathrm{KENO}^{[\mathrm{a}]}$ & 2.22 & & 2.01 & \\
\hline${\text { MPACT } \mathrm{P}_{2}{ }^{[\mathrm{b}]}}$ & 2.25 & -0.03 & 1.98 & 0.03 \\
\hline MPACT TCP $_{0}[\mathrm{~b}]$ & 2.23 & -0.02 & 1.96 & 0.05 \\
\hline
\end{tabular}

Figure 4.17. Comparison of Reactivities for the Uniform Temperature Distributions.
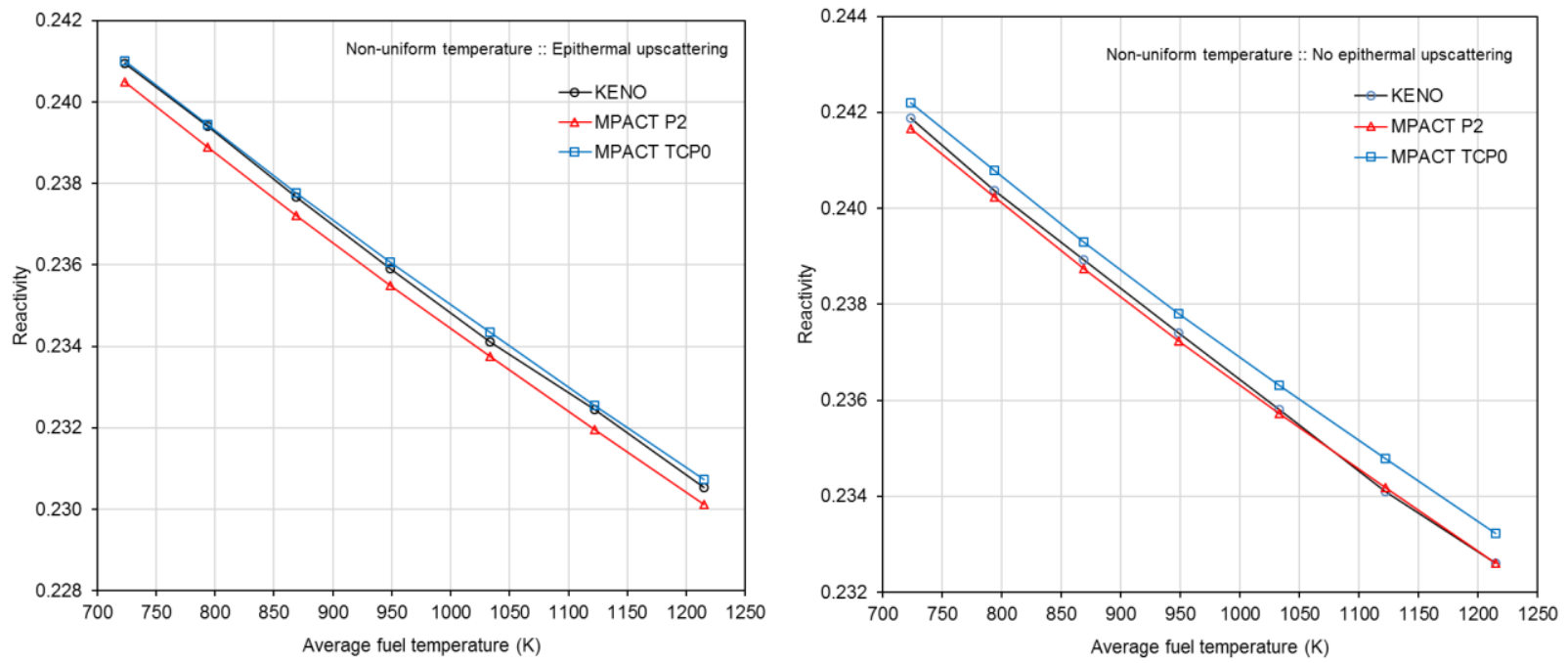

\begin{tabular}{|c|c|c|c|c|}
\hline \multirow{2}{*}{ Code } & \multicolumn{2}{|c|}{ Epithermal Upscattering } & \multicolumn{2}{c|}{ No Epithermal Upscattering } \\
\cline { 2 - 5 } & $\mathrm{FTC}(\mathrm{pcm} / \mathrm{K})$ & $\Delta \mathrm{FTC}(\mathrm{pcm} / \mathrm{K})$ & $\mathrm{FTC}(\mathrm{pcm} / \mathrm{K})$ & $\Delta \mathrm{FTC}(\mathrm{pcm} / \mathrm{K})$ \\
\hline $\mathrm{KENO}^{[\mathrm{a}]}$ & 2.13 & - & 1.90 & - \\
\hline${\text { MPACT } \mathrm{P}_{2}[\mathrm{~b}]}^{\left[\mathrm{MPACT} \mathrm{TCP}^{[\mathrm{b}]}\right.}$ & 2.12 & 0.01 & 1.86 & 0.04 \\
\hline
\end{tabular}

Figure 4.18. Comparison of Reactivities for the Nonuniform Temperature Distributions. 


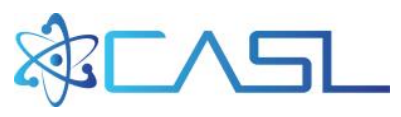

\subsection{MOSTELLER BENCHMARK PROBLEMS}

\subsubsection{Characteristics of Problems}

The Mosteller benchmark [Mos07] was developed to verify the Doppler temperature reactivity coefficient. Tables $4.18-4.20$ provide the compositional and geometrical specifications. The original benchmarks do not include $1,200 \mathrm{~K}$ cases, which have been added to these benchmark calculations.

Table 4.18. Atomic Number Densities of $\mathrm{UO}_{2}$ Fuels

\begin{tabular}{|c|c|c|c|c|c|c|c|c|}
\hline $\begin{array}{c}\text { Temp } \\
\text { (K) }\end{array}$ & \multirow{2}{*}{$\begin{array}{c}\text { Nuclide } \\
\end{array}$} & \multicolumn{7}{|c|}{ Atomic Number Density vs ${ }^{235}$ Enrichment } \\
\hline \multirow{4}{*}{600} & ${ }^{6} \mathrm{O}$ & $4.61171 \mathrm{E}-02$ & $4.61218 \mathrm{E}-02$ & $4.61260 \mathrm{E}-02$ & $4.61297 \mathrm{E}-02$ & $4.61339 \mathrm{E}-02$ & $4.61371 \mathrm{E}-02$ & $4.61397 \mathrm{E}-02$ \\
\cline { 2 - 9 } & $234 \mathrm{U}$ & $0.00000 \mathrm{E}+00$ & $3.00175 \mathrm{E}-06$ & $4.50257 \mathrm{E}-06$ & $5.81576 \mathrm{E}-06$ & $7.31651 \mathrm{E}-06$ & $8.44205 \mathrm{E}-06$ & $9.37998 \mathrm{E}-06$ \\
\cline { 2 - 9 } & $235 \mathrm{U}$ & $1.66029 \mathrm{E}-04$ & $3.73618 \mathrm{E}-04$ & $5.60420 \mathrm{E}-04$ & $7.23867 \mathrm{E}-04$ & $9.10661 \mathrm{E}-04$ & $1.05075 \mathrm{E}-03$ & $1.16749 \mathrm{E}-03$ \\
\cline { 2 - 9 } & $238 \mathrm{U}$ & $2.28925 \mathrm{E}-02$ & $2.26843 \mathrm{E}-02$ & $2.24981 \mathrm{E}-02$ & $2.23352 \mathrm{E}-02$ & $2.21490 \mathrm{E}-02$ & $2.20093 \mathrm{E}-02$ & $2.18930 \mathrm{E}-02$ \\
\hline \multirow{4}{*}{900} & $16 \mathrm{O}$ & $4.59967 \mathrm{E}-02$ & $4.60014 \mathrm{E}-02$ & $4.60056 \mathrm{E}-02$ & $4.60093 \mathrm{E}-02$ & $4.60134 \mathrm{E}-02$ & $4.60166 \mathrm{E}-02$ & $4.60192 \mathrm{E}-02$ \\
\cline { 2 - 9 } & $234 \mathrm{U}$ & $0.00000 \mathrm{E}+00$ & $2.99391 \mathrm{E}-06$ & $4.49081 \mathrm{E}-06$ & $5.80057 \mathrm{E}-06$ & $7.29740 \mathrm{E}-06$ & $8.42000 \mathrm{E}-06$ & $9.35548 \mathrm{E}-06$ \\
\cline { 2 - 9 } & $235 \mathrm{U}$ & $1.65595 \mathrm{E}-04$ & $3.72642 \mathrm{E}-04$ & $5.58956 \mathrm{E}-04$ & $7.21977 \mathrm{E}-04$ & $9.08283 \mathrm{E}-04$ & $1.04801 \mathrm{E}-03$ & $1.16445 \mathrm{E}-03$ \\
\cline { 2 - 9 } & $238 \mathrm{U}$ & $2.28328 \mathrm{E}-02$ & $2.26251 \mathrm{E}-02$ & $2.24393 \mathrm{E}-02$ & $2.22768 \mathrm{E}-02$ & $2.20911 \mathrm{E}-02$ & $2.19519 \mathrm{E}-02$ & $2.18358 \mathrm{E}-02$ \\
\hline \multirow{4}{*}{1200} & $16 \mathrm{O}$ & $4.58763 \mathrm{E}-02$ & $4.58810 \mathrm{E}-02$ & $4.58852 \mathrm{E}-02$ & $4.58889 \mathrm{E}-02$ & $4.58929 \mathrm{E}-02$ & $4.58961 \mathrm{E}-02$ & $4.58987 \mathrm{E}-02$ \\
\cline { 2 - 9 } & $234 \mathrm{U}$ & $0.00000 \mathrm{E}+00$ & $2.98607 \mathrm{E}-06$ & $4.47905 \mathrm{E}-06$ & $5.78538 \mathrm{E}-06$ & $7.27829 \mathrm{E}-06$ & $8.39795 \mathrm{E}-06$ & $9.33098 \mathrm{E}-06$ \\
\cline { 2 - 8 } & $235 \mathrm{U}$ & $1.65161 \mathrm{E}-04$ & $3.71666 \mathrm{E}-04$ & $5.57492 \mathrm{E}-04$ & $7.20087 \mathrm{E}-04$ & $9.05905 \mathrm{E}-04$ & $1.04527 \mathrm{E}-03$ & $1.16141 \mathrm{E}-03$ \\
\cline { 2 - 8 } & $238 \mathrm{U}$ & $2.27731 \mathrm{E}-02$ & $2.25659 \mathrm{E}-02$ & $2.23805 \mathrm{E}-02$ & $2.22184 \mathrm{E}-02$ & $2.20332 \mathrm{E}-02$ & $2.18945 \mathrm{E}-02$ & $2.17786 \mathrm{E}-02$ \\
\hline
\end{tabular}

Table 4.19. Geometrical Configurations

\begin{tabular}{|c|c|c|c|}
\hline & $600 \mathrm{~K}$ & $900 \mathrm{~K}$ & $1200 \mathrm{~K}$ \\
\hline Fuel outer radius $(\mathrm{cm})$ & 0.39398 & 0.39433 & 0.39468 \\
\hline Clad inner radius $(\mathrm{cm})$ & 0.40226 & 0.40226 & 0.40226 \\
\hline Clad outer radius $(\mathrm{cm})$ & 0.45972 & 0.45972 & 0.45972 \\
\hline Pin pitch $(\mathrm{cm})$ & 1.26678 & 1.26678 & 1.26678 \\
\hline
\end{tabular}

Table 4.20. Atomic Number Densities of Moderator and Clad

\begin{tabular}{|c|c|l|l|l|l|l|l|}
\hline Material & Temp & \multicolumn{7}{|c|}{ Atomic number density } \\
\hline Moderator & 600 & 1001 & $4.42326 \mathrm{E}-02$ & 8016 & $2.21163 \mathrm{E}-02$ & 5010 & $1.02133 \mathrm{E}-05$ \\
\cline { 3 - 9 } & & 5011 & $4.11098 \mathrm{E}-05$ & & & & \\
\hline Clad & 600 & 40090 & $2.17036 \mathrm{E}-02$ & 40091 & $4.73302 \mathrm{E}-03$ & 40092 & $7.23452 \mathrm{E}-03$ \\
\cline { 3 - 9 } & & 40094 & $7.33155 \mathrm{E}-03$ & 40096 & $1.18115 \mathrm{E}-03$ & & \\
\hline Gap & 600 & 8016 & $2.68714 \mathrm{E}-05$ & & & & \\
\hline
\end{tabular}

\subsubsection{Benchmark Results}

Benchmark calculations were performed using the continuous-energy Monte Carlo codes KENO and MCNP using the ENDF/B-VII.1 nuclear data and the VERA-CS MPACT using the ENDF/B-VII.1 v4.3m1 MPACT 51-group library.

Table 4.21 and Figures 4.19 and 4.20 provide the benchmark results with and without considering epithermal upscattering. The $\mathrm{P}_{2}$ MPACT results are consistent with the KENO results within $100 \mathrm{pcm}$ with both options with and without epithermal and 
upscattering. Though the TCP0 MPACT results are slightly worse than the $\mathrm{P}_{2}$ results, the maximum differences are still less than $117 \mathrm{pcm}$. Figures 4.19 and 4.20 show very good agreement between the MPACT and Monte Carlo results at any temperature range. It is noted that the ENDF/B-VII.1 v4.3m1 MPACT 51-group library does not include any Doppler temperature reactivity bias.

Table 4.21. Benchmark Results for Mosteller

\begin{tabular}{|c|c|c|c|c|c|c|c|c|}
\hline \multirow{3}{*}{$\begin{array}{c}235 U \\
\text { wgt } \%\end{array}$} & \multirow{3}{*}{ Temp.(K) } & \multicolumn{3}{|c|}{ Epithermal upscattering } & \multicolumn{4}{|c|}{ No epithermal upscattering } \\
\hline & & \multirow{2}{*}{ KENO } & \multicolumn{2}{|c|}{$\Delta \mathrm{k}(\mathrm{pcm})$} & \multirow{2}{*}{ KENO } & \multicolumn{3}{|c|}{$\Delta \mathrm{k}(\mathrm{pcm})$} \\
\hline & & & $\mathrm{P}_{2}$ & $\mathrm{TCP}_{0}$ & & MCNP & $\mathrm{P}_{2}$ & $\mathrm{TCP}_{0}$ \\
\hline \multirow{3}{*}{0.711} & 600 & 0.66515 & -16 & -16 & 0.66594 & 31 & -17 & -18 \\
\hline & 900 & 0.65878 & -15 & -18 & 0.66020 & 5 & -29 & -34 \\
\hline & 1,200 & 0.65317 & -4 & -10 & 0.65514 & -7 & -33 & -40 \\
\hline \multirow{3}{*}{1.6} & 600 & 0.95974 & -69 & -83 & 0.96104 & 27 & -55 & -70 \\
\hline & 900 & 0.95082 & -50 & -68 & 0.95273 & 16 & -35 & -55 \\
\hline & 1,200 & 0.94283 & -29 & -53 & 0.94579 & 15 & -30 & -56 \\
\hline \multirow{3}{*}{2.4} & 600 & 1.09801 & -57 & -78 & 1.09919 & 32 & -68 & -91 \\
\hline & 900 & 1.08771 & -44 & -71 & 1.08980 & 4 & -60 & -89 \\
\hline & 1,200 & 1.07879 & -40 & -73 & 1.08239 & 14 & -26 & -60 \\
\hline \multirow{3}{*}{3.1} & 600 & 1.17592 & -63 & -88 & 1.17731 & 35 & -58 & -85 \\
\hline & 900 & 1.16511 & -72 & -104 & 1.16757 & 26 & -33 & -67 \\
\hline & 1,200 & 1.15543 & -63 & -102 & 1.15930 & -9 & -45 & -86 \\
\hline \multirow{3}{*}{3.9} & 600 & 1.23842 & -77 & -106 & 1.23993 & 32 & -62 & -94 \\
\hline & 900 & 1.22733 & -60 & -96 & 1.22972 & 29 & -35 & -74 \\
\hline & 1,200 & 1.21746 & -73 & -117 & 1.22111 & -22 & -64 & -109 \\
\hline \multirow{3}{*}{4.5} & 600 & 1.27378 & -84 & -117 & 1.27550 & 51 & -49 & -84 \\
\hline & 900 & 1.26232 & -53 & -93 & 1.26524 & -2 & -48 & -90 \\
\hline & 1,200 & 1.25243 & -56 & -103 & 1.25653 & -10 & -44 & -93 \\
\hline \multirow{3}{*}{5.0} & 600 & 1.29829 & -68 & -103 & 1.29969 & 35 & -64 & -101 \\
\hline & 900 & 1.28659 & -74 & -117 & 1.28937 & 11 & -52 & -97 \\
\hline & 1200 & 1.27637 & -57 & -106 & 1.28053 & -28 & -61 & -112 \\
\hline
\end{tabular}




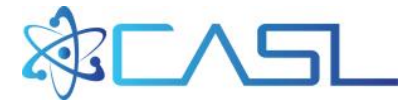

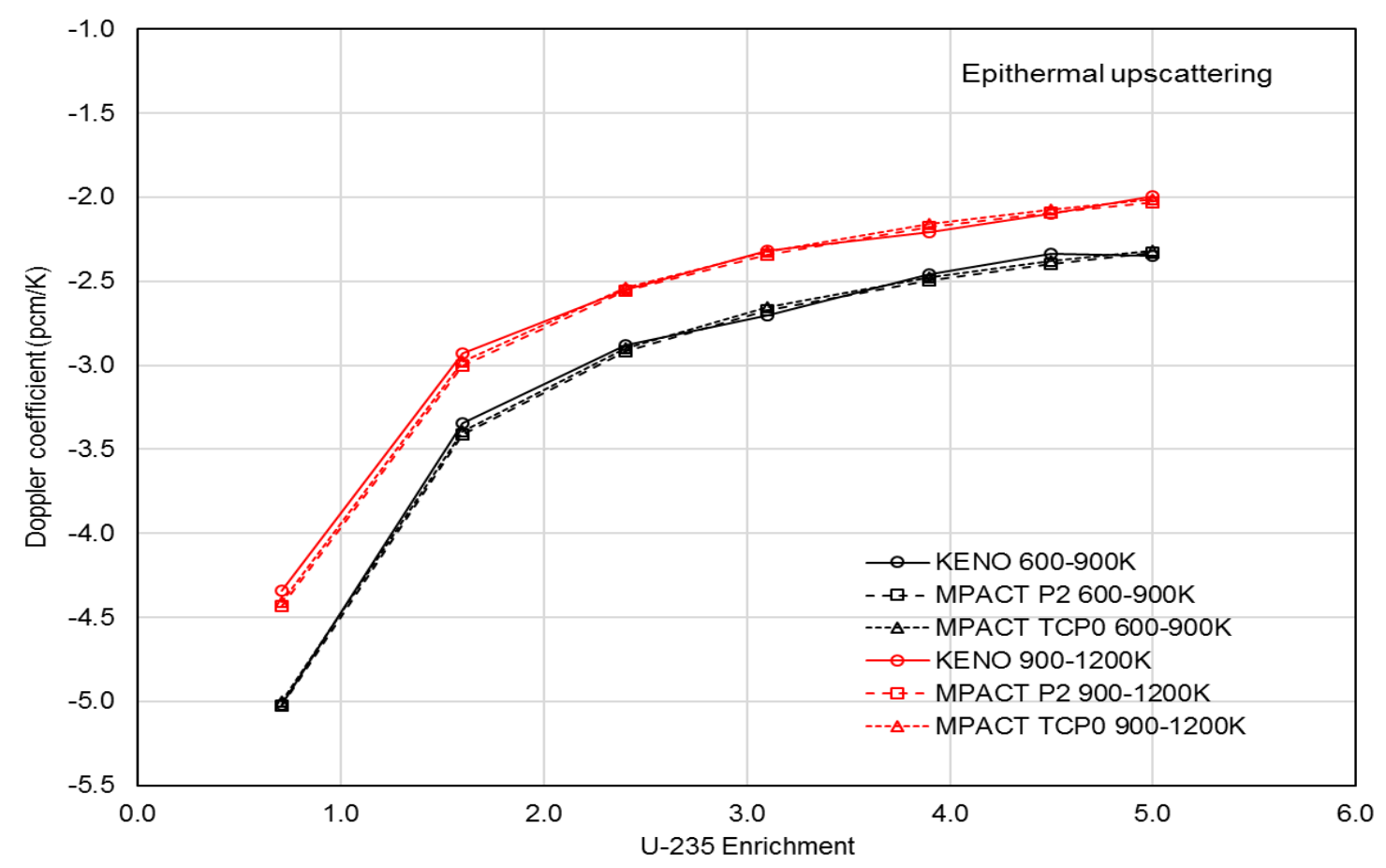

Figure 4.19. Comparison of Reactivities for the Nonuniform Temperature Distributions with Epithermal Upscattering.

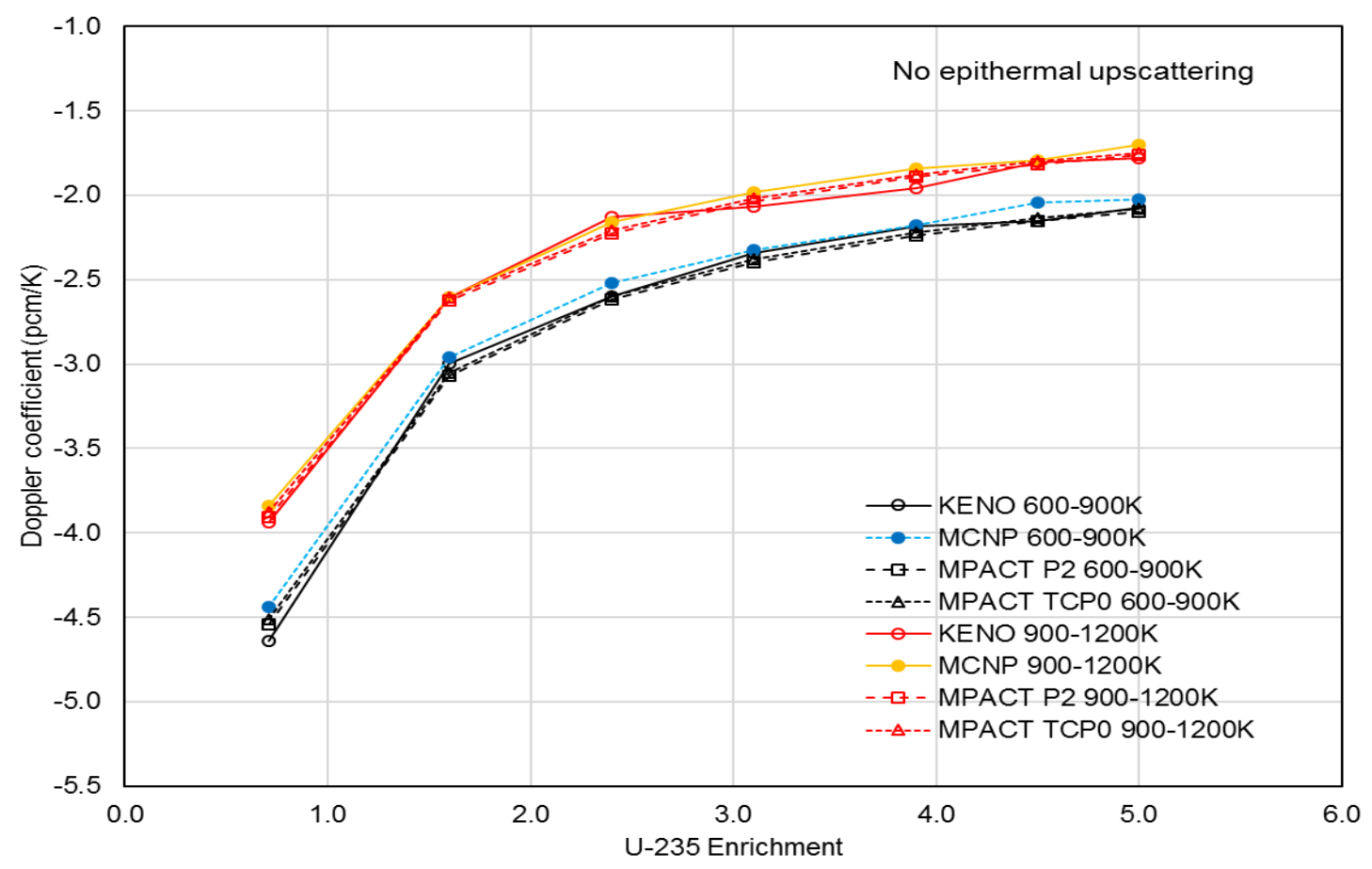

Figure 4.20 Comparison of Reactivities for the Nonuniform Temperature Distributions without Epithermal Upscattering. 


\section{CONCLUSIONS AND FUTURE WORK}

The ENDF/B-VII.1 v4.3m1 MPACT 51-group library has been successfully developed through verification and validation to meet VERA-CS SQA requirements and to satisfy accuracy requirements. Currently, the default cross section library for MPACT is the v4.2m5 ENDF/B-7.1 MPACT 51-g library. To overcome some of drawbacks of the default MPACT MG library, a new MPACT MG library has been developed. Table 5.1 provides the information for the ENDF/B-VII.1 v4.3m1 MPACT 51-group library.

Table 5.1. v4.3m1 MPACT 51-Group Library

\begin{tabular}{|c|c|}
\hline Description & File Name \\
\hline \multirow{2}{*}{ ENDE/B-7.1 MPACT 51-g library } & mpact51g_71_4.3m1 sph01.fmt \\
\cline { 2 - 2 } & $2018.2 .115: 45$ \\
\hline
\end{tabular}

Below are new features of the ENDF/B-VII.1 v4.3m1 MPACT 51-group library compared to the current default library, ENDF/B-VII.1 v4.2m5 MPACT 51-g library.

a. Improvement of $238 \mathrm{U}$ resonance data based on new CE KENO,

b. ${ }^{135 \mathrm{~m}} \mathrm{Xe}(54735)$ cross sections from TENDL,

c. Temperature-dependent ${ }^{135} \mathrm{Xe}$ cross sections,

d. No fuel temperature reactivity bias,

e. Improvement of ${ }^{167} \mathrm{Er}$ thermal resonance cross sections,

f. 2 new effective cross sections of ${ }^{103} \mathrm{Rh}$ (45001 and 45002) for the rhodium detector,

g. Improvement of ${ }^{155} \mathrm{Gd}$ and ${ }^{157} \mathrm{Gd}$ cross sections,

h. Improvement of ${ }^{107} \mathrm{Ag}$ and ${ }^{109} \mathrm{Ag}$ cross sections, and

i. New ${ }^{124} \mathrm{Sb}(51124)$ and ${ }^{125} \mathrm{Sb}$ (51125) cross section for the Sb-Be secondary neutron source. 


\section{REFERENCES}

[Bec10] B. Becker, On the influence of the Resonance Scattering Treatment in Monte Carlo Codes on High Temperature Reactor Characteristics," PhD Thesis, University Stuttgart (June 2010).

[CAS15] Consortium for Advanced Simulation of Light Water Reactors (CASL). http://www.casl.gov/ (2015).

[Cho02] J. Y. Cho, H. G. Joo, Kang Seog Kim, and S. Q. Zee, "Cell Based CMFD Formulation for Acceleration of Whole-core Method of Characteristics Calculation," Journal of the Korean Nuclear Society, 34, 3, 250-258 (2002).

[Cul74] Dermott E. Cullen, "Application of the Probability Table Method to Multigroup Calculations of Neutron Transport," Nucl. Sci. Eng., 55, 387-400 (1974).

[Gen17] C. Gentry, A. T. Godfrey, and F. Franceschini, " AP1000 ${ }^{\circledR}$ Benchmarking of VERA Neutronics Toolset," M\&C 2017 (Submitted).

[Gol62] R. Goldstein and E. R. Cohen, "Theory of Resonance Absorption of Neutrons," Nucl. Sci. Eng., 13, 132 (1962).

[God14] A. T. Godfrey, VERA Core Physics Benchmark Progression Problem Specifications, CASL-U-2012-0131-004, Rev. 4 (2014).

[God15] A. T. Godfrey et al., VERA Benchmarking Results for Watts Bar Nuclear Plant Unit 1 Cycles 1-12, CASL-U-2015-0206-000, Rev. 0 (2015).

[Her13] B. R. Herman, B. Forget, and K. Smith, "Improved Diffusion Coefficients Generated from Monte Carlo Codes," M\&C 2013, Sun Valley, Idaho, May 5-9, 2013.

[Jam99] M. F. James, "Energy Release in Fission of Th-232, U-233, U-234, U-236, Np-237, Pu-238, Pu-240 and Pu-242," J. Nucl. Energy, 23, 1999.

[Joo09] H. G. Joo and et al., "Subgroup Weight Generation Based on Shielded PinCell Cross Section Conservation," Ann. Nucl. Energ., 36, 859 (2009).

[Joo05] H. G. Joo, B. S. Han, C. H. Kim, and K. S. Kim, "Implementation of Subgroup Method in Direct Whole Core Transport Calculation Involving Nonuniform Temperature Distribution," M\&C 2005, Avignon, France, Sept. 12-15, 2005.

[Jun13] Y. S. Jung, C. B. Shim, C. H. Lim, and H. G. Joo, "Practical numerical reactor employing direct whole core neutron transport and subchannel thermal/hydraulic solvers," Ann. Nucl. Energ., 62, 357-374 (2013).

[Kim15] K. S. Kim, Procedure to Generate the MPACT Multigroup Library, CASL-U2015-1013-000, ORNL/TM-2016/52 (2015).

[Kim18] K. S. Kim, M. L. Williams, A. Holcomb, D. Wiarda, B. K. Jeon, and W. S. Yang, "The AMPX/SCALE Multigroup Cross Section Processing for Fast Reactor Analysis," PHYSOR 2018, Cancun, Mexico (2018).

[Kim03] K. S. Kim et al., "Monte Carlo Resonance Treatment for the Deterministic Transport Lattice Codes," Journal of the Korean Nuclear Society, 35, No.6, 581-595 (2003).

[Kim12] K. S. Kim and M. L. Williams, "The Method of Characteristics For 2-D Multigroup and Pointwise Transport Calculation in SCALE/CENTRM," PHYSOR 2012, Knoxville, Tennessee, USA, April 15-20, 2012. 
[Kim16a] K. S. Kim, Specification for the VERA Depletion Benchmark Suite, CASL-U2015-1014-000, Rev. 0, ORNL/TM-2016/53 (2016).

[Kim16b] K. S. Kim, M. L. Williams, and D. Wiarda, Investigation of Neutron Leakage Conservation Method to Generate ${ }^{1} \mathrm{H}$ Transport Correction Factors, CASLU-2016-1163-000, ORNL/TM-2016/266 (2016).

[Kim16c] K. S. Kim, SUBGR: A Program to Generate Subgroup Data for the Subgroup Resonance Self-Shielding Calculation, CASL-U-2016-1070-000 (2016).

[Kha71] A. Khairallah and J. Recolin, "Calcul de l'autoprotection résonnante dans les cellules complexes par la méthode des sous-groupes," Proc. Seminar IAEASM-154 on Numerical Reactor Calculations, 305-317, IAEA, Vienna (1972).

[Lee11] C. H. Lee and W. S. Yang, MC'2-3: Multigroup Cross Section Generation Code for Fast Reactor Analysis, ANL-NE-11-41, Argonne National Laboratory (2011).

[Lee09] D. J. Lee, K. Smith, and J. Rhodes, "The Impact of ${ }^{238} \mathrm{U}$ Resonance Elastic Scattering Approximations on Thermal Reactor Doppler Reactivity," Ann. Nucl. Energy, 36, 274-280 (2009).

[Les87] F. Leszczynski, "Neutron Resonance Treatment with Details in Space and Energy for Pin Cells and Rod Clusters," Ann. Nucl. Energy, 14, 589-601 (1987).

[Liu16a] Y. Liu, Reaction Rate Analysis for MPACT Cross Section Library Verification, CASL-U-2016-1255-000, Rev. 0 (2016).

[Liu16b] Y. Liu, et al., Runtime Improvements to the Cross Section Calculation in MPACT, CASL-X-2016-1105-000, May (2016).

[Mac94] R. E. MacFarlane and D. W. Muir, "The NJOY Nuclear Data Processing System Version 91," LA-12740-M Manual (1994).

[Mpa13] MPACT: User's Manual Version 1.0.0, November 8, 2013.

[Mos07] R. Mosteller, "The Doppler-Defect Benchmark: Overview and Summary of Results," M\&C+SNA 2007, Monterey, CA, April 15-19, 2007.

[Pal17a] S. Palmtag, MPACT Library Verification by Comparison of Pincell Calculations to Monte Carlo Results, CASL-U-2016-0281-002, Rev. 2 (2017).

[Pal16b] S. Palmtag, MPACT Library Verification by Comparison of Assembly Calculations to Monte Carlo Results, CASL-U-2016-1052-001, Rev. 0 (2017).

[Ryu14] M. R. et al., "Incorporation of Anisotropic Scattering in nTRACER," Transaction of the Korean Nuclear Society Autumn Meeting, Pyeongchang, Korea, October 30-31, 2014.

[Sca16] SCALE: A Modular Code System for Performing Standardized Computer Analyses for Licensing Evaluation, ORNL-TM/2005/39, Version 6.2, ORNL, Oak Ridge, Tennessee, available from Radiation Safety Information Computational Center at Oak Ridge National Laboratory as CCC-834 (2016).

[Sta83] R. J. J. Stamm'ler and M. J. Abbate, Methods of Steady-State Reactor Physics in Nuclear Design, Academic Press (1983). 
[Sta03] R. J. J. Stamm'ler et al., The HELIOS Methods, Studsvik Scandpower (2003).

[Tur16] J. Turner et al., "The Virtual Environment for Reactor Applications (VERA): Design and architecture," Journal of Computational Physics, 326, 544 (2016).

[Wia16] D. Wiarda, M.E. Dunn, N.M. Green, M. L. Williams, C. Celik and L. M. Petrie, AMPX-6: A Modular Code System for Processing ENDF/B, ORNL/TM-2016/43 (2016).

[Wem07] C. A. Wemple, et al., "Improved Temperature-Dependent Resonance Treatment in HELIOS-1.9," Trans. Am. Nucl. Soc., 96, 657-659 (2007).

[Wil12] M. L. Williams and K. S. Kim, "The Embedded Self-Shielding Method," PHYSOR 2012, Knoxville, Tennessee, USA, April 15-20, 2012.

[Wil06] M. L. Williams, M. Asgari, and D. F. Hollenbach, CENTRM: A OneDimensional Neutron Transport Code for Computing Pointwise Energy Spectra, ORNL/TM-2005/39, Version 5.1, Vol. II, Book 4, Sect. F18 (2006). 